DANILO AUGUSTO SALGADO

\title{
UMA ABORDAGEM PARAMÉTRICA DO IMPACTO DA GERAÇÃO DISTRIBUÍDA SOBRE AS CORRENTES DE CURTO-CIRCUITO E NA PROTEÇÃO DE REDES DE DISTRIBUIÇÃO
}




\section{UMA ABORDAGEM PARAMÉTRICA DO IMPACTO DA GERAÇÃO DISTRIBUÍDA SOBRE AS CORRENTES DE CURTO-CIRCUITO E NA PROTEÇÃO DE REDES DE DISTRIBUIÇÃO}

Dissertação apresentada à Escola Politécnica da Universidade de São Paulo para obtenção do título de Mestre em Engenharia

Área de Concentração:

Sistemas de Potência

Orientador:

Prof. Dr. Nelson Kagan

São Paulo 
Este exemplar foi revisado e corrigido em relação à versão original, sob responsabilidade única do autor e com a anuência de seu orientador.

São Paulo, de de

Assinatura do autor:

Assinatura do orientador:

\section{Catalogação-na-publicação}

Salgado, Danilo Augusto

UMA ABORDAGEM PARAMÉTRICA DO IMPACTO DA GERAÇÃO

DISTRIBUÍDA SOBRE AS CORRENTES DE CURTO-CIRCUITO E NA

PROTEÇÃO DE REDES DE DISTRIBUIÇÃO / D. A. Salgado - versão corr. -São Paulo, 2015.

$104 \mathrm{p}$.

Dissertação (Mestrado) - Escola Politécnica da Universidade de São Paulo. Departamento de Engenharia de Energia e Automação Elétricas.

Orientador: Nelson Kagan

1. Sistemas de Energia Elétrica 2. Geração Distribuída 3. Engenharia Elétrica 4. Análise Paramétrica I. Universidade de São Paulo. Escola

Politécnica. Departamento de Engenharia de Energia e Automação Elétricas II.t. 
Aos meus avós e aos meus pais, por tudo que fizeram.

À minha esposa pelo amor incondicional. 


\section{AGRADECIMENTOS}

Ao Prof. Dr. Nelson Kagan pela confiança depositada, por acreditar neste trabalho e pelos conselhos que deu ao longo da orientação. Seu empenho como professor foi fundamental na formação de inúmeros engenheiros da Escola Politécnica da USP, entre os quais me incluo e por isso lhe sou grato.

Ao Prof. Dr. Walmir Freitas da Unicamp, pela conversa esclarecedora que tivemos que serviu como um primeiro norte para o desenvolvimento deste trabalho. Seu pragmatismo foi essencial para que não me perdesse entre as diversas possibilidades que poderiam decorrer deste estudo.

Ao Prof. Dr. Carlos Frederico Meschini Almeida e à Prof ${ }^{a}$. Dr ${ }^{a}$. Fernanda Caseño Lima Trindade Arioli, pelas sugestões relevantes que fizeram durante e que foram incorporadas neste trabalho.

Aos chefes e colegas da Promon Engenharia que me incentivaram a entrar no programa de pós-graduação e que disponibilizaram as ferramentas e todo o auxílio necessário para que eu pudesse desenvolver essa dissertação.

À Universidade de São Paulo e ao povo paulista que a fomenta. Tenho orgulho de ter tido o privilégio de estudar nesta instituição que tanto contribuiu para o progresso do nosso país.

Aos meus avós, que não tiveram a oportunidade de estudar, mas que fizeram o que estava ao seu alcance para que seus filhos e netos a tivessem, apesar da vida árdua. A meus pais por tudo o que fizeram. A minha esposa pelo amor incondicional. A eles sou eternamente grato. 
"Non puoi insegnare qualcosa ad un uomo.

Lo puoi solo aiutare a scoprirla dentro di sé."

Galileo Galilei 


\section{RESUMO}

Esta dissertação tem por propósito analisar os impactos da geração distribuída sobre as correntes de curto-circuito e sobre a proteção das redes de média tensão das concessionárias de distribuição de energia elétrica usando uma abordagem paramétrica.

A principal motivação deste trabalho são os recentes incentivos regulatórios que estão fomentando a geração distribuída no Brasil. Contudo, as redes de distribuição convencionais foram projetadas para serem passivas e a introdução da geração poderá causar problemas de ordem técnica que ainda precisam ser resolvidos.

Tais problemas foram pesquisados e aqueles relacionados com os impactos sobre as correntes de curto-circuito foram enfatizados. As normas técnicas das concessionárias também foram investigadas porque seus requisitos, como a ligação dos transformadores de acoplamento, influem nas correntes de curto-circuito.

Para se calcular as correntes de curto-circuito, desenvolveu-se uma planilha eletrônica cujos resultados foram validados com programas comerciais de análise de redes elétricas. Esta ferramenta foi utilizada para demonstrar, através de exemplos, o impacto causado pela geração distribuída sobre as correntes de curto-circuito e, posteriormente, para realizar as análises paramétricas nas quais a influência de cada variável foi avaliada.

A aplicação do método paramétrico permitiu o estudo de possíveis limites para a potência de um gerador distribuído em função dos impactos admissíveis, de seu ponto de conexão, de seus parâmetros elétricos e dos parâmetros elétricos da rede.

Palavras-chave: Geração distribuída de energia elétrica. Distribuição de energia elétrica. Correntes de curto-circuito. Análise paramétrica. 


\begin{abstract}
The purpose of this thesis is to analyse the impacts of distributed generation on shortcircuit currents and protection of the distribution utilities medium voltage networks using a parametric approach.

The new regulations that are promoting the distributed generation in Brazil are the main motivation for this work. However, the conventional distribution networks were designed to be passive; therefore the integration of generation may cause some technical problems yet to be solved.
\end{abstract}

Such problems were researched and those related to the impacts on short-circuit currents were emphasized. The utilities technical standards were also explored as their requirements affect the short-circuit currents (e.g. the transformers connections).

A spreadsheet was developed in order to calculated the short-circuit currents and it was validated comparing its results to those of a commercial network analysis software. This tool was used to expose the impacts of distributed generation on short-circuit currents through examples and also to carry out parametric analysis in which the influence of every variable was evaluated.

The application of a parametric method made it possible to define the maximum installed capacity of a distributed generator as a function of the allowed limits to the impacts on the short-circuit currents, its point of coupling, its electrical parameters and the electrical parameters of the network.

Keywords: Distributed generation. Electric power distribution. Short-circuit currents. Parametric analysis. 


\section{SUMÁRIO}

1 Introdução.................................................................................................................................................1

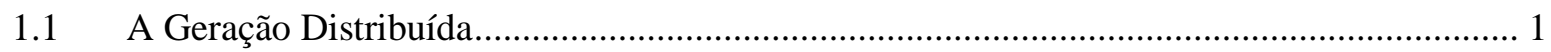

1.2 O Contexto Brasileiro........................................................................................... 3

1.3 Motivação e Objetivos .....................................................................................

1.4 Organização do Trabalho ............................................................................................... 8

2 Estado da Arte .......................................................................................................................10

2.1 Apontamentos sobre a Pesquisa Bibliográfica ............................................................... 10

2.2 O Estado Regulatório da Geração Distribuída no Brasil...................................................... 16

3 As Concessionárias de Distribuição e seus Requisitos em Relação à GD...................................20

$3.1 \quad$ As Redes de Distribuição de Energia Elétrica...………………………………………….. 20

3.2 A Importância da Filosofia de Aterramento....................................................................... 24

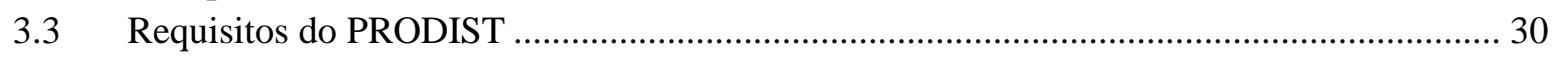

3.4 Requisitos das Concessionárias.................................................................................... 31

3.5 Principais Conclusões da Investigação.......................................................................... 39

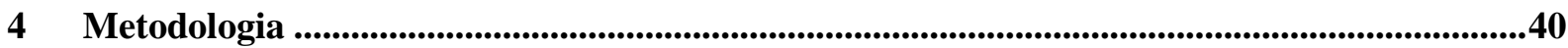

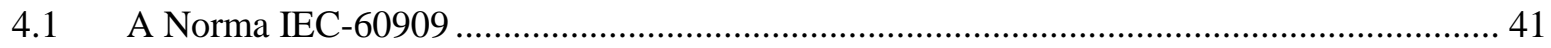

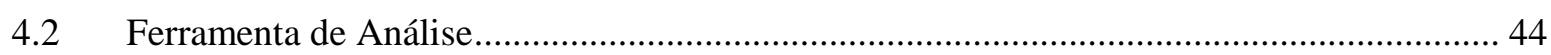

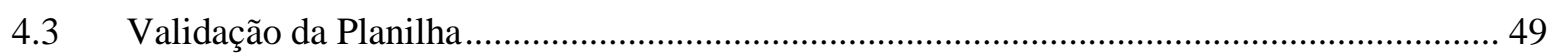

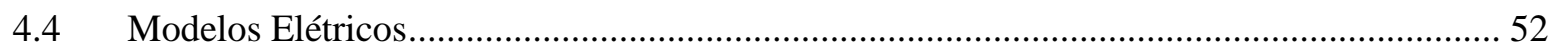

5 Impactos da GD no Curto-Circuito das Redes de Distribuição …………....................................55

5.1 Alteração nos Níveis de Curto-Circuito ……………………………………………....... 57

5.2 Alteração da Contribuição da Fonte .................................................................................. 62

5.3 Impacto nos Alimentadores Adjacentes .............................................................................. 67

6 Análises Paramétricas..................................................................................................................71

6.1 Critério A - Aumento no Nível de Curto-Circuito Local....................................................... 72

6.2 Critério B - Perda de Coordenação para Faltas a Jusante do Gerador …………………….... 74

6.3 Critério C - Impacto Máximo no Alimentador Adjacente.................................................... 78

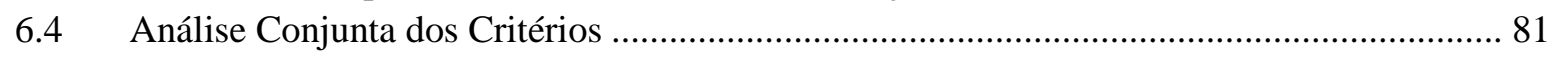

6.5 Determinação da Máxima Potência Admissível ................................................................. 86

$7 \quad$ Conclusões.............................................................................................................................................91

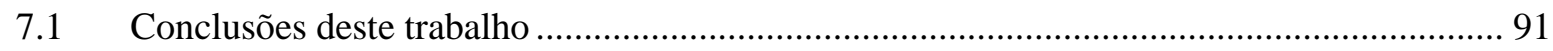

7.2 Sugestões para Trabalhos Futuros ………………………………………………......... 92

7.3 Considerações finais..................................................................................................... 93

Bibliografia

Anexo A - Modelos Elétricos para os Geradores Distribuídos ............................................................98

Anexo B - Modelos Elétricos para Linhas de Distribuição ................................................................102 


\section{GLOSSÁRIO}

$\begin{array}{ll}\text { ANEEL } & \text { Agência Nacional de Energia Elétrica } \\ \text { CIRED } & \text { Conseil International des Réseaux Électriques de Distribuition } \\ \text { CIGRÉ } & \text { Conseil International des Grands Réseaux Électriques } \\ \text { DG } & \text { Distributed Generation } \\ \text { EEG } & \text { Eneuerbare Energien Gesetz } \\ \text { ETAP } & \text { Electrical Transient and Analysis Program } \\ \text { ETH } & \text { Eidgenössische Technische Hochschule } \\ \text { GD } & \text { Geração Distribuída } \\ \text { IEC } & \text { International Electrotechnical Comission } \\ \text { IEEE } & \text { Institute of Electrical and Electronics Engineers } \\ \text { INEE } & \text { Instituto Nacional de Eficiência Energética } \\ \text { PES } & \text { Power Engineering Society } \\ \text { PRODIST } & \text { Procedimentos de Distribuição } \\ \text { PSERC } & \text { Power System Engineering Research Center } \\ \text { RESEB } & \text { Programa de Reestruturação do Setor Elétrico }\end{array}$




\section{INTRODUÇÃO}

\subsection{A Geração Distribuída}

Os primeiros sistemas de produção de energia elétrica desenvolvidos no final do século XIX eram descentralizados e atendiam as cargas locais em corrente contínua. A tensão não ultrapassava alguns poucos quilovolts e, portanto, a distribuição ocorria num raio de apenas alguns poucos quilômetros. Porém, essa eletrificação inicial foi rapidamente substituída pelo que então ficou conhecido como Sistema Universal, um sistema trifásico de corrente alternada que permitia elevar os níveis de tensão através de transformadores e assim aumentar as distâncias e as potências envolvidas. Este período de transição tecnológica ficou conhecido como A Guerra das Correntes (Hugues, 1983).

Aquelas primeiras estações descentralizadas de produção de energia passaram a se chamar subestações, pois agora serviam como instalações de transformação que se conectavam com a transmissão em um nível de tensão mais elevado. Os sistemas foram se interconectando e as potências e as distâncias envolvidas passaram a ser cada vez maiores. Durante o século XX, o Sistema Universal ganhou escala e o mundo passou por um processo de eletrificação. O sistema elétrico de potência se tornou um dos maiores e mais complexos sistemas já desenvolvidos pelo homem.

Ao final do século XX, o setor elétrico estava consolidado, mas passou a ser alvo das questões ambientais pelo fato de mais de $80 \%$ da produção de eletricidade no mundo ter origem em combustíveis fósseis ou nucleares (IEA, 2013). Ao mesmo tempo cresce o interesse da sociedade por fontes renováveis e fontes de maior eficiência energética, como a cogeração.

Com o avanço tecnológico das fontes renováveis e da cogeração, o meio acadêmico e a sociedade começaram a se interessar pela possibilidade da geração distribuída (GD), dispersa, embebida ou descentralizada, tal como ocorria nos primórdios da eletrificação, porém agora inseridas em um grande sistema interconectado. A geração distribuída trata de utilizar os 
mesmos circuitos de baixa e média tensão que os consumidores estão conectados para injetar energia.

A geração distribuída traz diversos benefícios para o sistema. Por gerar energia onde ela é consumida, reduz-se o uso do sistema de transmissão. Adicionalmente, caso a energia distribuída entre na base do sistema como, por exemplo, através de centrais de cogeração qualificada, pode-se liberar integralmente uma capacidade equivalente no sistema de transmissão, evitando-se custos com a sua expansão.

Pode-se dizer que, até determinado nível de penetração da geração distribuída ${ }^{1}$, também há liberação de capacidade instalada da rede de distribuição, sobretudo à montante do ponto de conexão do gerador. Analogamente, evitam-se os custos relacionados com o aumento da capacidade das linhas e de transformação.

Como a geração distribuída contribui para a redução do carregamento das redes até um dado nível de penetração, da mesma forma pode contribuir para a redução das perdas elétricas, uma vez que as perdas são proporcionais ao quadrado das correntes envolvidas.

Outro benefício trazido pela geração distribuída é o aumento da confiabilidade e da continuidade do fornecimento para o consumidor, pois ao produzir a sua própria energia, o consumidor poderá atender sua carga quando a rede externa estiver indisponível ou ainda, permitir o atendimento a outras cargas através do ilhamento de um trecho da rede quando da ocorrência de contingências na rede da concessionária. Além do mais, alguns tipos de tecnologia de geração distribuída podem contribuir com o controle de tensão da rede através do fornecimento ou consumo de potência reativa. Em uma rede inteligente, os geradores podem trabalhar em conjunto para melhorar o perfil de tensão e reduzir as perdas elétricas.

Por outro lado, a GD também traz alguns problemas que ainda precisam ser superados, pois a sua introdução causa impactos à operação tradicional das redes de distribuição, tais como: a alteração do perfil de tensão e o carregamento de alguns elementos da rede, as alterações nos níveis de curto-circuito e consequentes impactos sobre a proteção, a possível deterioração da qualidade de energia devido à injeção de correntes harmônicas por GD

\footnotetext{
${ }^{1}$ A penetração da geração distribuída é a relação entre a potência injetada pelos geradores e a carga elétrica de um determinado trecho da rede de distribuição.
} 
conectada através de inversores, flicker causado por fontes intermitentes, a impossibilidade do religamento de uma rede ilhada com GD sem a devida sincronização, entre outros.

A geração distribuída é um dos principais instrumentos para a implantação das políticas de transição energética para tornar as matrizes cada vez mais limpas. Por conta disso, muitos países fizeram mudanças regulatórias para promovê-la, principalmente sob a forma de fontes renováveis. A geração renovável tem prioridade no despacho, de maneira que há um efeito líquido de abatimento da geração das demais fontes, usualmente térmica.

A Alemanha foi pioneira com a implantação da lei das energias renováveis ${ }^{2}$ (EEG) em 2000, que promove fontes renováveis como a hidráulica, eólica, solar, geotérmica, biomassa e também a cogeração qualificada (que atende requisitos mínimos de eficiência). A EEG resultou em um desenvolvimento muito acelerado das energias renováveis na Alemanha ${ }^{3}$, que passaram de 6,5\% da matriz em 2000 para 27,8\% em 2014. Este crescimento também impulsionou a geração distribuída, sobretudo com a geração solar fotovoltaica e a cogeração eficiente a gás natural.

Por sua vez, nos Estados Unidos estima-se que a geração distribuída representará o valor de 28,4 GW de capacidade instalada até 2040 (EIA, 2013). Segundo o World Energy Outlook 2013, o mundo deverá aumentar a participação das fontes renováveis nas matrizes elétricas de 20,3\% em 2011 para 31,3\% (IEA, 2013). Parte significativa deste crescimento é baseada na geração distribuída. Esta é uma tendência mundial, que o Brasil deverá acompanhar.

\subsection{O Contexto Brasileiro}

O Brasil consolidou ao longo de sua história a tradição hidrelétrica. Este era o caminho natural para a expansão da geração de eletricidade no país uma vez que o potencial hidrelétrico a ser explorado era imenso. As usinas eram construídas com grandes reservatórios plurianuais, i.e., garantiam a geração mesmo que a hidrologia fosse muito desfavorável por vários anos seguidos.

\footnotetext{
${ }^{2}$ EEG - Enerneuerbare-Energien-Gesetz: http://www.bgbl.de/, (acessado em 31.03.2014)

3 AG Energie Bilanzen - Bruttostromerzeugung in Deutschland von 1990 bis 2014 nach Energieträgern: http://www.ag-energiebilanzen.de (acessado em 07.04.2014)
} 
Parte significativa destas usinas hidrelétricas foi financiada, construída e operada pelo Estado, até que as sucessivas crises que atingiram o país na década de 80 reduziram a capacidade do governo manter o ritmo de investimento necessário. O crescimento da carga continuava a ser atendido devido aos reservatórios plurianuais das usinas já construídas.

Na década de 90 o setor elétrico brasileiro passou por um programa de reestruturação (RESEB) que culminou na sua desverticalização e privatização. As empresas de geração passaram a competir entre si através dos leilões de energia realizados pelo governo. Ainda que os investimentos tenham sido retomados, não foram suficientes para conter o racionamento de 2001 causado por um grande período de estiagem.

Os reservatórios outrora plurianuais passaram a ser de regularização anual. Desde então, a ameaça de racionamento iminente por razões hidrológicas passou a ser preocupação, como no início de 2008 e, recentemente, desde o início de 2013. Neste último caso, foram despachados mais de $10 \mathrm{GW}$ médios de termelétricas fora da ordem de mérito.

Segundo o Plano Decenal de Energia PDE 2023 (EPE, 2014), as novas usinas hidrelétricas serão a fio d'água, i.e., contam apenas com um pequeno reservatório para regulação diária, mas que tem pouco efeito prático para o armazenamento de energia. Isto se deve ao fato dos novos padrões ambientais aplicados aos novos projetos, que se localizam no Norte do Brasil, onde resta o potencial hidrelétrico a ser aproveitado.

Como pode ser visto na Figura 1.1, entre 2014 e 2023 a carga elétrica irá aumentar 41\%, a geração térmica firme $69 \%$ e o armazenamento apenas $2 \%$. A desproporção entre carga e armazenamento deveria ser compensada pela geração térmica, ainda assim, a razão entre a energia armazenada máxima e a carga caiu de 6,3 para 5,1 meses no período (-20\%).

O PDE 2023 também mostra que parte significativa do crescimento da matriz elétrica está sendo feita através da fonte eólica, conforme mostra a Figura 1.2. Esta fonte sairá de 5,5 GW em 2014 para 22,4 GW em 2023, o que representa de 4,1\% e 11,5\% da matriz elétrica, respectivamente. Por sua vez, ainda que as hidrelétricas (considerando PCHs) passem de 94,2 GW em 2014 para 124,2 GW em 2023, sua participação relativa na matriz irá reduzir de $71,1 \%$ para $63,4 \%$, respectivamente. 

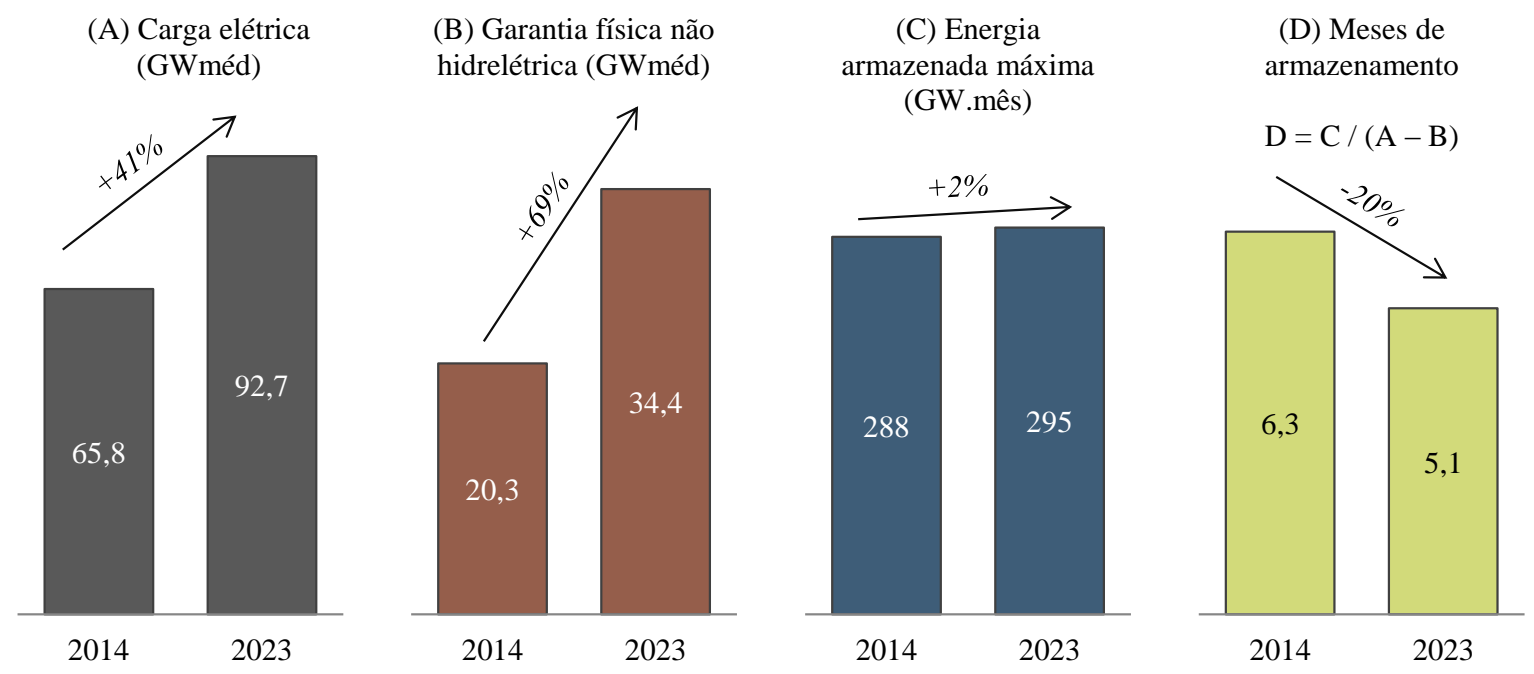

Figura 1.1 - Evolução da carga, da geração térmica, do armazenamento dos reservatórios e de sua duração para o período de 2014 a 2023. Fonte: elaboração própria a partir dos dados do PDE 2023 (EPE).

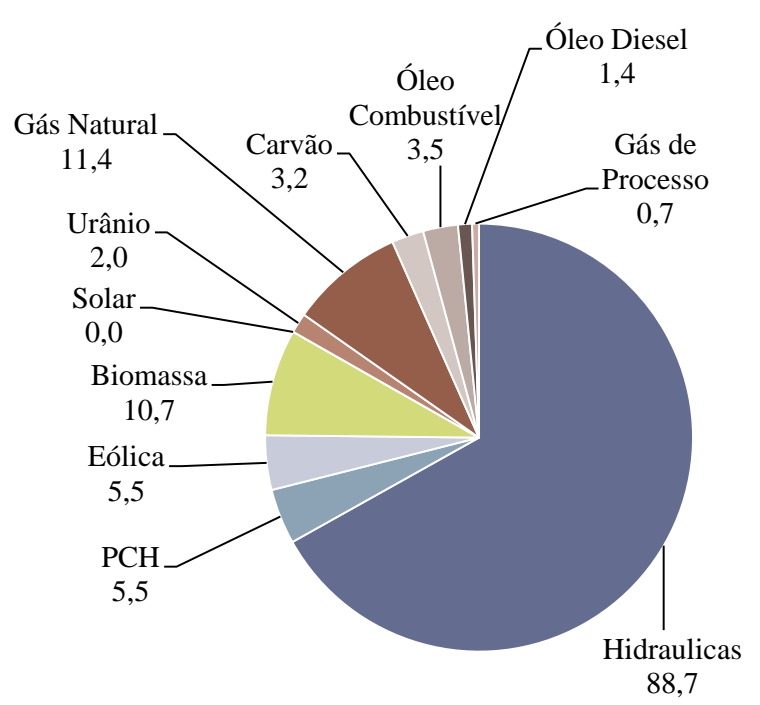

$\mathbf{2 0 1 4}$
$132,6 \mathrm{GW}$

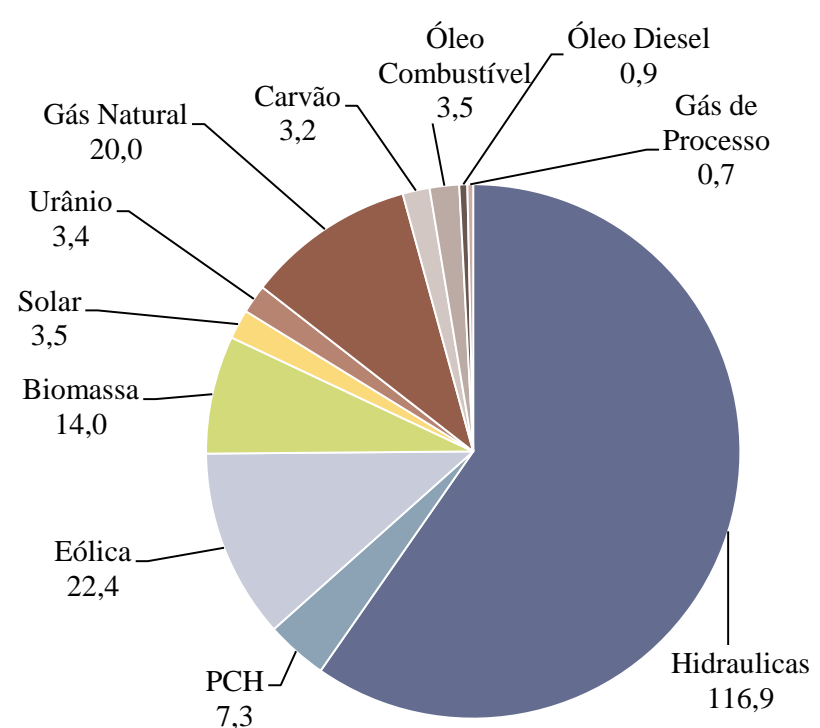

2023

Figura 1.2 - Evolução da matriz elétrica do Sistema Interligado Nacional. Fonte: Elaboração própria a partir dos dados do PDE 2023 (EPE).

O PDE2023 trata brevemente da geração distribuída em seu capítulo IX, juntamente com os ganhos de eficiência energética. Os dados são apresentados de forma consolidada sob a ótica da autoprodução de energia, de forma que não é possível saber a participação de cada fonte. Contudo as análises desse plano indicam um crescimento médio de 5,4\% a.a. para a 
autoprodução nos próximos 10 anos. Certamente parte da expansão da demanda de energia brasileira poderia ser atendida pela geração distribuída, ajudando a poupar os reservatórios das usinas, tão necessários nesse cenário de expansão com usinas a fio d'água.

Atualmente já existe um grande montante de pequenos geradores espalhados por todo o país. Segundo o Banco de Informação da Geração da ANEEL ${ }^{4}$, há 2.084 MW de capacidade instalada de centrais com potência menor ou igual a 5 MW, conforme mostra a Tabela 1.1. Isto representa $1,7 \%$ de toda a capacidade instalada do país.

Tabela 1.1 - Capacidade instalada de centrais com potência menor ou igual a 5 MW (fonte: Banco de Informação da Geração ANEEL, elaboração própria)

\begin{tabular}{lcccc}
\hline Tipo de fonte & No de usinas & $\begin{array}{c}\text { Potência } \\
\text { (MW) }\end{array}$ & $\begin{array}{c}\text { Participação } \\
\text { relativa na } \\
\text { potência }\end{array}$ & $\begin{array}{c}\text { Potência } \\
\text { média das } \\
\text { usinas (MW) }\end{array}$ \\
\hline Termelétrica & 603 & 1.027 & $49,3 \%$ & 1,7 \\
\hline Óleo Diesel & 445 & 539 & $25,8 \%$ & 1,2 \\
Bagaço de cana de açúcar & 93 & 308 & $14,8 \%$ & 3,3 \\
Gás Natural & 33 & 92 & $4,4 \%$ & 2,8 \\
$\quad$ Outros (resíduos de madeira, etc.) & 32 & 88 & $4,2 \%$ & 2,8 \\
\hline Hidrelétrica & 745 & 937 & $45,0 \%$ & 1,3 \\
Eólica & 32 & 109 & $5,2 \%$ & 3,4 \\
Fotovoltaica & 25 & 11 & $0,5 \%$ & 0,4 \\
\hline Total & $\mathbf{1 . 4 0 5}$ & $\mathbf{2 . 0 8 4}$ & $\mathbf{1 0 0 , 0 \%}$ & $\mathbf{1 , 5}$ \\
\hline
\end{tabular}

Os dados do Banco de Informação da Geração mostram que as centrais termelétricas correspondem à metade da potência dos geradores com até $5 \mathrm{MW}$ de capacidade instalada, representadas principalmente pelas unidades diesel e cogerações a partir da cana de açúcar e gás natural. As pequenas centrais hidrelétricas correspondem a quase outra metade, de forma que as duas fontes em conjunto representam aproximadamente $95 \%$ da geração até $5 \mathrm{MW}$.

As eólicas não tem grande representatividade nessa faixa de potência, pois usualmente esta fonte é implantada no Brasil sob a forma de grandes parques com capacidade instalada

\footnotetext{
${ }^{4}$ Banco de Informações da Geração da ANEEL. Acessado em 27.08.2015.

Site: http://www.aneel.gov.br/aplicacoes/capacidadebrasil/capacidadebrasil.cfm
} 
até $30 \mathrm{MW}$. Por sua vez, as centrais fotovoltaicas com até $5 \mathrm{MW}$ de capacidade ainda não têm grande participação na matriz elétrica e a tendência é que o grande volume contratado desta fonte nos últimos leilões seja implementado em parques solares de até $30 \mathrm{MW}$, de maneira semelhante ao que ocorreu com a geração eólica.

Ainda que a ANEEL não informe o nível de tensão em que essas centrais estão conectadas, acredita-se que parte significativa delas seja ligada em redes de distribuição de média tensão, pois em muitos casos não seria econômico ligá-las diretamente à alta tensão. Portanto, a conexão de geração na distribuição já é um fato, e que deve aumentar conforme indicam os planos do setor.

\subsection{Motivação e Objetivos}

Em 2012, a ANEEL publicou a Resolução Normativa $n^{\circ} 482 / 2012$, que introduziu o regime de compensação de energia no Brasil (net-metering), no qual o consumidor pode gerar sua própria energia e abater seu consumo, pagando para a concessionária apenas seu consumo líquido, contanto que capacidade do gerador fosse inferior a $1 \mathrm{MW}$. Caso a geração ultrapasse a sua demanda, configurando uma exportação de energia, o consumidor terá créditos com a distribuidora e poderá usá-los nos meses seguintes.

Esta resolução abriu um novo horizonte para geração distribuída no Brasil, ainda que com alguns percalços relativos à tributação deste novo modelo. Em 2014 mais um passo adiante foi dado, quando a ANEEL realizou a Consulta Pública ${ }^{\circ}$ 005/2014 que tratava do aumento do limite de $1 \mathrm{MW}$, com o objetivo de fomentar a cogeração qualificada, que é aquela que atende requisitos de eficiência energética.

Apesar do recente avanço das questões econômicas e regulatórias que estão viabilizando um mercado para a geração distribuída, ainda há questões de ordens técnicas a resolver, sobretudo quanto aos impactos sobre a proteção da rede de distribuição.

Tradicionalmente, as redes de distribuição sempre foram planejadas e projetadas como redes passivas de topologia radial, em que o fluxo de potência sempre se dá num único sentido. Por essa razão, as correntes de curto-circuito são geralmente bem determinadas e 
pouco dependentes do estado de operação da rede, de forma que a proteção e seus ajustes se tornam relativamente simples. Contudo, a inserção da GD nas redes de distribuição desafia este paradigma, pois ela pode modificar o sentido e as magnitudes das correntes de carga e de curto-circuito. É deste desafio que surgiu a motivação para esta dissertação.

Este trabalho tem como objetivo apresentar os impactos nas correntes de curto-circuito das redes de distribuição causados pela conexão da geração distribuída e analisá-los de maneira paramétrica. Dessa maneira é possível avaliar a influência de cada parâmetro e determinar quais são os mais significativos.

\subsection{Organização do Trabalho}

O capítulo 1 introduz o conceito de geração distribuída, descreve o problema abordado, o contexto da geração distribuída no Brasil e as motivações e justificativas para este trabalho.

Em seguida, no capítulo 2, apresenta-se a visão mais atual relacionada aos impactos da geração distribuída sobre as redes de distribuição, sobretudo no que se refere às correntes de curto-circuito e à proteção. As referências mais significativas encontradas durante o período de pesquisa bibliográfica são analisadas. Em seguida, o estado regulatório da geração distribuída no Brasil é resumido, pois traz considerações importantes para o trabalho.

O capítulo 3 faz uma breve introdução às redes de distribuição e suas filosofias de operação, proteção e aterramento. Estes conceitos são necessários para o entendimento dos tópicos que se desenvolvem ao longo do texto. O mesmo capítulo também trata da regulação técnica aplicável no Brasil, nomeadamente o PRODIST (Procedimentos de Distribuição) e das exigências das concessionárias em relação à conexão de geração em suas redes. Ao final, resumem-se as principais conclusões da pesquisa, que serviram de premissas para o trabalho.

O capítulo 4 explica com detalhes os métodos empregados no desenvolvimento do trabalho, como os modelos elétricos implementados sob a forma de uma planilha e a norma IEC-60909 que define o cálculo das correntes de curto-circuito. A planilha é validada e posteriormente são apresentadas as definiçõoes das análises paramétricas e dos estudos de casos realizados. 
No capítulo 5 são discutidos os principais problemas que a geração distribuída causa à proteção das redes, como a alteração dos níveis de curto-circuito, a alteração da contribuição da fonte e o impacto sobre a proteção dos alimentadores adjacentes. As análises das equações introduzidas neste capítulo levaram a algumas conclusões importantes sobre o aterramento do transformador de acoplamento do gerador e sobre o ponto de falta.

As análises paramétricas são desenvolvidas no capítulo 6, sob a forma de três critérios que posteriormente são avaliados em conjunto para se determinar qual deles é o mais crítico para a conexão de um gerador em uma rede de distribuição. A partir do critério mais severo demonstra-se que é possível estabelecer limites para a potência de um gerador distribuído dado um limite admissível para os impactos sobre as correntes de curto-circuito na rede.

Finalmente, no capítulo 7, discorre-se sobre as conclusões desta dissertação, sugerem-se estudos futuros que possam complementar ou continuar esse trabalho e se faz considerações finais sobre a relevância do tema. 


\section{Estado da Arte}

\subsection{Apontamentos sobre a Pesquisa Bibliográfica}

Os artigos mais antigos que tratam de geração distribuída encontrados durante a pesquisa bibliográfica datam do início da década de 90 e logo se formaram grupos de trabalho (CIGRÈ, 1998) e (CIRED, 1999) para discutir os impactos que esse novo conceito traria às redes de distribuição de energia. Estes primeiros trabalhos já apontavam para possíveis problemas com a proteção das redes convencionais de distribuição, como a alteração das magnitudes das correntes de curto-circuito e a possível perda de coordenação entre os dispositivos de proteção.

Nesta altura, a terminologia ainda não estava padronizada e se utilizava tanto o termo distributed generation (geração distribuída) quanto dispersed generation (geração dispersa), porém ambos foram abreviados na literatura de língua inglesa como DG. Neste trabalho usouse o acrônimo em português (GD). Outros termos comuns são: embedded generation ou decentralized generation, por conta da influência inglesa e alemã, respectivamente.

Por falta de uma definição mais exata do conceito de geração distribuída, Ackermann, Andersson e Soder publicaram um artigo em 2001 que se intitula "Distributed Generation: a definition" (Ackermann, et al., 2001). O artigo é amplamente citado e se tornou uma referência na área. Este artigo analisou alguns tópicos que poderiam ajudar a definir a geração distribuída, tais como seu propósito, localização, capacidade, região elétrica, tecnologia de geração, impacto ambiental, modo de operação, propriedade e penetração e por fim, apresenta a seguinte definição:

\footnotetext{
"Distributed generation is an electric power source connected directly to the distribution network or on the customer side of the meter."
} 
Apesar do conceito simples, ela evidencia o fato de que as redes de distribuição do modelo tradicional serviam apenas para distribuir a energia produzida em grandes centrais, isto é, tratavam-se de redes passivas. Além do conceito geral, o artigo também propõe alguma categorização da geração distribuída em função da potência instalada e do tipo de fonte, como renováveis, modulares e cogeração.

Os principais problemas oriundos da conexão da geração em redes de distribuição também foram discutidos em diversos artigos publicados pelo IEEE por volta do ano 2000 (Barker \& Mello, 2000), (Ackermann \& Knyazkin, 2002) e (Lopes, 2002). Nesta época também foi publicado um dos primeiros livros sobre a geração distribuída e seus impactos (Jenkins, et al., 2000). Estes livros, artigos e os trabalhos mencionados discorrem por diversos problemas, tais como:

a) Regulação de tensão e de reativos (volt/var)

Pode-se demonstrar que a queda de tensão em um trecho de rede depende basicamente da resistência e reatância da linha e da potência ativa e reativa transportada. Nas redes em que não há geração distribuída, o perfil de tensão é geralmente decrescente da fonte para a carga e, quando necessário, pode existir um regulador de tensão localizado no início do alimentador ou em posição mais conveniente.

De forma geral, pode-se dizer que a potência ativa transportada é mais significativa para a queda de tensão em uma rede de distribuição porque sua razão $\mathrm{R} / \mathrm{X}$ é tipicamente maior do que no caso das redes de transmissão. De fato, pode-se demonstrar que a queda de tensão em um alimentador $(\Delta V)$ pode ser aproximada como uma função da potência ativa $(P)$ e reativa $(Q)$ transportada e da resistência $(R)$ e reatância $(X)$ da rede, no sistema por unidade (p.u.):

$$
\Delta V \approx \frac{R \cdot P+X \cdot Q}{V}
$$


Na presença de um gerador, a distribuição de potência ativa pela rede é alterada e há, portanto, grandes impactos sobre no seu perfil de tensão.

Ademais, os controles de tensão dos geradores distribuídos podem conflitar com o controle dos reguladores de tensão instalados na rede, sobretudo porque os reguladores de tensão da rede têm uma atuação lenta e os dos geradores têm uma atuação rápida. Pelas razões apresentadas, os elementos da rede, inclusive as cargas, podem ficar em sub ou sobretensão por períodos prolongados.

\section{b) Carregamento das linhas e equipamentos}

De uma maneira geral, a presença da geração distribuída tende a diminuir o carregamento da rede, mas caso a penetração da geração seja muito elevada, o carregamento pode crescer substancialmente. Isto pode fazer com que cabos e transformadores ultrapassem seus limites térmicos, antecipando o fim de sua vida útil ou até mesmo causando sobrecargas que os danifiquem permanentemente.

\section{c) Alteração dos níveis de curto-circuito}

Nos casos em que a rede contém geradores que contribuem para o curto-circuito, notadamente aqueles baseados em máquinas rotativas (síncronas ou assíncronas diretamente conectadas), há um aumento das correntes de falta, de maneira que alguns elementos da rede possam ultrapassar seus limites de suportabilidade térmica ou dinâmica ao curto-circuito, como TCs, cabos, transformadores, etc. As malhas de aterramento também podem ficar comprometidas em alguns casos.

Em virtude da alteração dos níveis de curto-circuito, mencionada anteriormente, pode haver perda da coordenação da proteção nas redes protegidas por elementos de sobrecorrente, como relés, religadores e fusíveis. As proteções das redes convencionais passivas e radiais foram projetadas considerando-se que a corrente de curto-circuito é bem determinada e flui apenas em uma única direção, aumentando conforme a proximidade da fonte. Contudo, ao se 
conectar geração na rede, surgem correntes de curto-circuito reversas não consideradas no projeto original da distribuidora.

Os primeiros artigos especificamente dedicados aos impactos da geração distribuída sobre a coordenação da proteção surgiram no começo da década de 2000. Os autores Girgis e Brahma publicaram em 2001 um artigo (Girgis \& Brahma, 2001) que trata da perda de coordenação de uma forma geral e outro artigo (Brahma \& Girgis, 2001) dedicado especificamente à perda de coordenação entre relés e fusíveis sob a presença de geração distribuída. Estes autores produziram diversos outros trabalhos sobre o assunto ao longo dos últimos anos.

A Power Engineering Society (PES) do IEEE criou um grupo de trabalho que culminou na publicação do relatório “Impact of Distributed Resources on Distribution Relay Protection" em 2004 (Seegers \& Birt, 2004). O relatório aborda questões como o tipo de ligação do transformador do gerador, perda de coordenação das proteções, aumento dos níveis de falta, ilhamento, mas também trata de outras questões de automação, como o desempenho dos reguladores de tensão e do chaveamento automático dos bancos de capacitores.

A referência (Nimpitiwan \& Heydt, 2006) é um trabalho completo e interessante sobre as consequências das correntes de falta criadas pela geração distribuída publicado pelo PSERC (Power Systems Engineering Research Center). O trabalho não trata apenas das correntes de curto-circuito, mas também de seus impactos sobre a proteção, sobre a estimação de correntes de falta em tempo real e trata, por fim, de um método de otimização denominado "colônia de formigas" (ACO - Ant Colony Optimization) para encontrar os ajustes ótimos (ou quase ótimos) dos dispositivos de proteção da rede que minimizem os casos de perda de seletividade.

Um dos artigos mais relevantes no que se refere ao estado da arte da proteção de redes com geração distribuída foi publicado por Martin Geidl (Geidl, 2005) da ETH de Zürich, em 2005. Entre todos os artigos levantados durante o período de pesquisa bibliográfica este é o que aborda o assunto de maneira mais abrangente e serviu como um norte para guiar a pesquisa. Em sua introdução descreve rapidamente o que é a geração distribuída e os requisitos gerais dos sistemas de proteção, a influência do tipo de máquina utilizada e os métodos de interconexão com a rede de distribuição. 
O artigo de Geidl relaciona cinco problemas básicos: alteração dos níveis de curtocircuito, o subalcance dos relés de distância, a alteração na direção do fluxo de carga e o perfil de tensão ao longo da rede, o ilhamento e auto-religamento e, por fim, alguns problemas como ferroressonância e aterramento. Em um capítulo seguinte, descreve as práticas mais correntes em alguns tópicos como: detecção de ilhamento, técnicas de interconexão, aplicação dos relés mais sofisticados e também as normas e recomendações internacionais. Ao final do artigo, Geidl discute as novas técnicas que estão surgindo e que podem contribuir para resolver os problemas apontados, como os sistemas de proteção adaptativos, a medição fasorial sincronizada (PMUs) e o uso de sistemas inteligentes como as redes neurais.

\section{d) Ilhamento e demais problemas}

O ilhamento é um fenômeno que decorre da separação elétrica entre um trecho da rede que possui geração distribuída conectada e o restante da rede. Este evento pode ocorrer quando um relé ou religador desligar por ocasião de uma falta em um trecho da rede que continuará energizado devido à presença de um gerador. Este trecho ilhado não poderá ser reconectado ao restante da rede enquanto ambas estiverem dessincronizadas.

A solução mais simples para o problema é desligar o gerador do trecho ilhado para então proceder ao religamento. Portanto, o gerador precisa perceber que está ilhado e para isso pode ser usada diversas técnicas de proteção, por exemplo, com o emprego de relés de frequência, de tensão, de salto de vetor, PMU's (Phasor Measurement Units), medição de impedância, etc. Um grande problema que decorre da utilização destas proteções é o desligamento indevido do gerador e sua entrada e saída repentina da rede pode causar problemas de estabilidade dinâmica e de tensão.

As publicações mais recentes sobre a geração distribuída tendem a tratar de problemas como o ilhamento, como, por exemplo, o artigo (Freitas, et al., 2005) que faz uma comparação entre o uso de relés de variação de frequência (ROCOF) e de salto de vetor (Vector Surge Relay) em aplicações de geração distribuída. 
A referência (Bollen \& Hassan, 2011) trata-se de um livro abrangente sobre os impactos da geração na rede de distribuição. Sua abordagem é técnica e detalha todos os aspectos de um determinado problema. Os assuntos tratados são: fontes de energia, desempenho do sistema de potência, sobrecargas e perdas, variação da magnitude de tensão, distúrbios na qualidade de energia, proteção, operação do sistema de transmissão, todos sob a ótica do impacto da geração distribuída.

Outro aspecto interessante deste livro é sua abordagem de "capacidade de acolhimento da geração distribuída" (Host Capacity). Em outras palavras, os autores criaram métodos para determinar analiticamente a capacidade de geração distribuída que uma dada rede pode absorver sem ultrapassar determinados limites pré-estabelecidos que, por exemplo, podem ser definidos pelo engenheiro que está projetando a rede ou pelas normas da concessionária. Este critério de Host Capacity é aplicado para todos os tópicos tratados no livro, isto é, para a regulação de tensão, perdas e carregamento da rede, níveis de corrente de curto-circuito, proteção e qualidade de energia.

A geração distribuída também pode causar problemas de qualidade de tensão, sobretudo quando há eletrônica de potência envolvida na tecnologia de geração. Pode-se dizer que este contratempo foi mitigado com a aplicação de conversores de frequência com elevado desempenho em relação à produção de harmônicos. Outro tema a envolver a qualidade de tensão é o fato de geradores entrarem e saírem da rede causando rápidos afundamentos (sags) ou elevações (swells) de tensão.

Em relação à normalização, foi publicado em 2003 o padrão americano IEEE Std 1547 (IEEE, 2003) que trata das principais recomendações relacionadas ao desempenho, segurança, operação e manutenção, comissionamento e testes para a interconexão da geração distribuída à rede das concessionárias nos Estados Unidos. Segundo o padrão, seu limite de escopo são as plantas com capacidade de até 10 MVA. No Brasil, os requisitos técnicos para conexão da geração distribuída são mencionados no PRODIST (ver item 3.3) e nos manuais das concessionárias de distribuição (ver item 3.4). 


\subsection{O Estado Regulatório da Geração Distribuída no Brasil}

A geração distribuída começou a ser discutida no Brasil fora dos meios acadêmicos quando houve racionamento em 2001. Em 2002, o Instituto Nacional de Eficiência Energética (INEE) apresentou uma proposta de revisão da Resolução ANEEL 281/99 para contemplar o acesso dos geradores distribuídos às redes das concessionárias (INEE, 2002), mas que não chegou a ser incorporada. O conceito somente foi introduzido no Brasil quando o Decreto $\mathrm{n}^{\circ} 5.163$ de 30 de julho de 2004 foi publicado, um dos marcos regulatórios do setor elétrico brasileiro que trata da comercialização da energia elétrica, conforme o artigo 15:

“Art. 15. A contratação de energia elétrica proveniente de empreendimentos de geração distribuída será precedida de chamada pública promovida diretamente pelo agente de distribuição, de forma a garantir publicidade, transparência e igualdade de acesso aos interessados.

$\S 1^{o} O$ montante total da energia elétrica contratada proveniente de empreendimentos de geração distribuída não poderá exceder a dez por cento da carga do agente de distribuição.

(...)

$\S 4^{\circ}$ As eventuais reduções de custos de aquisição de energia elétrica referida no $\S$ $3^{\circ}$ deverão ser consideradas no repasse às tarifas dos consumidores finais com vistas à modicidade tarifária, vedado o repasse de custos adicionais. ”

Apesar do Decreto $\mathrm{n}^{\circ}$ 5.163/2004 regularizar a figura do gerador distribuído ele não forneceu nenhum incentivo para que sua energia fosse comprada pela distribuidora, pois qualquer ganho obtido na contratação deveria ser repassado ao consumidor.

Este mesmo Decreto também definiu o Valor de Referência (VR) como um valor médio que representasse o custo marginal de expansão do sistema, i.e., o custo médio dos leilões de energia nova, e que seria utilizado posteriormente para limitar o preço de contratação da geração distribuída. 
Na tentativa de se introduzir algum incentivo à contratação da geração distribuída, a ANEEL emitiu a Resolução Normativa $n^{\circ} 167$ de 10 de outubro de 2005. Além de outras alterações no texto do Decreto $n^{0} 5.163 / 2004$, esta resolução estabeleceu que o custo da aquisição de energia de geração distribuída poderia ser repassado ao consumidor até o limite do Valor de Referência (VR):

" $\$ 3^{\circ}$ A ANEEL autorizará o repasse, às tarifas dos consumidores finais, do preço da energia elétrica adquirida conforme o caput, até o limite do Valor Anual de Referência - VR vigente no ano de início da entrega da energia contratada e, nos reajustes subseqüentes, no valor atualizado pelo IPCA."

Naquela ocasião, o VR estava muito baixo e apenas algumas cogerações implantadas no período de racionamento conseguiram ser contratadas. Além disso, com o aumento da competitividade nos leilões de energia o VR foi se tornando cada vez menor.

Como exemplo, toma-se o Despacho SEM/ANEEL no 289 de 11 de fevereiro de 2014, que estabelece o Valor de Referência para 2015 em R \$ 80,69 / MWh, com base em dezembro de 2010. Ao se atualizar o valor pelo IPCA, o VR passa a valer $\mathrm{R} \$ 104,43$ / MWh em janeiro de $2015^{5}$.

O custo da energia produzida pela geração distribuída tem sido muito maior que o VR, que representa o custo médio da energia nos últimos Leilões de Energia Nova. Além da imensa diferença de escala, a geração convencional utiliza tecnologias já consolidadas. Dessa forma, pode-se dizer que a Resolução Normativa $n^{\circ} 167 / 2005$ inviabilizou economicamente a geração distribuída.

Em 2006 um passo adiante foi dado com a publicação da Resolução Normativa ANEEL $\mathrm{n}^{\circ} 235$ de 14 de novembro de 2006, que estabelece os requisitos para a qualificação de centrais termelétricas cogeradoras. Isto é, criou-se a figura da cogeração qualificada, que é a produção combinada de calor útil e eletricidade com elevada eficiência global.

\footnotetext{
${ }^{5}$ Valor corrigido através da ferramenta do Banco Central do Brasil: https://www3.bcb.gov.br/CALCIDADAO/jsp/index.jsp
} 
O tema geração distribuída voltou a ser discutido seis anos mais tarde, com a publicação da Resolução Normativa ANEEL n 482 de 17 de abril de 2012, mas desta vez o enfoque foi o da compensação de energia (net-metering).

"Art. $1^{\circ}$ Estabelecer as condições gerais para o acesso de microgeração e minigeração distribuídas aos sistemas de distribuição de energia elétrica e o sistema de compensação de energia elétrica.

Art. $2^{\circ}$ Para efeitos desta Resolução ficam adotadas as seguintes definições:

I - microgeração distribuída: central geradora de energia elétrica, com potência instalada menor ou igual a $100 \mathrm{~kW}$ e que utilize fontes com base em energia hidráulica, solar, eólica, biomassa ou cogeração qualificada, conforme regulamentação da ANEEL, conectada na rede de distribuição por meio de instalações de unidades consumidoras;

II - minigeração distribuída: central geradora de energia elétrica, com potência instalada superior a $100 \mathrm{~kW}$ e menor ou igual a $1 \mathrm{MW}$ para fontes com base em energia hidráulica, solar, eólica, biomassa ou cogeração qualificada, conforme regulamentação da ANEEL, conectada na rede de distribuição por meio de instalações de unidades consumidoras;

III - sistema de compensação de energia elétrica: sistema no qual a energia ativa gerada por unidade consumidora com microgeração distribuída ou minigeração distribuída compense o consumo de energia elétrica ativa.

Art. $3^{\circ}$ As distribuidoras deverão adequar seus sistemas comerciais e elaborar ou revisar normas técnicas para tratar do acesso de microgeração e minigeração distribuída, utilizando como referência os Procedimentos de Distribuição de Energia Elétrica no Sistema Elétrico Nacional - PRODIST, as normas técnicas brasileiras e, de forma complementar, as normas internacionais."

Porém, ainda no mesmo ano, algumas barreiras para a geração distribuída foram impostas com a Resolução Normativa ANEEL nº 517 de 11 de dezembro de 2012, que alterava o texto da Resolução n 482/2012, estabelecendo limites para a injeção de potência na rede: 


\begin{abstract}
"§ $1^{\circ}$ A potência instalada da microgeração ou minigeração distribuida participante do sistema de compensação de energia elétrica fica limitada à carga instalada, no caso de unidade consumidora do grupo B, ou à demanda contratada, no caso de unidade consumidora do grupo $A$

$\$ 2^{\circ}$ Caso o consumidor deseje instalar microgeração ou minigeração distribuída com potência superior ao limite estabelecido no $\$ 1^{o}$, deve solicitar aumento da carga instalada, no caso de unidade consumidora do grupo B, ou aumento da demanda contratada, no caso de unidade consumidora do grupo A."
\end{abstract}

Em 2013, o Conselho Nacional de Política Fazendária (CONFAZ), através do Convênio ICMS No 6 de 5 de abril de 2013, determinou que o ICMS não deveria ser cobrado apenas sobre o consumo líquido de energia, mas sobre todo o montante de energia transacionado com a distribuidora. Isto se tornou mais um empecilho à proliferação da GD no Brasil.

A despeito de alguns percalços, o conceito de net-metering introduzido pela Resolução Normativa ANEEL nº 482/2012 criou um ambiente regulatório favorável ao desenvolvimento da geração distribuída no Brasil.

Em março de 2014, a ANEEL abriu a Audiência Pública nº. 005/2014 para estudar a possibilidade de se ampliar o limite do net-metering além de 1 MW. Em maio de 2015, a ANEEL abriu a Audiência Pública nº $.026 / 2015$ para receber propostas de aprimoramento da Resolução Normativa $n^{\circ}$ 482/2012. Muitas destas propostas foram acatadas, como ampliar o limite do net-metering para o conceito de registro da ANEEL (3 MW para CGHs e 5 MW para demais fontes). A revisão desta resolução e sua publicação estão previstas para 2016 e deverão trazer um ambiente mais propício para o desenvolvimento da GD.

Ainda em relação à geração distribuída, há outras duas definições importantes. De acordo com as Lei $n^{\circ}$ 9.074/1995, a exploração de centrais termelétricas, eólicas e de outras fontes alternativas de energia com potência acima de $5 \mathrm{MW}$ e as centrais hidrelétricas com potência acima de $3 \mathrm{MW}$ precisam ser autorizadas pela ANEEL. Caso as potências sejam menores do que as indicadas, basta apenas o registro neste órgão regulador, o que simplifica significativamente a sua implantação. 


\section{As CONCESSIONÁRIAS DE DISTRIBUIÇÃO E SEUS REQUISITOS EM RELAÇÃO À GD}

Este capítulo introduz os aspectos conceituais das redes de distribuição de energia, sua filosofia de operação, proteção e aterramento, e os requisitos normativos das concessionárias de distribuição em relação à GD. O entendimento destes pontos de fazem necessários para que os impactos da geração nestas redes sejam evidenciados nos próximos capítulos.

\subsection{As Redes de Distribuição de Energia Elétrica}

As redes de distribuição no Brasil são tradicionalmente radiais, isto é, redes em que há uma única fonte e apenas uma direção para o fluxo de potência (da fonte para a carga). Um alimentador é um circuito com origem na subestação da distribuidora e que normalmente possui um tronco de onde derivam ramais (também chamados laterais) para atendimento da carga. A Figura 3.1 ilustra este conceito.

Estas redes operam tipicamente em média tensão ( $1 \mathrm{kV}$ a $35 \mathrm{kV})$, sendo $13,8 \mathrm{kV}, 23 \mathrm{kV}$ e $34,5 \mathrm{kV}$ as tensões mais comuns no Brasil, mas podem operar em tensões diferentes como 6,9 $\mathrm{kV}, 11 \mathrm{kV}, 13,2 \mathrm{kV}$, etc.

As redes radiais possuem características que tornam sua proteção relativamente simples. Nestas redes, a corrente de curto-circuito diminui com o aumento da distância do ponto de falta em relação à fonte (subestação da concessionária). Esta característica permite o uso de proteções de sobrecorrente de tempo inverso que se baseiam na diferença entre as magnitudes das correntes de curto-circuito nos diferentes pontos da rede. 


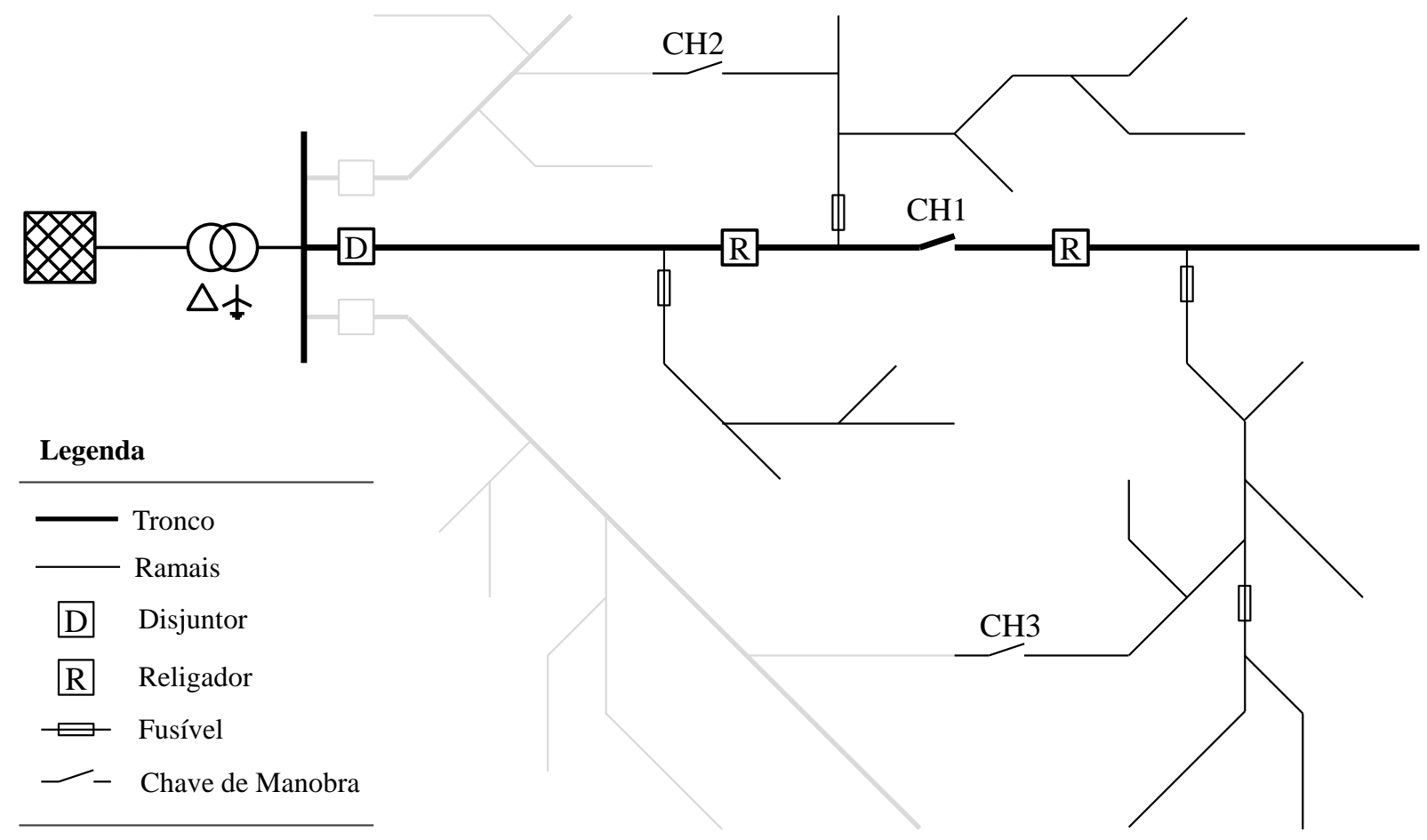

Figura 3.1 - Típica rede de distribuição radial e seus elementos de proteção

Todo alimentador possui um disjuntor em sua origem (subestação da distribuidora) que o protege em toda a sua extensão. Este disjuntor é a retaguarda, em última instância, de todas as proteções instaladas ao longo do alimentador. Os ramais do alimentador são geralmente protegidos por fusíveis, como mostrado na Figura 3.1. Em alguns deles podem existir outros fusíveis a jusante, seletivos com os fusíveis à montante.

Quando um trecho muito grande da rede for desligado pela proteção, parte dele poderá voltar a ser atendido manobrando-se as chaves da rede e, em alguns casos, as manobras poderão também transferir parte da carga para outro alimentador.

Em algumas redes aéreas mais automatizadas existe a presença de religadores, que são equipamentos que atuam como um disjuntor que tenta eliminar faltas temporárias através do desligamento e religamento sucessivo do circuito. A maioria destas faltas pode ser extinta porque ao se desligar o circuito o ar ionizado ao redor da falta se esvai e a isolação elétrica retorna. Por sua vez, o religamento não funciona com as redes subterrâneas, pois as faltas passam a ser permanentes assim que a isolação do cabo é perdida. 
A introdução dos religadores permitiu o desenvolvimento de duas filosofias de proteção para as redes aéreas: fuse blowing e fuse saving. Elas são brevemente discutidas neste texto e são explicadas em detalhes em (Gers \& Holmes, 2004) e (Short, 2014).

Conforme pode ser visto na Figura 3.2, quando uma falta ocorrer em um ramal a jusante de um religador e de um fusível, podem ocorrer duas situações: a) o fusível desliga o ramal sob falta antes do religador (fuse-blowing) ou b) o religador tenta religar o circuito antes de o fusível interrompê-lo (fuse-saving):

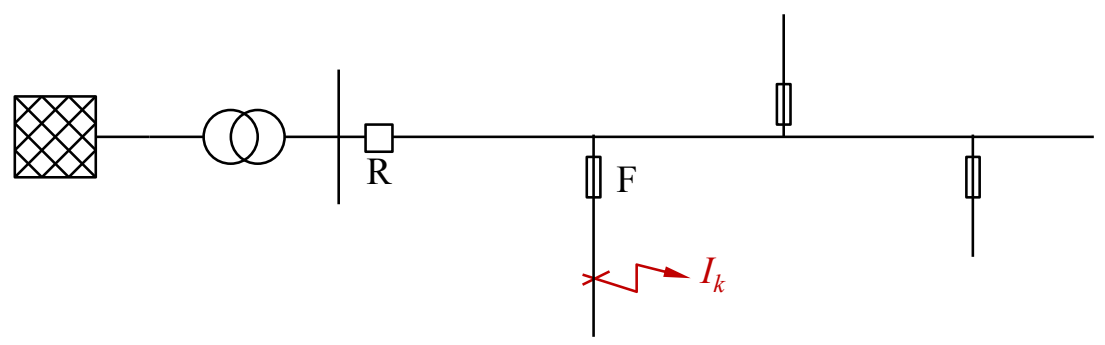

(a) fuse-blowing

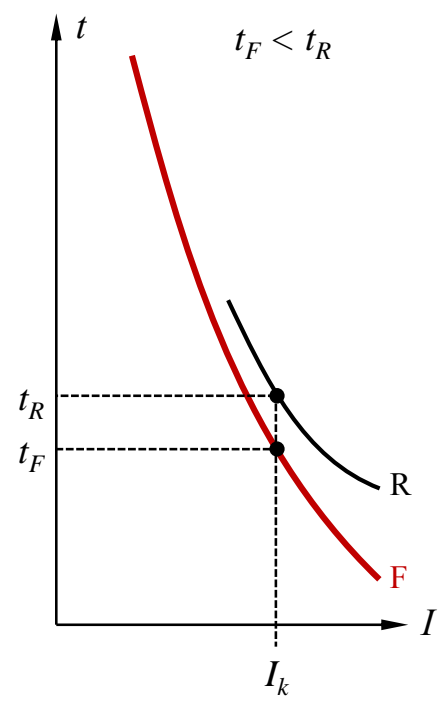

(b) fuse-saving

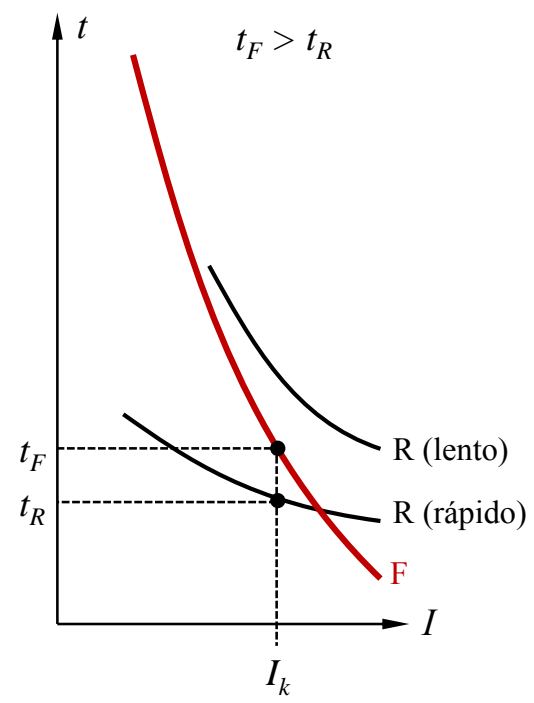

Figura 3.2 - Filosofias de proteção fuse-blowing e fuse-saving de redes aéreas 


\section{a) Fuse-blowing}

Neste esquema os religadores são ajustados de forma atuar como retaguarda dos fusíveis que protegem os ramais, isto é, ao ocorrer uma falta em um ramal, o fusível deverá fundir primeiro eliminando o defeito.

A vantagem deste esquema é o fato dos consumidores nos demais trechos da rede não serem desligados, mesmo que temporariamente, o que é um ponto importante para clientes industriais que possuem cargas sensíveis. Por outro lado, os consumidores do ramal que foi interrompido permanecerão desligados por muito tempo, até que a concessionária troque os elementos fusíveis.

\section{b) Fuse-saving}

Neste esquema, os religadores possuem ao menos dois ajustes, um rápido e outro lento. Ao ocorrer uma falta em um ramal, o religador deverá atuar rapidamente, abrindo o circuito em um tempo curto o suficiente para que o fusível do ramal não se funda. Dessa forma, o religador poderá fechar o circuito dentro de alguns segundos, possivelmente com sucesso caso a falta seja temporária. Entretanto, caso após sucessivas tentativas de religamento a falta ainda persista, o religador entrará no modo lento fazendo com que o fusível a jusante se rompa, isolando o trecho em falta.

A vantagem deste esquema é reduzir o tempo de interrupção para os consumidores do ramal onde houve a falta, porém interrompe-se momentaneamente o fornecimento de energia a todos os consumidores a jusante do religador durante as tentativas de religamento. Portanto, este método não é apropriado para redes onde há clientes industriais com cargas sensíveis, mas é adequado para consumidores residenciais ou pequenos clientes comerciais.

Segundo (Short, 2014), as concessionárias estão abandonando a filosofia fuse-saving cada vez mais em favor da fuse-blowing, para melhorar a qualidade do fornecimento. 


\subsection{A Importância da Filosofia de Aterramento}

A filosofia de aterramento (ou regime de neutro) trata do método de ligação dos neutros dos equipamentos da rede de distribuição à terra e tem relação direta com a corrente do curtocircuito monofásico e com a filosofia de proteção contra este tipo de falta. Mais adiante, será demonstrado que a filosofia de aterramento da rede da concessionária e a forma de ligação do transformador de acoplamento têm grande relação com o impacto que um gerador distribuído irá causar sobre a rede em que está conectado.

Quando se introduz uma impedância entre o neutro de um transformador e a terra, alterase a impedância de sequência zero vista no ponto de falta e, portanto, a magnitude da corrente do curto-circuito fase-terra. Pode-se demonstrar que a relação entre a corrente de falta

monofásica $\left(\dot{I}_{k 1}^{\prime \prime}\right)$ e a corrente de falta trifásica $\left(\dot{I}_{k}^{\prime \prime}\right)$ é dada pela equação abaixo, onde $Z_{0}$ e $Z_{1}$ são os equivalentes de Thévénin de sequência zero e sequência positiva vistas no ponto de falta, respectivamente.

$$
\frac{\dot{I}_{k 1}^{\prime \prime}}{\dot{I}_{k}^{\prime \prime}}=\frac{3}{2+\dot{Z}_{0} / \dot{Z}_{1}}
$$

No caso extremo em que a impedância de sequência zero torna-se muito baixa $\left(Z_{0} \rightarrow 0\right)$, a Equação 3.1 demonstra que a corrente de curto-circuito da falta fase-terra torna-se $50 \%$ maior que a da falta trifásica. Na prática, essa situação é inatingível, pois os transformadores sempre possuem alguma reatância de dispersão de sequência zero e a malha de terra tem resistência de alguns ohms. Dessa forma, no caso de um sistema solidamente aterrado, na prática a corrente do curto-circuito monofásico será no máximo cerca de $10 \%$ superior ao da falta trifásica nas proximidades do ponto de aterramento. Por sua vez, como a impedância de sequência zero das linhas de distribuição é cerca de 2 a 5 vezes maior que sua impedância de sequência positiva, a corrente de curto-circuito monofásico ao longo da rede geralmente se situa entre $50 \%$ a $75 \%$ daque la do curto-circuito trifásico em uma rede solidamente aterrada (Dietrich Oeding, 2011). 
No outro extremo, como demonstra a Figura 3.3, ao se levar a impedância de sequência zero vista pelo ponto de falta a infinito $\left(Z_{0} \rightarrow \infty\right)$, elimina-se a corrente de falta monofásica. A princípio, poder-se-ia imaginar que bastaria isolar o neutro da terra para tornar a impedância de sequência zero infinita e, portanto, eliminar a corrente de falta monofásica. No entanto, há de se considerar que os condutores da rede de distribuição possuem uma capacitância natural em relação à terra, mesmo que seja pequena, de forma que ao se isolar o neutro ainda haverá uma pequena corrente de falta monofásica capacitiva da ordem de alguns Ampères.

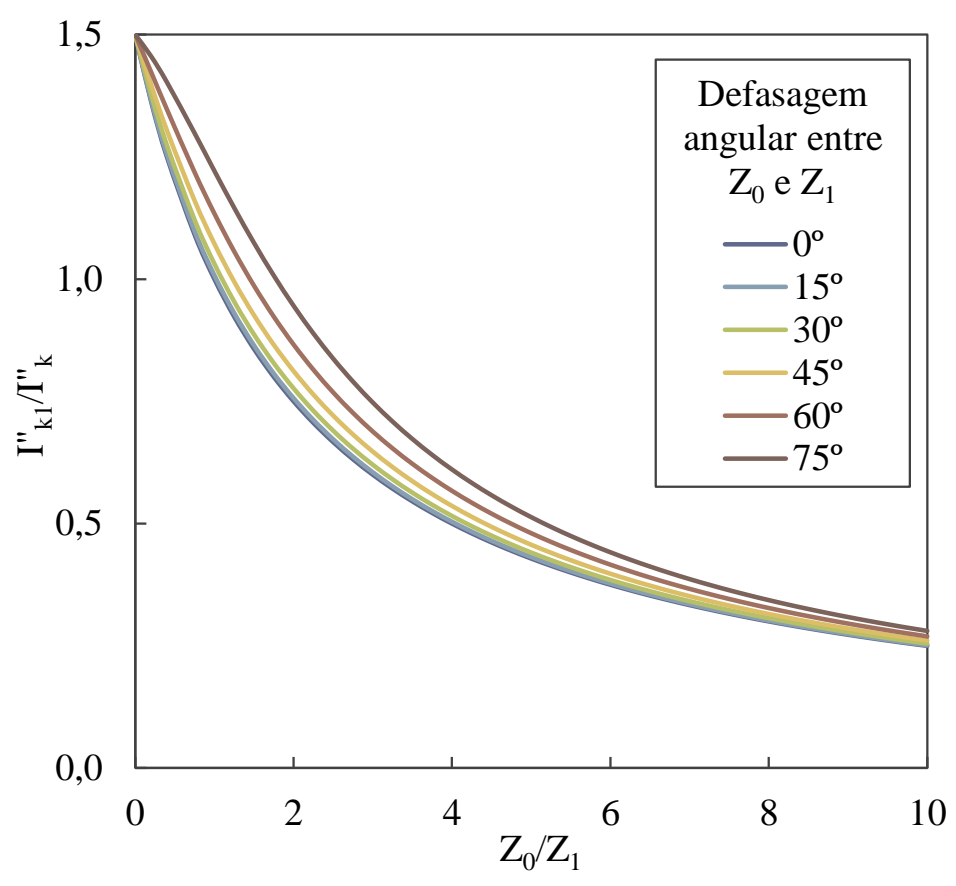

Figura 3.3 - Relação entre as magnitudes das correntes de curto-circuito monofásico e trifásico

Para se anular os efeitos da capacitância natural da rede, instala-se uma reatância no neutro do transformador. Este método de aterramento é denominado ressonante e a reatância que se põe no neutro é denominada bobina de Petersen ou bobina de extinção. Esta se trata de uma bobina com derivações que permitem ajustar sua reatância. Na prática, a sintonia nunca é perfeita de forma que a corrente de falta monofásica fica na ordem de poucos Ampères, mas pequena o bastante para que ela posse se extinguir sozinha na maioria dos casos. 
Alternativamente, uma impedância pode ser colocada no neutro, limitando a corrente de falta monofásica até $10 \mathrm{~A}$. Este método é denominado aterramento por alta impedância, ou simplesmente impedância, e geralmente é executado através de uma resistência.

As correntes de curto-circuito monofásico para os casos de neutro isolado, neutro ressonante e alta impedância são tão pequenas que podem permanecer durante muito tempo, por vezes até durante horas. Geralmente estes regimes de neutro são empregados em situações que exijam elevada continuidade de fornecimento, até que haja um momento propício para a resolução do defeito (Blackburn, 2006). Ainda que estes métodos possuam o benefício das pequenas correntes de curto-circuito monofásico, eles apresentam o inconveniente de elevar a tensão de fase das fases sãs a níveis próximos da tensão de linha nominal do sistema.

Pode-se demonstrar que a tensão das fases sãs após uma falta monofásica vale:

$$
\begin{aligned}
& \dot{U}_{S}=\dot{E}\left(\alpha^{2}-\frac{\dot{Z}_{0} / \dot{Z}_{1}-1}{\dot{Z}_{0} / \dot{Z}_{1}+2}\right) \\
& \dot{U}_{T}=\dot{E}\left(\alpha-\frac{\dot{Z}_{0} / \dot{Z}_{1}-1}{\dot{Z}_{0} / \dot{Z}_{1}+2}\right)
\end{aligned}
$$

Onde E é a tensão de fase do sistema.

A partir da Equação 3.2 e da Equação 3.3 nota-se que quando a impedância de sequência zero tende a infinito $\left(Z_{0} \rightarrow \infty\right)$ a tensão de fase das fases sãs tende a $\sqrt{3} \dot{E}$, isto é, passam a valer a tensão de linha do sistema. Por outro lado, quando a impedância de sequência zero aproximar-se de zero $\left(Z_{0}=0\right)$, a tensão de fase das fases sã passa a $\sqrt{3} / 2 \dot{E}$, isto é, $87 \%$ da tensão de fase do sistema.

A referência (Schlabbach, 2005) define o fator de falta à terra $(\delta)$ que é a relação entre a maior tensão de fase das fases sãs em relação à tensão de fase nominal do sistema após um curto-circuito monofásico. Esta é uma medida da sobretensão causada nas fases sãs devido à uma falta fase-terra.

$$
\delta=\max \left(\left|\frac{\dot{U}_{S}}{\dot{E}}\right|,\left|\frac{\dot{U}_{T}}{\dot{E}}\right|\right)
$$


A Figura 3.4 mostra a evolução do fator de falta à terra para diferentes relações de impedância de sequência zero e sequência positiva. A partir dela, é possível perceber que sistemas solidamente aterrados, que levam a uma menor relação $Z_{\delta} / Z_{1}$, possuem a vantagem de causar sobretensões menores nas fases sãs quando da ocorrência de um curto-circuito faseterra, o que se traduz em uma menor solicitação do isolamento elétrico. Por essa razão, geralmente adota-se o esquema solidamente aterrado nas redes de alta tensão, pois as sobretensões passam a ser muito importantes.

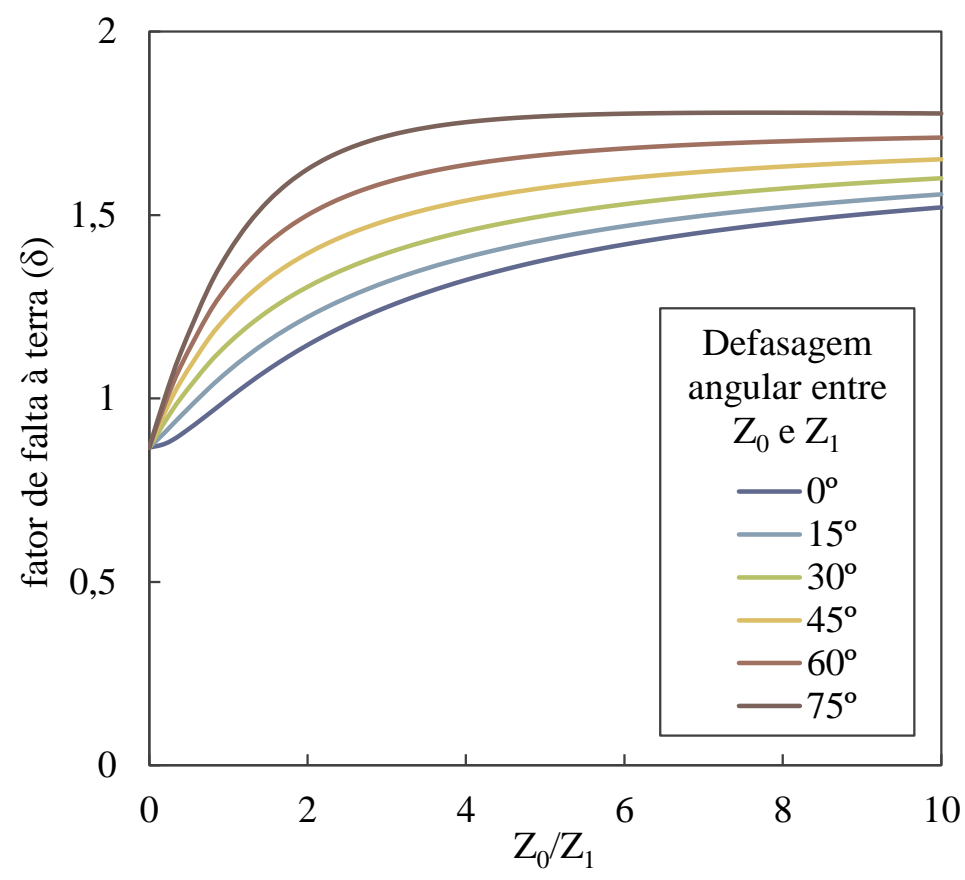

Figura 3.4 - Relação entre a maior tensão de fase das fases sãs em relação à tensão de fase pré-falta do sistema após um curto-circuito monofásico. A relação também é chamada fator de falta à terra $(\delta)$.

De maneira geral, há um compromisso entre a magnitude da corrente de falta monofásica e a tensão das fases sãs, pois ao se aumentar a impedância que liga o neutro do transformador à terra, diminui-se a corrente de curto-circuito monofásico e, por outro lado, aumentam-se as tensões da fases sãs em relação à terra, que solicitam mais da isolação.

A referência (Schlabbach, 2005) define o valor $\delta=1,4$ como um limite que classifica os aterramentos em "baixa impedância" e "elevada impedância". Por sua vez, a norma americana IEEE 100 estabelece um sistema como efetivamente aterrado se no ponto de falta valer as relações: $X_{0} / X_{1} \leq 3$ e $R_{0} / X_{1} \leq 1$ (Blackburn, 2006). 
Na prática, existe um método de aterramento de baixa impedância em que se instala um resistor ou reatância no neutro de forma a limitar a corrente de falta monofásica a um valor entre 50 A a 600 A (Blackburn, 2006). Este é um caso intermediário onde as sobretensões não são muito elevadas, ao passo que as correntes de falta são significativamente menores do que no caso solidamente aterrado, melhorando a segurança das pessoas e dos equipamentos da rede. Por outro lado, a corrente de falta permanece suficientemente elevada ao ponto de não permitir a operação contínua sob falta.

A Tabela 3.1 mostra os métodos de ligação à terra e suas principais vantagens e desvantagens. Os dois primeiros métodos (a) e (b) são os casos em que o neutro é solidamente aterrado, sendo que a diferença reside apenas na distribuição do condutor de neutro, que pode ser aterrado em múltiplos pontos ou apenas na subestação de origem.

De forma resumida, os três primeiros métodos são de baixa impedância, isto é, produzem correntes de falta monofásica elevadas que devem ser imediatamente interrompidas ao passo que as sobretensão das fases sãs são menores. De forma inversa, os três últimos métodos são de alta impedância, produzem correntes de falta monofásicas muito pequenas ou desprezíveis ao ponto de permitir a operação contínua sob falta, por outro lado as sobretensões são muito mais significativas e permeiam toda a rede.

A principal justificativa para a adoção dos sistemas de neutro isolado, ressonante ou aterrado por alta impedância é a elevada continuidade do serviço e a segurança devido às pequenas correntes de curto-circuito. O sistema isolado tem sido usado em países como Japão, Itália, Irlanda e Rússia e o sistema ressonante na Alemanha, Escandinávia, Leste Europeu, China e Israel (Jeff Roberts, 2001). Nestes países, as redes de distribuição são, em sua maioria, subterrâneas com cabos isolados (Puret, 1991), situação onde o religamento não é recomendável.

Por sua vez, a principal justificativa para a adoção dos sistemas solidamente aterrados tem sido a fácil detecção das faltas monofásicas e, portanto, a possibilidade de eliminá-las o mais rápido possível, reduzindo o risco às pessoas e aos equipamentos da rede. Entretanto, faltas de alta impedância podem ser difíceis de detectar quando há cargas monofásicas na rede, pois o ajuste dos relés de terra devem ser maiores que o desequilíbrio das cargas (Jeff Roberts, 2001). 
Tabela 3.1 - Métodos de aterramento das redes de distribuição de energia elétrica

a) Solidamente aterrado com neutro

distribuído e multi-aterrado

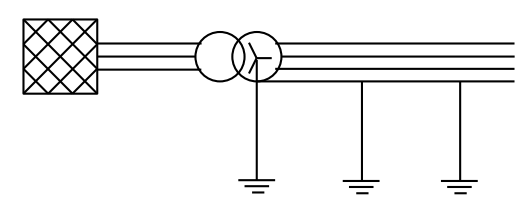

- Permite cargas monofásicas

- Limita as sobretensões no caso de falta fase-terra

- Proteção simples
- Custo (um condutor a mais e várias malhas de aterramento)

- Elevada corrente de falta monofásica

- Falta deve ser eliminada imediatamente

b) Solidamente aterrado sem neutro distribuído

- Permite cargas monofásicas com retorno pela terra (MRT)

- Limita as sobretensões no caso de falta fase-terra

- Proteção muito simples
- Elevada corrente de falta monofásica

- Falta deve ser eliminada imediatamente

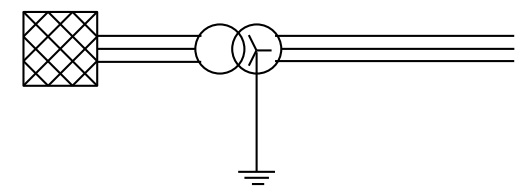

c) Aterrado por baixa impedância

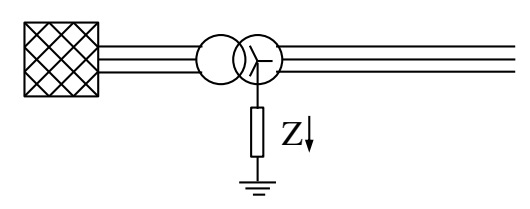

- Limita a corrente de falta fase-terra para níveis menores $(50 \mathrm{~A}-600 \mathrm{~A})$

- Pequenas sobretensões no caso de falta fase-terra

- Proteção simples (temporização)
- Elevado custo (resistor de aterramento)

- Falta deve ser eliminada imediatamente

d) Aterrado por alta impedância

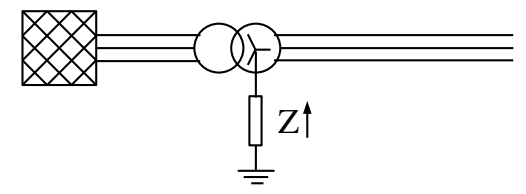

- Reduz significativamente a corrente de falta fase-terra $(<10 \mathrm{~A})$

- Permite operação contínua sob falta
- Dificuldade em localizar a falta

- Elevadas sobretensões no caso de falta monofásica (maior isolamento)

- Proteção complexa e) Aterramento ressonante

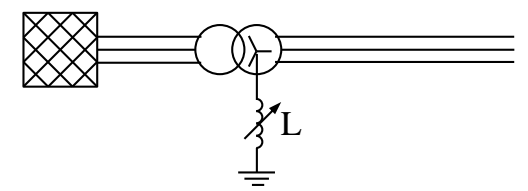

- Elimina ou favorece a auto-extinção da corrente de falta monofásica

- Permite operação contínua sob falta
- Dificuldade em se ajustar a bobina (circulação de pequena corrente em regime devido à desequilíbrios)

- Dificuldade em localizar a falta

- Elevadas sobretensões no caso de falta monofásica (maior isolamento)

- Proteção complexa f) Sistema isolado

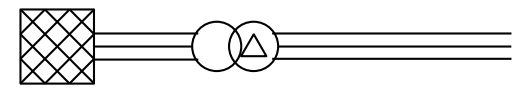

- Pequena corrente de falta fase-terra

- Permite operação contínua sob falta
- Dificuldade em localizar a falta

- Sujeito à sobretensões extremas

- Sujeito à ferroressonância

- Proteção muito difícil 
Historicamente, o neutro solidamente aterrado e distribuído tem sido o método predominante nos Estados Unidos, Canadá, Austrália e países da América Latina. A Inglaterra também utiliza o neutro solidamente aterrado, mas não o distribui (Jeff Roberts, 2001) e (Puret, 1991). Nestes países, as redes de distribuição são majoritariamente aéreas e neste tipo de rede quase todas as faltas são temporárias e podem ser eliminadas através de religamento, pois ao se desligar o circuito o dielétrico natural se recupera. Portanto, mesmo que o neutro solidamente aterrado não permita a operação contínua sob falta, o religamento permite uma boa disponibilidade da rede.

O Brasil, por sua vez, herdou o neutro solidamente aterrado das primeiras concessionárias americanas e canadenses que aqui operaram. As redes de distribuição brasileiras são majoritariamente aéreas e apenas no centro de algumas grandes cidades há redes subterrâneas como São Paulo, Rio de Janeiro e Brasília.

Por fim, as redes aterradas por baixa impedância são um meio termo entre os aterramentos de alta impedância e os solidamente aterrados. São comuns em França, Espanha e Portugal.

\subsection{Requisitos do PRODIST}

O PRODIST (ANEEL, 2012), acrônimo de Procedimentos de Distribuição de Energia Elétrica no Sistema Elétrico Nacional, é o conjunto das normas técnicas da ANEEL que regulam e estabelecem padrões para a distribuição de energia no Brasil. O módulo 3 do PRODIST trata do acesso ao sistemas de distribuição, inclusive da geração distribuída e da geração sob o regime de compensação (net-metering). Em seu item 5 trata da proteção e do controle para a conexão de centrais geradoras e estabelece os limites de tensão para conexão em função da potência da central e a exigência de um transformador de acoplamento, conforme a Tabela 3.2. 
Tabela 3.2 - Níveis de tensão requeridos para conexão e exigência do transformador de acoplamento para centrais geradoras na distribuição (fonte: módulo 3 do PRODIST, elaboração própria)

\begin{tabular}{ccc}
\hline Potência Instalada & Nível de Tensão de Conexão & $\begin{array}{c}\text { Transformador } \\
\text { de Acoplamento }\end{array}$ \\
\hline$<10 \mathrm{~kW}$ & Baixa Tensão (monofásico) & Não \\
10 a $75 \mathrm{~kW}$ & Baixa Tensão (trifásico) & Sim \\
76 a $500 \mathrm{~kW}$ & Baixa Tensão (trifásico) / Média Tensão & Sim \\
$501 \mathrm{~kW} \mathrm{a} 30 \mathrm{MW}$ & Média Tensão / Alta Tensão & Sim \\
$>30 \mathrm{MW}$ & Alta Tensão & Sim \\
\hline
\end{tabular}

O uso de um transformador de acoplamento ajuda a mitigar os efeitos da geração distribuída sobre as correntes de curto-circuito na rede da acessada. Na prática, há algumas exceções quando se torna muito custoso atender a esta norma, sobretudo no caso da conexão de pequenos geradores entre 10 e $75 \mathrm{~kW}$ em regiões onde a rede não é trifásica. O PRODIST também não estabelece como deve ser a ligação desse transformador e isso, geralmente, fica a cargo dos padrões técnicos da distribuidora, que serão discutidos mais adiante.

\subsection{Requisitos das Concessionárias}

As principais concessionárias de distribuição do país sempre possuíram normas técnicas para regular o acesso de geração à sua rede, principalmente aquelas que atuam em regiões em que há muita geração conectada na rede distribuição, como no interior de São Paulo onde há inúmeras usinas de açúcar e álcool com cogeração. Estas normas foram elaboradas tendo em vista o acesso de grandes geradores síncronos na rede primária (média tensão) e determinam a forma de conexão, as ligações dos transformadores de acoplamento, os requisitos de proteção e automação, os equipamentos de medição e faturamento, a forma de operação da geração, as responsabilidades das partes envolvidas, etc.

Após a publicação da Resolução Normativa ANEEL nº 482/2012, as concessionárias de distribuição também publicaram outras normas técnicas para regular e padronizar o acesso dos micro e mini-geradores distribuídos e, portanto, se limitam a geradores de até $1 \mathrm{MW}$ no regime de compensação de energia. Consequentemente, algumas concessionárias passaram a 
ter duas normas técnicas que se complementam para a geração distribuída: uma mais antiga que trata do caso geral e outra mais recente que trata da micro e minigeração.

Neste trabalho foram analisadas as normas das principais distribuidoras do país, quando disponíveis, com o intuito de se levantar duas exigências que causam impacto direto sobre os níveis de curto-circuito: os limites de potência envolvidos (capacidade dos geradores e limite de injeção nas redes) e a ligações dos transformadores de acoplamento.

Em relação à potência, a principal exigência destas normas é determinar que geradores acima de $75 \mathrm{~kW}$ (ou $100 \mathrm{~kW}$ para algumas concessionárias ${ }^{6}$ ) sejam conectados na rede primária (média tensão) de maneira trifásica, ainda que o PRODIST permita que geradores de até $500 \mathrm{~kW}$ se conectem na rede secundária (baixa tensão). Este requisito é importante porque minimiza o impacto de grandes geradores ao conectá-los em um nível de tensão adequado.

De forma geral, as concessionárias não estipulam um limite máximo a ser injetado na sua rede, tampouco um limite máximo para a capacidade de um gerador individual e subentendese que os limites serão definidos caso a caso, conforme estudos desenvolvidos para cada solicitação de acesso levando-se em conta os princípios do Livre Acesso e da Modicidade Tarifária $^{7}$. A $\mathrm{CEMIG}^{8}$ faz exceção a esta regra e define claramente limites de potência injetada por alimentador:

\section{“8.2.7.1. Máxima geração a ser conectada ao alimentador}

Em um mesmo alimentador poderão ser conectadas no máximo 03 centrais geradoras em média tensão. A soma total de potências injetadas das centrais geradoras conectadas a um único alimentador não poderá exceder os seguintes limites:

- $7 \mathrm{MW}$ no $13,8 \mathrm{kV}$

- $10 \mathrm{MW}$ no $22 \mathrm{kV}$;

- 15 MW para conexões em 34,5 kV (no caso de alimentadores interligados a subestações por meio de transformações 138-34,5 kV)"

\footnotetext{
${ }^{6}$ COPEL, CPFL, EDP, ELEKTRO e COSERN

${ }^{7}$ Lei n ${ }^{\circ} 9.074 / 1995$, art. 15, $\S 6^{\circ}$ (Livre Acesso) e Lei no 8.987/1995, art. $6^{\circ}, \S 1^{\circ}$ (Modicidade Tarifária)

${ }^{8}$ Subitem 8.2.7.1 da Norma Técnica ND 5.31 (fev/2015) - Requisitos Para Conexão de Acessantes Produtores de Energia Elétrica ao Sistema de Distribuição da Cemig D - Média Tensão
} 
Por sua vez, a $\operatorname{COPEL}^{9}$ não estabelece um limite de injeção de potência por alimentador, mas determina que geradores acima de $2 \mathrm{MW}$ devam possuir uma linha expressa, isto é, uma linha exclusiva até a subestação da concessionária:

\begin{abstract}
"v. Acessantes de Geração acima de 2000 kW
A conexão deverá ser em linha expressa em MT (34,5 ou 13,8 kV) ou AT (69 ou 138 $k V$ ), a partir de uma subestação da COPEL, com disjuntor ou religador, relés de proteção secundários e transformador exclusivo do acessante. Serão exigidas adequações nas proteções dos setores 69/138 kV das subestações. Os equipamentos de proteção e operação devem ser automatizados, disponibilizando a supervisão e comandos no COD."
\end{abstract}

Na mesma norma, a COPEL cita a possibilidade de geradores entre $300 \mathrm{~kW}$ e $2.000 \mathrm{~kW}$ serem instalados em um alimentador expresso, a depender dos estudos de conexão realizados pela concessionária.

O outro aspecto importante tratado pelas normas técnicas das concessionárias é o método de ligação dos transformadores de acoplamento da geração distribuída, pois isto determina a contribuição do gerador para o curto-circuito monofásico. A Figura 3.5 resume as principais formas de ligação do transformador de acoplamento e suas consequências.

A princípio, poder-se-ia supor que se o transformador de conexão possui ligação $\Delta$ no lado de média tensão então o gerador não deveria contribuir para o curto-circuito fase-terra. Entretanto, até mesmo essa conexão permite que o gerador contribua para o curto-circuito, pois apesar dela não permitir a circulação das correntes de sequência zero entre o primário e o secundário, ela permite a circulação das correntes de sequência positiva e negativa.

A Figura 3.6 ajuda a entender melhor este fenômeno através das componentes simétricas, onde é possível ver que toda a componente de sequência zero é fornecida pela fonte, que vem pelo aterramento do neutro na subestação da concessionária. Por sua vez, a fonte contribui com uma fração $f$ das correntes de sequência positiva e negativa e o transformador do gerador contribui com uma fração $(1-f)$ da mesma corrente.

\footnotetext{
${ }^{9}$ Subitem 4.1.4.1 da Norma Técnica NTC 905100 (dez/2013) - Acesso de Geração Distribuída ao Sistema da COPEL (com comercialização de energia)
} 


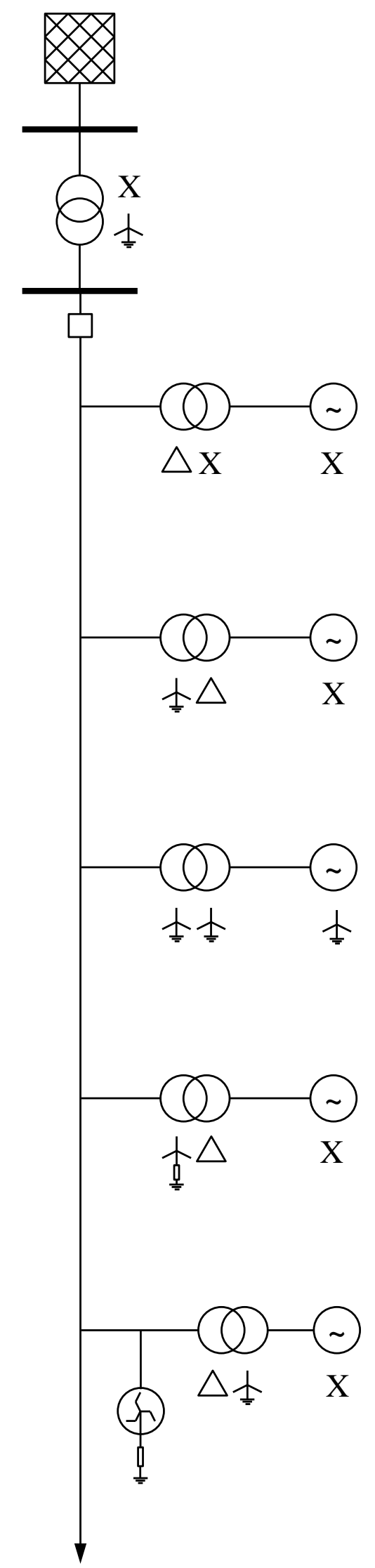

A

B

C

Permite a circulação de sequência zero entre o primário e o secundário. A contribuição do gerador para a falta monofásica situa-se em um valor entre os casos A e B.

Alta impedância para a sequência zero no lado de média tensão. Não permite a circulação de sequência zero entre o primário e o secundário. A contribuição do gerador para a falta monofásica é pequena.

Aterrado através de um transformador de aterramento. A impedância de sequência zero no lado de média tensão depende

E da impedância conectada no neutro do transformador de aterramento.

Obs: $\mathrm{X}$ indica que qualquer ligação é permitida $(\Delta, \mathrm{Y}$, etc.)

Figura 3.5 - Formas de ligação do transformador de acoplamento do gerador distribuído 
Ao se escrever as equações da contribuição da fonte e do gerador em termos das correntes de componente simétrica e da fração $f$, fica evidente que as correntes das fases sãs (b e c) são idênticas em fase e magnitude, tanto para a contribuição da fonte quanto para a contribuição do transformador do gerador. Além disso, a corrente da fase sob falta (a) do lado do gerador trata-se do retorno das correntes das fases sãs (b e c) que circulam pelo $\Delta$ do transformador. Isto fica mais claro através de um exemplo como o da Figura 3.7.
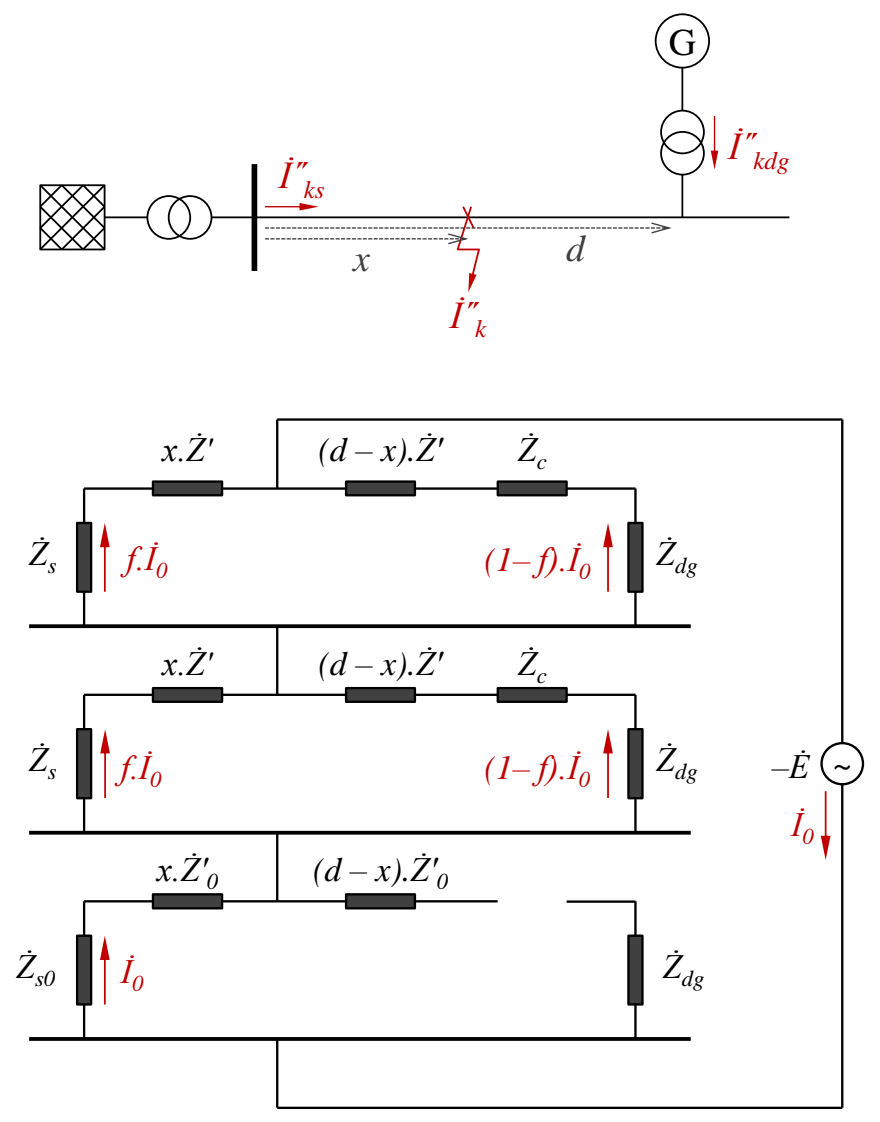

\section{Lado da fonte}

$\left[\begin{array}{c}\dot{I}_{a} \\ \dot{I}_{b} \\ \dot{I}_{c}\end{array}\right]=\left[\begin{array}{ccc}1 & 1 & 1 \\ 1 & \alpha^{2} & \alpha \\ 1 & \alpha & \alpha^{2}\end{array}\right]\left[\begin{array}{c}\dot{I}_{0} \\ f \dot{I}_{0} \\ f \dot{I}_{0}\end{array}\right]=\left[\begin{array}{c}(1+2 f) \dot{I}_{0} \\ (1-f) \dot{I}_{0} \\ (1-f) \dot{I}_{0}\end{array}\right]$
Lado do gerador

$$
\left[\begin{array}{c}
\dot{I}_{a} \\
\dot{I}_{b} \\
\dot{I}_{c}
\end{array}\right]=\left[\begin{array}{ccc}
1 & 1 & 1 \\
1 & \alpha^{2} & \alpha \\
1 & \alpha & \alpha^{2}
\end{array}\right]\left[\begin{array}{c}
0 \\
(1-f) \dot{I}_{0} \\
(1-f) \dot{I}_{0}
\end{array}\right]=\left[\begin{array}{c}
2(1-f) \dot{I}_{0} \\
-(1-f) \dot{I}_{0} \\
-(1-f) \dot{I}_{0}
\end{array}\right]
$$

Figura 3.6 - Divisão da corrente de sequência zero para a formação das contribuições para a corrente de curto-circuito monofásico. $O$ parâmetro $f$ é a fração da corrente que circula pela fonte. 


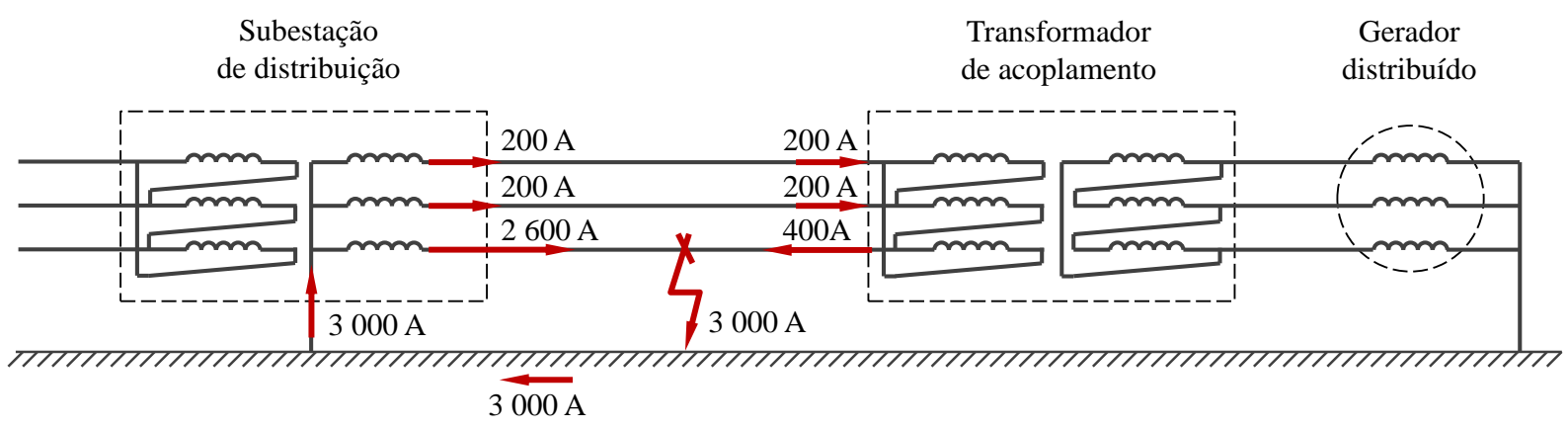

Figura 3.7 - Exemplo de contribuições da fonte e do gerador para a formação da corrente de curtocircuito fase-terra para transformador ligado em $\Delta .\left(I_{0}=1 \mathrm{kA}, f=0,8, I_{k l}=3 \mathrm{kA}\right)$

Algumas proteções para faltas monofásicas se baseiam na estimação da corrente de sequência zero a partir da soma vetorial das correntes das fases. Nestes casos, mesmo que o gerador esteja contribuindo para a falta monofásica, sua proteção não deverá atuar. Contudo, outras proteções, como fusíveis, atuam com base na corrente de fase e devem atuar, mesmo que o gerador não contribua com corrente de sequência zero.

Conforme visto, as ligações dos enrolamentos do transformador do gerador impactam a formação da corrente de curto-circuito monofásico e este assunto é abordado e definido pelas normas técnicas das distribuidoras.

A Tabela 3.3 resume os requisitos das concessionárias para a ligação dos transformadores de acoplamento. De maneira geral, a ligação em $\Delta$ no lado de média tensão é predominante, provavelmente porque mitiga os impactos do acessante sobre a rede de distribuição. Algumas distribuidoras que possuem redes muito extensas, como CEMIG e a CELPA solicitam que o neutro seja sempre solidamente aterrado. No caso da ENERGISA, a justificativa é limitar as sobretensões ${ }^{10}$.

Algumas concessionárias fazem exigências para manterem a característica de suas redes como efetivamente aterrada. Por exemplo, a AES-SUL, COPEL e DME fazem uma ressalva exigindo que o lado de média tensão seja solidamente aterrado para geradores com potência acima de $500 \mathrm{~kW}$. A AES também cita em uma de suas normas ${ }^{11}$ :

\footnotetext{
${ }^{10}$ Item 8.3.2 da norma técnica unificada NDU-015 (dez.2012) - Critérios de Conexão de Acessantes de Geração Distribuída ao Sistema de Distribuição da ENERGISA - Conexão em Média Tensão

${ }^{11}$ Item 3.2.1 da norma NTD 002.008 (15.02.2008) - Interconexão de Geração ao Sistema Elétrico da AES-SUL
} 


\begin{abstract}
"Todos os geradores do acessante devem estar acoplados ao sistema elétrico da concessionária através de um transformador de potência. Este transformador deve isolar o circuito de sequência zero da geração do acessante do circuito de sequência zero da concessionária. Um enrolamento deste transformador deve ser ligado em delta, visando também o bloqueio do harmônico de terceira ordem e seus múltiplos ímpares. Preferencialmente o lado da AES Sul deverá ser aterrado, visando manter o sistema com característica de efetivamente aterrada $\left(X_{0} / X_{1} \leq 3\right)$."
\end{abstract}

A concessionária $\mathrm{EDP}^{12}$ exige que a fonte de terra local seja implantada através de um transformador de aterramento, como mostra o caso E da Figura 3.5. Por sua vez, a CEMIG ${ }^{13}$ faz esta exigência apenas quando os geradores tiverem potência acima de $300 \mathrm{~kW}$.

Os transformadores de aterramento também são uma forma de se proporcionar uma fonte de terra local para clientes já existentes que desejam instalar uma geração, mas que possuíam um transformador ligado em $\Delta$ no lado de média tensão.

\footnotetext{
12 Item 6.13.1 da norma PR.PN.03.14.001 V1 (04.07.2014) - Conexão de Mini e Microgeradores ao Sistema de Distribuição em Média Tensão.

${ }^{13}$ Subitem 8.3.2 da Norma Técnica ND 5.31 (fev/2015) - Requisitos Para Conexão de Acessantes Produtores de Energia Elétrica ao Sistema de Distribuição da Cemig D - Média Tensão
} 
Tabela 3.3 - Requisitos das principais concessionárias brasileiras para ligação dos transformadores de acoplamento em média tensão (fonte: normas das concessionárias, elaboração própria)

\begin{tabular}{|c|c|c|c|c|}
\hline CONCESSIONÁRIA & ESTADO & $\begin{array}{l}\text { REFERÊNCIA } \\
\text { (data de emissão) }\end{array}$ & $\begin{array}{l}\text { LIGAÇÃO NO LADO DA } \\
\text { CONCESSIONÁRIA }\end{array}$ & $\begin{array}{l}\text { LIGAÇÃO NO LADO DO } \\
\text { GERADOR }\end{array}$ \\
\hline AES-SUL & RS & $\begin{array}{l}\text { NTD } 014.001(13.02 .2012) \\
\text { NTD } 002.008(15.02 .2008)\end{array}$ & $\begin{array}{c}\Delta(\mathrm{P} \leq 500 \mathrm{~kW}) \\
\mathrm{Yn}(\mathrm{P}>500 \mathrm{~kW})\end{array}$ & - \\
\hline CEEE & RS & NTD-00.081 (17.12.2012) & $\Delta$ & - \\
\hline CELESC & $\mathrm{SC}$ & $\begin{array}{l}\mathrm{I}-432.0004(10.09 .2014) \\
\text { e I-432.0003 (29.06.2006) }\end{array}$ & $\Delta(\mathrm{U} \leq 34,5 \mathrm{kV})$ & Livre escolha \\
\hline COPEL & PR & $\begin{array}{l}\text { NTC } 905100(\text { dez.2013) e } \\
\text { NTC } 905200(\text { ago.2014) }\end{array}$ & $\begin{array}{c}\Delta(\mathrm{P} \leq 500 \mathrm{~kW} \mathrm{U}<34,5 \mathrm{kV}) \\
\mathrm{Yn}(\mathrm{P}>500 \mathrm{~kW} \mathrm{U}<34,5 \mathrm{kV}) \\
\mathrm{Yn}(\mathrm{U}=34,5 \mathrm{kV})\end{array}$ & $\begin{array}{c}\text { Yn }(U=13,8 \mathrm{kV}) \\
\text { Yn }(\mathrm{P}<1 \mathrm{MW} \mathrm{U}=34,5 \mathrm{kV}) \\
\Delta(\geq 1 \mathrm{MW} \mathrm{U}=34,5 \mathrm{kV})\end{array}$ \\
\hline AES ELETROPAULO & SP & $\begin{array}{l}\text { NT } 6.012(27.12 .2012) \\
\text { NT } 6.009(05.01 .2011)\end{array}$ & $\Delta$ & Yn \\
\hline CPFL & SP & $\begin{array}{l}\text { GED } 15303(28.08 .2013) \\
\text { GED } 33(30.10 .2013)\end{array}$ & $\Delta$ & Yn \\
\hline EDP & $\mathrm{SP}, \mathrm{ES}$ & PR.PN.03.14.001 V1 (04.07.2014) & $\begin{array}{l}\Delta \text { (com transformador de } \\
\text { aterramento em paralelo })\end{array}$ & Yn \\
\hline ELEKTRO & SP & ND.65 rev. 1 (14.12.2012) & $\Delta$ & Yn \\
\hline LIGHT & $\mathrm{RJ}$ & DTE/DTP-01/12 r1 (dez.2013) & $\Delta$ & Yn \\
\hline CEMIG & MG & ND 5.31 (fev.2015) & $\begin{array}{c}\text { Yn (ou } \Delta \text { com transformador } \\
\text { de aterramento se } \mathrm{P}>300 \mathrm{~kW})\end{array}$ & Yn \\
\hline DME & MG & NT 0705014 rev. 1 (ago.2014) & $\begin{array}{c}\Delta(\mathrm{P} \leq 500 \mathrm{~kW}) \\
\mathrm{Yn}(\mathrm{P}>500 \mathrm{~kW})\end{array}$ & Yn \\
\hline ELFSM & ES & $\begin{array}{c}\mathrm{S} / \mathrm{N} \\
(\mathrm{dez} .2012)\end{array}$ & $\Delta$ & Yn \\
\hline CELG & GO & NTC-071 rev. 1(set.2014) & $\Delta(\mathrm{P} \leq 500 \mathrm{kVA})$ & $\mathrm{Yn}(\mathrm{P} \leq 500 \mathrm{kVA})$ \\
\hline COELBA & BA & $\begin{array}{l}\text { SM04.08-01.009 (27.12.2013) } \\
\text { SM04.08-01.003 (23.10.2008) }\end{array}$ & $\Delta$ & - \\
\hline CELPE & $\mathrm{PE}$ & $\begin{array}{l}\text { VM02.00-00.005 (01.11.2013) } \\
\text { e VM02.00-00.001 (20.12.2011) }\end{array}$ & $\Delta$ & - \\
\hline COSERN & $\mathrm{RN}$ & VR01.01-00.13 (08.07.2013) & $\Delta$ & Aterrado (Yn) \\
\hline COELCE & $\mathrm{CE}$ & $\begin{array}{l}\text { NT-010/2012 R-00 (12.12.2012) e } \\
\text { NT-008/2012 R-02 (06.07.2012) }\end{array}$ & $\Delta$ & - \\
\hline ENERGISA & $\begin{array}{l}\text { SE, PB, MG, RJ, } \\
\text { SP, TO, MS, MT }\end{array}$ & $\begin{array}{l}\text { NDU-015 } \\
(\text { dez.2012) }\end{array}$ & Yn & $\Delta$ \\
\hline CELPA & PA & NTE-042 (04.02.2013) & Yn & $\Delta$ \\
\hline AMPLA & $\mathrm{RJ}$ & ETA-020 rev. 1 (fev.2013) & - & - \\
\hline CEB & DF & NTD-6.09(ago.2014) & - & - \\
\hline SULGIPE & SE & NTD-33 rev. 0 (12.11.2013) & - & - \\
\hline ELETROBRAS & $\begin{array}{l}\mathrm{AL}, \mathrm{RO}, \mathrm{AC} \\
\mathrm{AM}, \mathrm{RR}\end{array}$ & MPN-DC-01/N-006 (19.11.2013) & - & - \\
\hline CEA & AP & NTD-09(dez.2013) & - & - \\
\hline IGUAÇU & SC & Instrução Normativa s/ No (sem data) & - & - \\
\hline
\end{tabular}




\subsection{Principais Conclusões da Investigação}

As investigações realizadas neste trabalho levantaram aspectos importantes que levaram a algumas conclusões, aqui resumidas em seis pontos principais:

I. A literatura demonstra que o impacto da geração distribuída sobre as correntes de curto-circuito da rede é uma questão relevante e que ainda não foi totalmente superada. Portanto, este é um tema relevante que vale a pena investigar.

II. Mais de $90 \%$ das usinas brasileiras com menos de $5 \mathrm{MW}$ de potência instalada são termelétricas e hidrelétricas, que tipicamente usam geradores síncronos, um tipo de máquina que contribui significativamente para a corrente de curto-circuito.

III. As redes de distribuição no Brasil são do tipo solidamente aterradas com neutro distribuído e, portanto, é importante analisar os impactos da geração distribuída sobre as correntes de curto-circuito monofásico.

IV. As concessionárias de distribuição possuem exigências distintas quanto à ligação dos transformadores de acoplamento, portanto os casos em que o transformador do gerador está ligado em delta ou estrela aterrada no lado de média tensão devem ser igualmente analisados.

V. As normas das concessionárias impõem que geradores com potência nominal acima de $75 \mathrm{~kW}$ ou $100 \mathrm{~kW}$ devem ser conectados na média tensão trifásica. Isto permite que o trabalho se limite ao estudo de redes trifásicas simétricas simples.

VI. As normas da ANEEL criaram limites regulatórios de potência que valem a pena ser analisados neste trabalho: 100 kW (microgeração), 1 MW (minigeração e CGHs), 5 MW (centrais registradas na ANEEL) e $30 \mathrm{MW}$ (fontes incentivadas e limite de conexão na média tensão do PRODIST).

Estes entendimentos limitaram o escopo deste trabalho e serviram de premissas para as análises desenvolvidas daqui para frente. 


\section{Metodologia}

Os impactos da geração distribuída sobre as correntes de curto-circuito de uma rede de distribuição poderiam ser avaliados por vários métodos, por exemplo, no desenvolvimento desse trabalho experimentou-se o método analítico através do equacionamento das correntes de falta e da tentativa de se tirar conclusões a partir das relações matemáticas envolvidas. Contudo, as expressões tornavam-se grandes rapidamente, complexas e com muitas variáveis, sobretudo para o caso das faltas monofásicas. As hipóteses que simplificavam as expressões geralmente não eram válidas porque as ordens de magnitude das impedâncias eram parecidas e levavam a erros grosseiros.

Uma possibilidade de se contornar as dificuldades do método analítico seria o uso de um programa de análise de redes, porém o número de casos a serem analisados para um estudo mais completo seria grande demais e o trabalho muito dispendioso. Por esta razão foi escolhido o método paramétrico, onde os modelos elétricos são implantados em um programa e realiza-se uma análise extensiva dos parâmetros envolvidos nos modelos.

O método paramétrico foi elaborado em uma planilha justamente pelo fato de ser uma ferramenta muito flexível, permitindo realizar análises e gráficos de maneira simples. Além disso, permite análises de sensibilidade e otimização de parâmetros que foram usadas durante o desenvolvimento do estudo. Ademais, a interface gráfica e a maneira tabular das planilhas eletrônicas facilitam a alteração dos dados para se gerar os casos.

Para garantir que os resultados obtidos com a planilha estivessem corretos, pois é comum que erros ocorram durante a programação, ela foi validada comparando-se seus resultados com aqueles obtidos através do programa comercial de análise de redes ETAP®.

Outra decisão importante foi a escolha de um dentre os diversos métodos de cálculo da corrente de curto-circuito. Adotou-se a norma IEC 60909 (IEC, 2001), explicada de maneira sucinta no item 4.1. Os cálculos elétricos implantados na planilha e validação de seus resultados são discutidos nos itens 4.2 e 4.3 deste capítulo, respectivamente. Ao final do capítulo os modelos elétricos dos componentes da rede são apresentados. 


\subsection{A Norma IEC-60909}

O cálculo exato da corrente de curto-circuito e sua evolução no tempo é uma tarefa complexa, pois ele depende de inúmeros fatores, entre eles o fluxo de potência da rede e as tensões imediatamente antes da falta. As normas técnicas ANSI/IEEE Std 141 (IEEE, 1993) (americana) e IEC 60909 (IEC, 2001) (europeia) padronizam e simplificam estes cálculos significativamente.

Neste trabalho foi usada a norma internacional IEC 60909 que se baseia no método da fonte de tensão no ponto de falta. Este método desconsidera as correntes de carga (condição de operação do sistema) e assume que o sistema está operando com sobretensão na pré-falta, fazendo com que os valores de curto-circuito obtidos sejam conservativos.

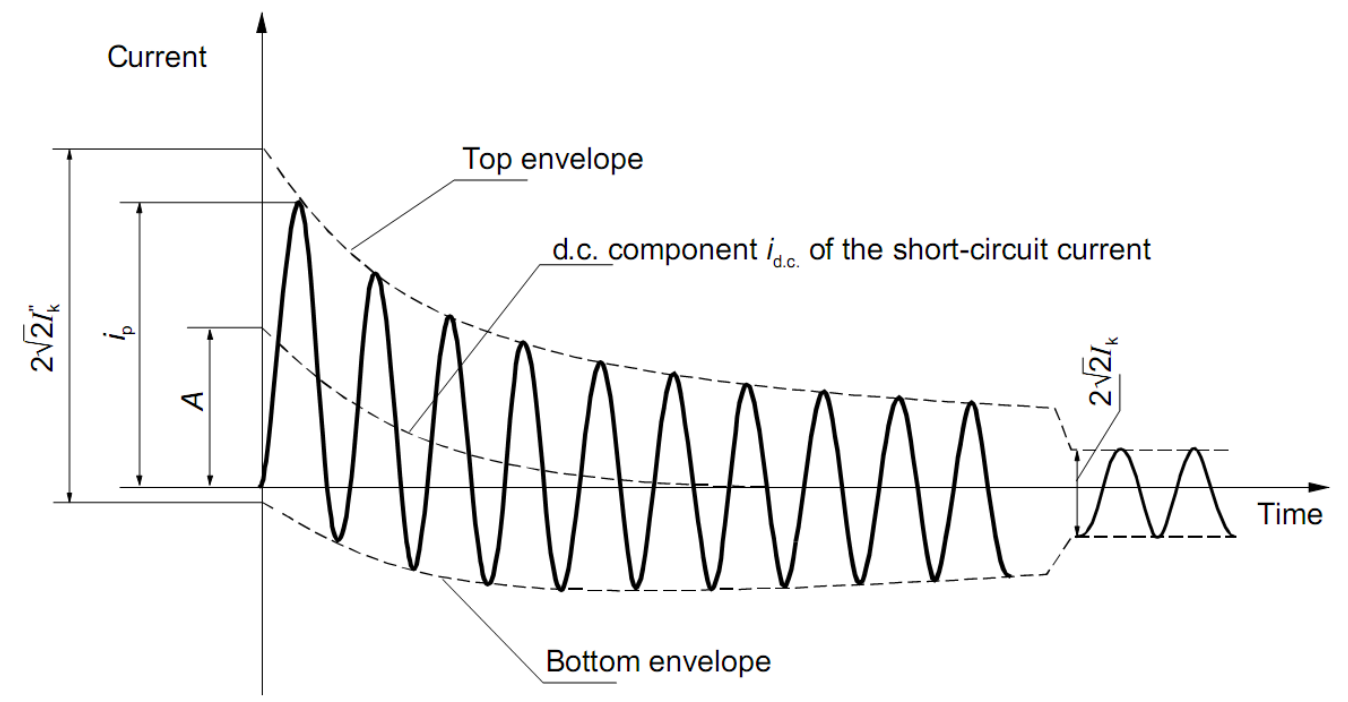

Figura 4.1 - Definições da norma IEC 60909 para a corrente de curto-circuito

Onde:

$I_{k}^{\prime \prime} \quad$ Corrente simétrica inicial (subtransitória) de curto-circuito: valor eficaz da componente alternada da corrente de curto-circuito no instante da falta.

$i_{p} \quad \begin{aligned} & \text { Corrente } \\ & \text { circuito. }\end{aligned}$

$I_{k} \quad$ Corrente permanente de curto-circuito: valor eficaz da corrente de curto-circuito após o decaimento do período transitório.

A Componente contínua de curto-circuito: valor inicial da componente aperiódica da corrente de curto-circuito. 
A corrente inicial simétrica de curto-circuito $\left(\dot{I}^{\prime \prime}{ }_{k}\right)$ é calculada a partir da relação entre a tensão de fase de pré-falta $(\dot{E})$ e da impedância equivalente de Thévénin do ponto de falta $\left(\dot{Z}_{t h}\right)$, olhando-se para dentro do sistema.

$$
\dot{I}_{k}^{\prime \prime}=\frac{\dot{E}}{\dot{Z}_{t h}}=\frac{c U_{n} / \sqrt{3}}{\dot{Z}_{t h}}
$$

Por sua vez, a corrente inicial simétrica de curto-circuito fase-terra $\left(\dot{I}^{\prime \prime}{ }_{k 1}\right)$ é calculada a partir das impedâncias equivalentes de Thévénin do ponto de falta para a sequência positiva $\left(\dot{Z}_{t h}\right)$ e zero $\left(\dot{Z}_{t h 0}\right)$.

$$
\dot{I}_{k 1}^{\prime \prime}=3 \dot{I}_{0}=3 \frac{\dot{E}}{\dot{Z}_{t h 1}+\dot{Z}_{t h 2}+\dot{Z}_{t h 0}}=3 \frac{c U_{n} / \sqrt{3}}{\dot{Z}_{t h 1}+\dot{Z}_{t h 2}+\dot{Z}_{t h 0}}
$$

Para que o método seja independente do fluxo de potência da rede, isto é, das correntes imediatamente antes da falta, a norma IEC 60909 assume uma tensão de pré-falta através de um fator de tensão $(c)$ que multiplica a tensão nominal do ponto de falta $\left(U_{n}\right)$. Adotando-se o valor mínimo ou máximo para $c$, calcula-se a corrente de curto-circuito mínima ou máxima, respectivamente. $\mathrm{O}$ fator de tensão depende da tensão nominal da rede e pode ser visto na Tabela 4.1.

Tabela 4.1 - Fator de tensão c da norma IEC 60909

\begin{tabular}{cc|cc}
\hline \multicolumn{2}{c}{ Tensão Nominal $\left(U_{n}\right)$} & $c$ máx. & $c$ mín. \\
\hline \multirow{2}{*}{ BT } & $200-400 \mathrm{~V}$ & 1 & 0,95 \\
& $400-1000 \mathrm{~V}$ & 1,05 & 1 \\
MT & $1-35 \mathrm{kV}$ & 1,10 & 1 \\
AT & $>35 \mathrm{kV}$ & 1,10 & 1 \\
\hline
\end{tabular}


A norma classifica as faltas em dois grandes grupos: curto-circuito próximo ao gerador $\mathrm{e}$ curto-circuito longe do gerador. Estes termos (próximo e longe) se referem à impedância que existe entre o ponto de falta e as fontes do sistema.

Quando as impedâncias da rede até o ponto de falta forem significativamente maiores que as impedâncias substransitórias das fontes, diz-se tratar de um curto-circuito longe do gerador, a corrente simétrica inicial de curto-circuito $\left(I^{\prime \prime}{ }_{k}\right)$ passa a ter uma magnitude muito próxima da corrente simétrica permanente de curto-circuito $\left(I_{k}\right)$. Em outras palavras, o decaimento da corrente simétrica de curto-circuito é pequeno. Por exemplo, faltas nas redes de distribuição são consideradas curto-circuito longe do gerador (Roeper, 1990).

Outra decorrência disso é que a impedância de Thévénin de sequência positiva vista pelo ponto de falta é praticamente igual à de sequência negativa, e pode-se lançar mão da simplificação $Z_{t h 2}=Z_{t h l}=Z_{t h}$.

Do ponto de vista da proteção, a norma também estabelece um método para o cálculo da corrente simétrica no instante de sua atuação, denominada corrente de interrupção $\left(I_{b}\right)$, conforme a Equação 4.3:

$$
I_{b}=\mu I_{k}^{\prime \prime}
$$

Equação 4.3

$\mathrm{O}$ fator $\mu$ considera o decaimento da corrente simétrica de curto-circuito e depende do tempo de atuação da proteção e da distância do ponto de falta às fontes do sistema, medida indiretamente através da relação $I_{k}{ }^{\prime} / I_{k}$.

No caso de falta longe do gerador, a corrente simétrica de interrupção de curto-circuito $\left(I_{b}\right)$ é igual à corrente simétrica inicial de curto-circuito $\left(I^{\prime \prime}{ }_{k}\right)$, pois a componente alternada não decai (Schlabbach, 2005), i.e., $\mu=1$. Este é o caso geral das redes de distribuição, e por esta razão, considerou-se a corrente simétrica inicial $\left(I^{\prime \prime}{ }_{k}\right)$ como o parâmetro a ser estudado neste trabalho. 


\subsection{Ferramenta de Análise}

Uma planilha eletrônica foi elaborada para se calcular as magnitudes das correntes de curto-circuito segundo a norma IEC 60909 em uma rede de distribuição radial com um gerador conectado. A mesma ferramenta permite calcular as contribuições da fonte e do gerador para a formação da corrente de curto-circuito e atende tanto os casos de falta trifásica quanto os casos fase-terra.

O modelo implantando na planilha calcula as correntes de curto-circuito e também as contribuições da fonte e do gerador para três condições: curto-circuito à montante do gerador, à jusante do gerador e no alimentador adjacente. Cada uma dessas condições é representada por um circuito elétrico equivalente diferente, que podem ser vistos na Figura 4.2, na Figura 4.3 e na Figura 4.4, respectivamente.

Nestas figuras estão relacionados os seguintes parâmetros elétricos:

$\dot{Z}_{s} \quad$ Impedância de Thévénin da fonte

$\dot{Z}^{\prime} \quad$ Impedância da linha de distribuição por km

$\dot{Z}_{c} \quad$ Impedância do elemento de conexão do GD

$\dot{Z}_{d g} \quad$ Impedância do gerador distribuído

$\dot{Z}_{t h} \quad$ Impedância de Thévénin visto pelo ponto de falta

$\dot{E} \quad$ Tensão de fase de pré-falta no ponto de curto-circuito

$x \quad$ Distância do ponto de falta à subestação

$d \quad$ Distância de conexão do GD à subestação

$\dot{I}^{\prime \prime}{ }_{k} \quad$ Corrente subtransitória de curto-circuito trifásico

$\dot{I}^{\prime \prime}{ }_{k 1} \quad$ Corrente subtransitória de curto-circuito fase-terra

$\dot{I}^{\prime \prime}{ }_{k s} \quad$ Contribuição da fonte para a corrente de curto-circuito

$\dot{I}^{\prime \prime}{ }_{k d g} \quad$ Contribuição do gerador para a corrente de curto-circuito

As impedâncias com o subscrito zero representam as impedâncias de sequência zero e servem para o cálculo da corrente de curto-circuito fase terra.

Ao se analisar o primeiro circuito elétrico, isto é, o caso em que a falta ocorre em um trecho do alimentador entre a subestação e o gerador, a falta é alimentada em dois sentidos, como mostra a Figura 4.2, onde $I_{k f}$ e $I_{k g d}$ são as contribuições da fonte e do gerador para o curto-circuito, respectivamente. 
Por sua vez, o segundo circuito (Figura 4.3) representa o caso em que a falta ocorre à jusante do ponto de conexão do gerador. Neste caso tanto a fonte quanto o gerador contribuem para a corrente de falta no mesmo sentido.

O último circuito (Figura 4.4) representa uma falta que ocorre em um alimentador adjacente àquele em que o gerador está conectado. Neste caso, o gerador contribui para a falta com uma corrente reversa, que se soma à contribuição da fonte para formar a corrente de curto-circuito no ponto de falta.

Nos três modelos apresentados há uma impedância $\dot{Z}_{g}$ que representa a impedância de sequência zero vista no lado de média tensão do transformador olhando-se para o gerador. Esta impedância pode ter diferentes valores em função das ligações do transformador de acoplamento, conforme mostra a Tabela 4.2.

Tabela 4.2 - Impedância de sequência zero do conjunto gerador-transformador vista pelo lado de média tensão do transformador (concessionária)

\begin{tabular}{|c|c|c|}
\hline Ligação do Transformador & Diagrama de Sequência Zero & Impedância $\dot{Z}_{g}$ \\
\hline$\underset{1}{G}$ & $\dot{Z}_{c 0}$ & $\dot{Z}_{g}=\dot{Z}_{c 0}$ \\
\hline $\begin{array}{l}\text { G } \\
\frac{1}{=}\end{array}$ & $\dot{Z}_{c 0}$ & $\dot{Z}_{g}=\dot{Z}_{c 0}+\dot{Z}_{d g 0}$ \\
\hline $\begin{array}{l}\text { G } \\
\frac{1}{2}\end{array}$ & $\overbrace{3 \dot{Z}_{n}}^{\dot{Z}_{c 0}}$ & $\dot{Z}_{g}=\dot{Z}_{c 0}+3 \dot{Z}_{n}$ \\
\hline$\triangle$ & $\dot{Z}_{c 0}$ & $\dot{Z}_{g} \rightarrow \infty$ \\
\hline
\end{tabular}




\section{Curto-circuito trifásico}

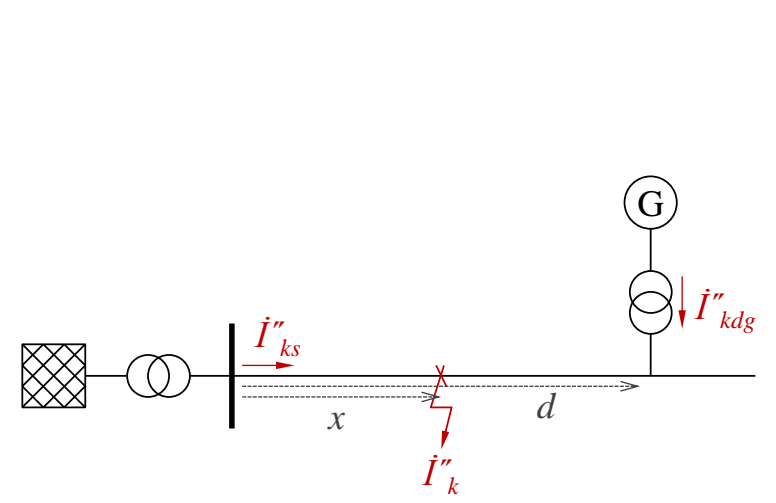

Equação 4.4 - equivalente de Thévénin de sequência positiva

$$
\dot{Z}_{t h}=\frac{\left(\dot{Z}_{s}+x \dot{Z}^{\prime}\right)\left((d-x) \dot{Z}^{\prime}+\dot{Z}_{c}+\dot{Z}_{d g}\right)}{\dot{Z}_{s}+d \dot{Z}^{\prime}+\dot{Z}_{c}+\dot{Z}_{d g}}
$$

Equação 4.5 - contribuição da fonte para o curto-circuito trifásico

$$
\dot{I}_{k s}^{\prime \prime}=\dot{I}_{k}^{\prime \prime}\left(\frac{(d-x) \dot{Z}^{\prime}+\dot{Z}_{c}+\dot{Z}_{d g}}{\dot{Z}_{s}+d \dot{Z}^{\prime}+\dot{Z}_{c}+\dot{Z}_{d g}}\right)
$$

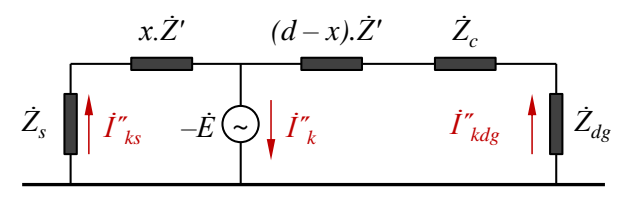

Equação 4.6 - contribuição do gerador para o curtocircuito trifásico

$$
\dot{I}_{k d g}^{\prime \prime}=\dot{I}_{k}^{\prime \prime}\left(\frac{\dot{Z}_{s}+x \dot{Z}^{\prime}}{\dot{Z}_{s}+d \dot{Z}^{\prime}+\dot{Z}_{c}+\dot{Z}_{d g}}\right)
$$

\section{Curto-circuito monofásico}

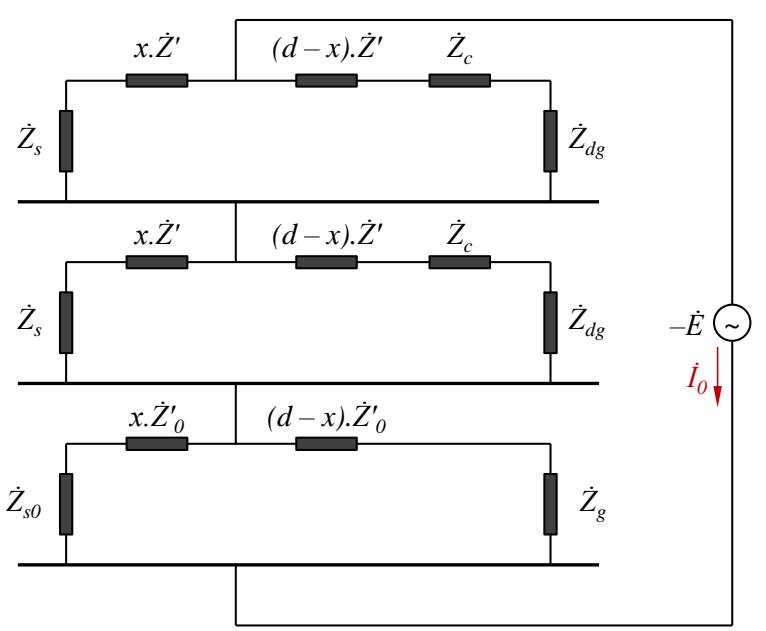

Equação 4.7 - equivalente de Thévénin de sequência zero

$\dot{Z}_{t h 0}=\frac{\left(\dot{Z}_{s 0}+x \dot{Z}_{0}^{\prime}\right)\left((d-x) \dot{Z}_{0}^{\prime}+\dot{Z}_{g}\right)}{\dot{Z}_{s 0}+d \dot{Z}_{0}^{\prime}+\dot{Z}_{g}}$

Equação 4.8 - contribuição da fonte para o curto-circuito monofásico

$$
\dot{I}_{k 1 s}^{\prime \prime}=2 \dot{I}_{0}\left(\frac{(d-x) \dot{Z}^{\prime}+\dot{Z}_{c}+\dot{Z}_{d g}}{\dot{Z}_{s}+d \dot{Z}^{\prime}+\dot{Z}_{c}+\dot{Z}_{d g}}\right)+\dot{I}_{0}\left(\frac{(d-x) \dot{Z}_{0}^{\prime}+\dot{Z}_{g}}{\dot{Z}_{s 0}+d \dot{Z}_{0}^{\prime}+\dot{Z}_{g}}\right)
$$

Equação 4.9 - contribuição do gerador para o curtocircuito monofásico

$$
\dot{I}_{k 1 d g}^{\prime \prime}=2 \dot{I}_{0}\left(\frac{\dot{Z}_{s}+x \dot{Z}^{\prime}}{\dot{Z}_{s}+d \dot{Z}^{\prime}+\dot{Z}_{c}+\dot{Z}_{d g}}\right)+\dot{I}_{0}\left(\frac{\dot{Z}_{s 0}+x \dot{Z}_{0}^{\prime}}{\dot{Z}_{s 0}+d \dot{Z}_{0}^{\prime}+\dot{Z}_{g}}\right)
$$




\section{Curto-circuito trifásico}

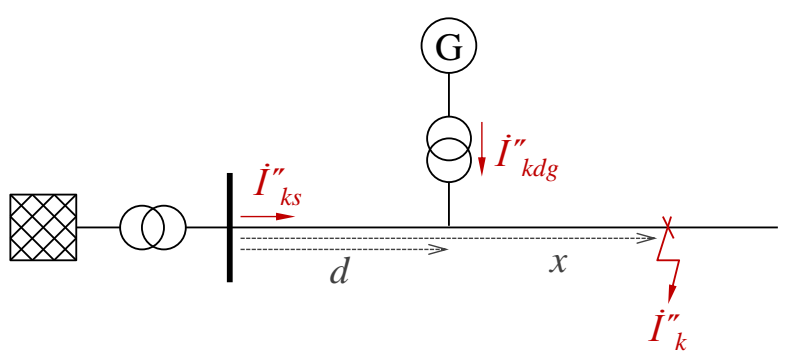

Equação 4.10 - equivalente de Thévénin de sequência positiva

$\dot{Z}_{t h}=(x-d) \dot{Z}^{\prime}+\frac{\left(\dot{Z}_{s}+d \dot{Z}^{\prime}\right)\left(\dot{Z}_{c}+\dot{Z}_{d g}\right)}{\dot{Z}_{s}+d \dot{Z}^{\prime}+\dot{Z}_{c}+\dot{Z}_{d g}}$

Equação 4.11 - contribuição da fonte para o curto-circuito trifásico

$$
\dot{I}_{k s}^{\prime \prime}=\dot{I}_{k}^{\prime \prime}\left(\frac{\dot{Z}_{c}+\dot{Z}_{d g}}{\dot{Z}_{s}+d \dot{Z}^{\prime}+\dot{Z}_{c}+\dot{Z}_{d g}}\right)
$$

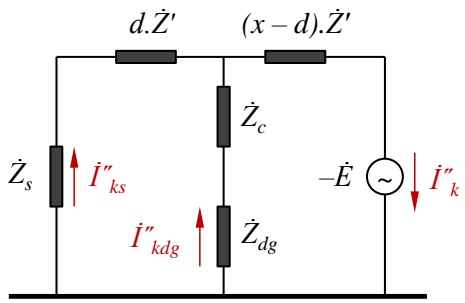

Equação 4.12 - contribuição do gerador para o curtocircuito trifásico

$$
\dot{I}_{k d g}^{\prime \prime}=\dot{I}_{k}^{\prime \prime}\left(\frac{\dot{Z}_{s}+d \dot{Z}^{\prime}}{\dot{Z}_{s}+d \dot{Z}^{\prime}+\dot{Z}_{c}+\dot{Z}_{d g}}\right)
$$

\section{Curto-circuito monofásico}

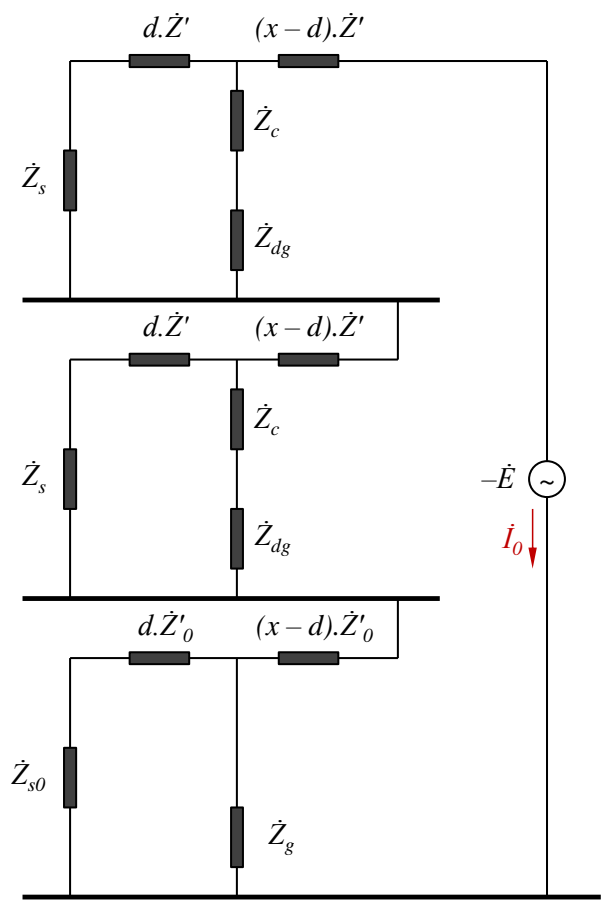

Equação 4.13 - equivalente de Thévénin de sequência zero

$\dot{Z}_{t h 0}=(x-d) \dot{Z}_{0}^{\prime}+\frac{\left(\dot{Z}_{s 0}+d \dot{Z}_{0}^{\prime}\right) \dot{Z}_{g}}{\dot{Z}_{s 0}+d \dot{Z}_{0}^{\prime}+\dot{Z}_{g}}$

Equação 4.14 - contribuição da fonte para o curto-circuito monofásico

$$
\dot{I}_{k 1 s}^{\prime \prime}=2 \dot{I}_{0}\left(\frac{\dot{Z}_{c}+\dot{Z}_{d g}}{\dot{Z}_{s}+d \dot{Z}^{\prime}+\dot{Z}_{c}+\dot{Z}_{d g}}\right)+\dot{I}_{0}\left(\frac{\dot{Z}_{g}}{\dot{Z}_{s 0}+d \dot{Z}_{0}^{\prime}+\dot{Z}_{g}}\right)
$$

Equação 4.15 - contribuição do gerador para o curtocircuito monofásico

$$
\dot{I}_{k 1 d g}^{\prime \prime}=2 \dot{I}_{0}\left(\frac{\dot{Z}_{s}+d \dot{Z}^{\prime}}{\dot{Z}_{s}+d \dot{Z}^{\prime}+\dot{Z}_{c}+\dot{Z}_{d g}}\right)+\dot{I}_{0}\left(\frac{\dot{Z}_{s 0}+d \dot{Z}_{0}^{\prime}}{\dot{Z}_{s 0}+d \dot{Z}_{0}^{\prime}+\dot{Z}_{g}}\right)
$$


Figura 4.4 - Modelos elétricos para curto-circuito no alimentador adjacente ao do gerador

\section{Curto-circuito trifásico}
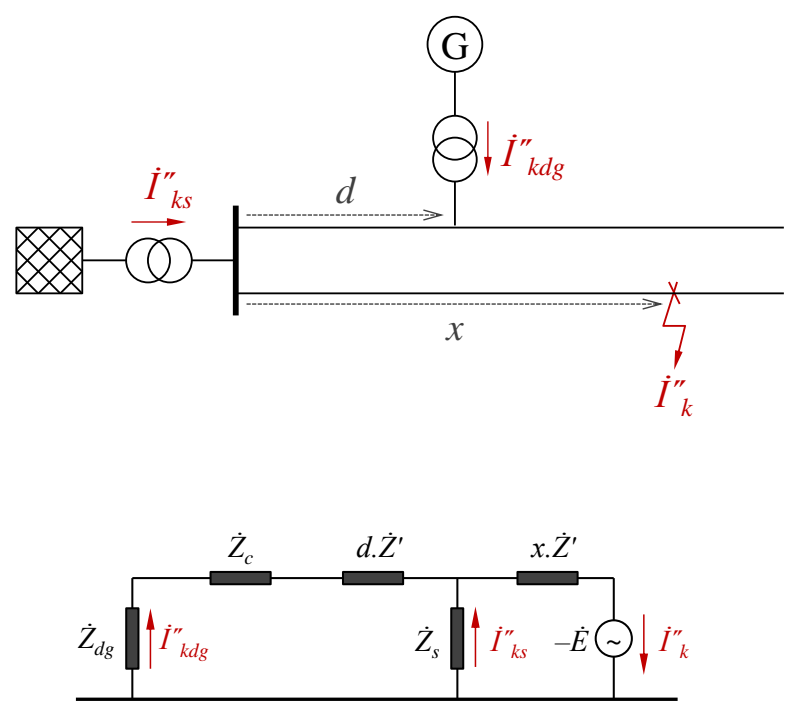

Equação 4.16 - equivalente de Thévénin de sequência positiva

$\dot{Z}_{t h}=x \dot{Z}^{\prime}+\frac{\dot{Z}_{s}\left(d \dot{Z}^{\prime}+\dot{Z}_{c}+\dot{Z}_{d g}\right)}{\dot{Z}_{s}+d \dot{Z}^{\prime}+\dot{Z}_{c}+\dot{Z}_{d g}}$

Equação 4.17 - contribuição da fonte para o curto-circuito trifásico

$$
\dot{I}_{k s}^{\prime \prime}=\dot{I}_{k}^{\prime \prime}\left(\frac{d \dot{Z}^{\prime}+\dot{Z}_{c}+\dot{Z}_{d g}}{\dot{Z}_{s}+d \dot{Z}^{\prime}+\dot{Z}_{c}+\dot{Z}_{d g}}\right)
$$

Equação 4.18 - contribuição do gerador para o curtocircuito trifásico

$$
\dot{I}_{k d g}^{\prime \prime}=\dot{I}_{k}^{\prime \prime}\left(\frac{\dot{Z}_{s}}{\dot{Z}_{s}+d \dot{Z}^{\prime}+\dot{Z}_{c}+\dot{Z}_{d g}}\right)
$$

\section{Curto-circuito monofásico}

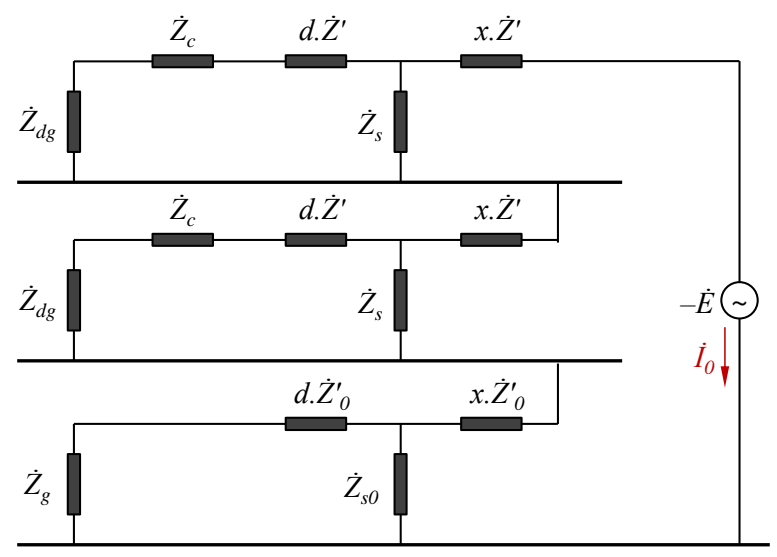

Equação 4.19 - equivalente de Thévénin de sequência zero

$\dot{Z}_{t h 0}=x \dot{Z}_{0}^{\prime}+\frac{\dot{Z}_{s 0}\left(d \dot{Z}_{0}^{\prime}+\dot{Z}_{g}\right)}{\dot{Z}_{s 0}+d \dot{Z}_{0}^{\prime}+\dot{Z}_{g}}$

Equação 4.20 - contribuição da fonte para o curto-circuito monofásico

$\dot{I}_{k 1 s}^{\prime \prime}=2 \dot{I}_{0}\left(\frac{d \dot{Z}^{\prime}+\dot{Z}_{c}+\dot{Z}_{d g}}{\dot{Z}_{s}+d \dot{Z}^{\prime}+\dot{Z}_{c}+\dot{Z}_{d g}}\right)+\dot{I}_{0}\left(\frac{d \dot{Z}_{0}^{\prime}+\dot{Z}_{g}}{\dot{Z}_{s 0}+d \dot{Z}_{0}^{\prime}+\dot{Z}_{g}}\right)$

Equação 4.21 - contribuição do gerador para o curtocircuito monofásico

$$
\dot{I}_{k 1 d g}^{\prime \prime}=2 \dot{I}_{0}\left(\frac{\dot{Z}_{s}}{\dot{Z}_{s}+d \dot{Z}^{\prime}+\dot{Z}_{c}+\dot{Z}_{d g}}\right)+\dot{I}_{0}\left(\frac{\dot{Z}_{s 0}}{\dot{Z}_{s 0}+d \dot{Z}_{0}^{\prime}+\dot{Z}_{g}}\right)
$$




\subsection{Validação da Planilha}

A planilha de cálculo foi validada através de uma comparação de seus resultados com aqueles obtidos pela simulação de uma rede de distribuição no programa ETAP®, que é um pacote comercial de simulação elétrica já validado.

A rede teste é composta de dois alimentadores de $13,8 \mathrm{kV}$ com $10 \mathrm{~km}$ de comprimento cada, ambos supridos por um transformador de 10 MVA cujo primário é alimentado por um barramento infinito. A impedância deste transformador é tal que a potência de curto-circuito trifásico no secundário é igual a 125 MVA, que é um valor típico para sistemas de média tensão (limitação pela capacidade disruptiva de disjuntores MT das subestações).

A geração distribuída é representada através de um gerador síncrono de $4 \mathrm{MW}$ ligado a um dos alimentadores através de um transformador de conexão de 5 MVA e se situa à uma distância de 4 km da subestação. A modelagem deste sistema pode ser visto na Figura 4.5.

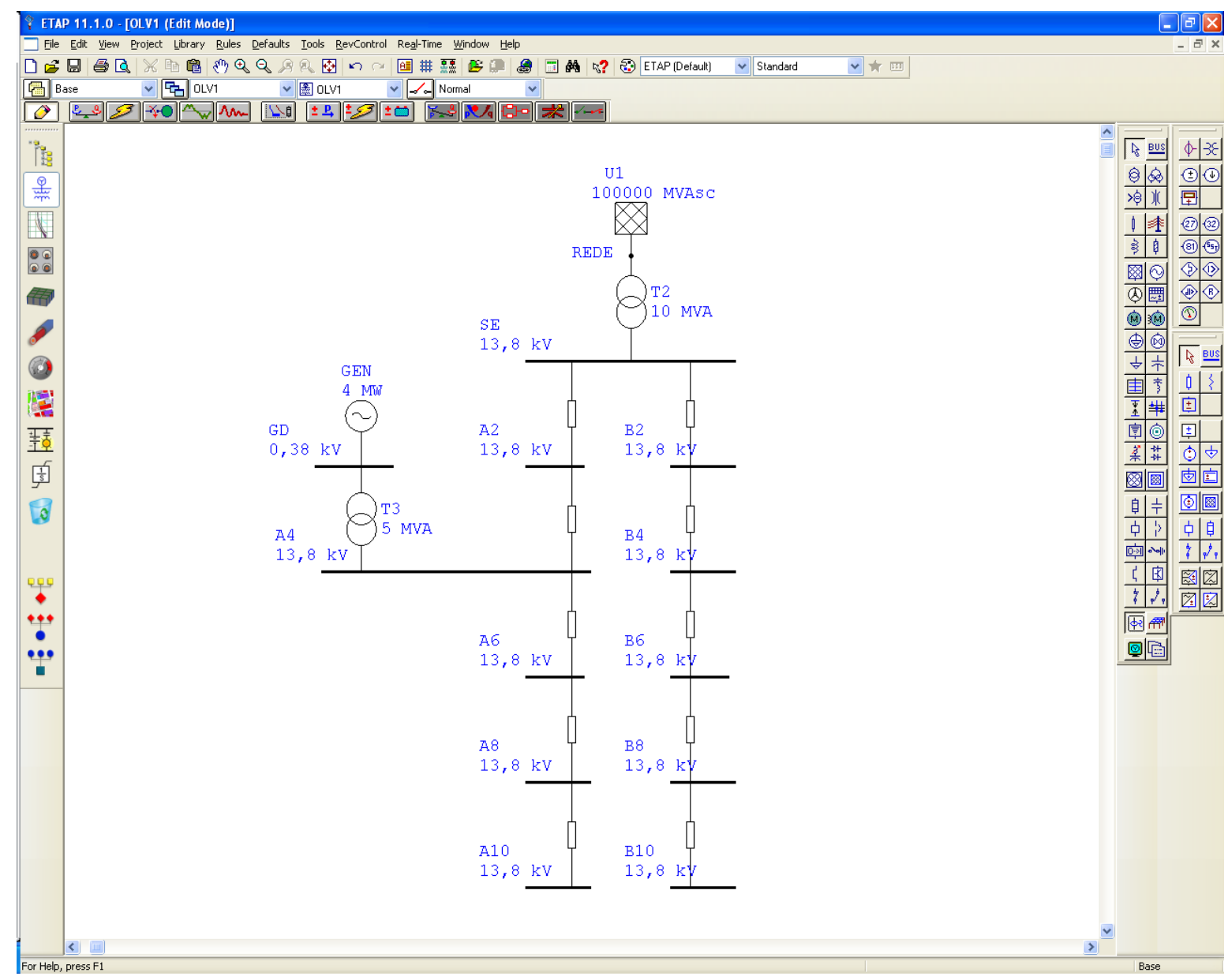

Figura 4.5 - Rede teste modelada no programa ETAP® 
Os dados elétricos da rede simulada são apresentados na Tabela 4.3. É importante notar que a ligação do lado de média tensão do transformador pode variar de acordo com o caso simulado.

Tabela 4.3 - Dados elétricos da rede teste para validação da planilha

\begin{tabular}{lc} 
Transformador da Fonte & \\
\hline Potência nominal & $10 \mathrm{MVA}$ \\
Relação de tensão & $138 / 13,8 \mathrm{kV}$ \\
Ligação & $\Delta / \mathrm{y}$ \\
Reatância seq. Positiva & $8 \%$ \\
Reatância seq. Negativa & $8 \%$ \\
\hline
\end{tabular}

\begin{tabular}{lc} 
Transformador de Conexão & \\
\hline Potência nominal & $5 \mathrm{MVA}$ \\
Relação de tensão & $0,38 / 13,8 \mathrm{kV}$ \\
Ligação & $\Delta /\left(^{*}\right)$ \\
Reatância seq. Positiva & $7 \%$ \\
Reatância seq. Negativa & $7 \%$ \\
\hline
\end{tabular}

\begin{tabular}{lc} 
Alimentador & \\
\hline Condutor & $336 \mathrm{kcmil}$ \\
Impedância seq. positiva & $0,20+\mathrm{j} .0,38 \Omega / \mathrm{km}$ \\
Impedância seq. negativa & $0,39+\mathrm{j} .1,89 \Omega / \mathrm{km}$ \\
Capacidade de condução & $578 \mathrm{~A}$ \\
\hline
\end{tabular}

\begin{tabular}{lc} 
Gerador Distribuído & \\
\hline Potência ativa & $4 \mathrm{MW}$ \\
Potência nominal & $5 \mathrm{MVA}$ \\
Fator de potência & 0,80 \\
Reatância subtransitória & $14 \%$ \\
\hline
\end{tabular}

(*) O lado de média tensão $(13,8 \mathrm{kV})$ pode ser ligado em estrela ou triângulo, conforme o caso simulado

As correntes de curto-circuito trifásicas e fase-terra foram calculadas a cada $2 \mathrm{~km}$ de rede segundo a norma IEC 60909. Nas tabelas a seguir, com exceção do barramento SE que é a fonte do sistema, a primeira letra do nome do ponto de falta representa o alimentador e o número que se segue representa a distância do ponto em relação à subestação da fonte.

Primeiramente, dois casos foram analisados para a corrente de curto-circuito trifásico, sendo um sem o gerador distribuído e outro com o gerador conectado à rede. Os resultados estão resumidos na Tabela 4.4 .

Por sua vez, foram analisados três casos para o curto-circuito monofásico, o primeiro sendo sem o gerador distribuído e os outros dois com o gerador conectado à rede. Há apenas uma única diferença entre os dois últimos casos: o tipo de ligação feito no lado de alta tensão do transformador de conexão com a rede. Os resultados estão resumidos na Tabela 4.5. 
Tabela 4.4 - Validação da planilha para o curto-circuito trifásico

\begin{tabular}{|c|c|c|c|c|c|c|}
\hline \multicolumn{7}{|c|}{ Validação da Corrente de Curto-Circuito Trifásica (kA) } \\
\hline \multirow{2}{*}{ Ponto de falta } & \multicolumn{3}{|c|}{ Sem GD } & \multicolumn{3}{|c|}{ Com GD } \\
\hline & ETAP & Planilha & Dif. & ETAP & Planilha & Dif. \\
\hline SE & 5,76 & 5,75 & $-0,1 \%$ & 6,70 & 6,68 & $-0,3 \%$ \\
\hline $\mathrm{A}-2 \mathrm{~km}$ & 3,78 & 3,78 & $-0,1 \%$ & 4,81 & 4,79 & $-0,4 \%$ \\
\hline $\mathrm{A}-4 \mathrm{~km}$ & 2,79 & 2,79 & $-0,1 \%$ & 3,90 & 3,88 & $-0,5 \%$ \\
\hline $\mathrm{A}-6 \mathrm{~km}$ & 2,20 & 2,20 & $-0,1 \%$ & 2,85 & 2,84 & $-0,3 \%$ \\
\hline $\mathrm{A}-8 \mathrm{~km}$ & 1,81 & 1,81 & $0,0 \%$ & 2,23 & 2,23 & $-0,3 \%$ \\
\hline $\mathrm{A}-10 \mathrm{~km}$ & 1,54 & 1,54 & $-0,1 \%$ & 1,84 & 1,83 & $-0,2 \%$ \\
\hline $\mathrm{B}-2 \mathrm{~km}$ & 3,78 & 3,78 & $-0,1 \%$ & 4,16 & 4,15 & $-0,2 \%$ \\
\hline $\mathrm{B}-4 \mathrm{~km}$ & 2,79 & 2,79 & $-0,1 \%$ & 2,98 & 2,97 & $-0,1 \%$ \\
\hline $\mathrm{B}-6 \mathrm{~km}$ & 2,20 & 2,20 & $-0,1 \%$ & 2,31 & 2,31 & $-0,1 \%$ \\
\hline $\mathrm{B}-8 \mathrm{~km}$ & 1,81 & 1,81 & $0,0 \%$ & 1,89 & 1,89 & $-0,1 \%$ \\
\hline $\mathrm{B}-10 \mathrm{~km}$ & 1,54 & 1,54 & $-0,1 \%$ & 1,60 & 1,60 & $-0,1 \%$ \\
\hline
\end{tabular}

Tabela 4.5 - Validação da planilha para o curto-circuito fase-terra

\begin{tabular}{|c|c|c|c|c|c|c|c|c|c|}
\hline \multicolumn{10}{|c|}{ Validação da Corrente de Curto-Circuito Fase-Terra (kA) } \\
\hline \multirow{2}{*}{ Ponto de falta } & \multicolumn{3}{|c|}{ Sem GD } & \multicolumn{3}{|c|}{ Com GD aterrada } & \multicolumn{3}{|c|}{ Com GD isolada } \\
\hline & ETAP & Planilha & Dif. & ETAP & Planilha & Dif. & ETAP & Planilha & Dif. \\
\hline SE & 5,76 & 5,75 & $-0,2 \%$ & 6,67 & 6,65 & $-0,3 \%$ & 6,36 & 6,34 & $-0,3 \%$ \\
\hline $\mathrm{A}-2 \mathrm{~km}$ & 2,60 & 2,60 & $-0,1 \%$ & 3,98 & 3,95 & $-0,6 \%$ & 2,88 & 2,88 & $-0,2 \%$ \\
\hline $\mathrm{A}-4 \mathrm{~km}$ & 1,67 & 1,67 & $-0,1 \%$ & 4,05 & 3,99 & $-1,4 \%$ & 1,89 & 1,88 & $-0,2 \%$ \\
\hline $\mathrm{A}-6 \mathrm{~km}$ & 1,23 & 1,23 & $-0,1 \%$ & 2,17 & 2,15 & $-0,8 \%$ & 1,34 & 1,34 & $-0,2 \%$ \\
\hline $\mathrm{A}-8 \mathrm{~km}$ & 0,98 & 0,97 & $-0,1 \%$ & 1,48 & 1,47 & $-0,6 \%$ & 1,04 & 1,04 & $-0,2 \%$ \\
\hline $\mathrm{A}-10 \mathrm{~km}$ & 0,81 & 0,81 & $-0,1 \%$ & 1,13 & 1,12 & $-0,4 \%$ & 0,85 & 0,85 & $-0,1 \%$ \\
\hline $\mathrm{B}-2 \mathrm{~km}$ & 2,60 & 2,60 & $-0,1 \%$ & 2,77 & 2,76 & $-0,2 \%$ & 2,72 & 2,71 & $-0,2 \%$ \\
\hline $\mathrm{B}-4 \mathrm{~km}$ & 1,67 & 1,67 & $-0,1 \%$ & 1,74 & 1,74 & $-0,1 \%$ & 1,72 & 1,72 & $-0,1 \%$ \\
\hline $\mathrm{B}-6 \mathrm{~km}$ & 1,23 & 1,23 & $-0,1 \%$ & 1,27 & 1,27 & $-0,1 \%$ & 1,26 & 1,25 & $-0,1 \%$ \\
\hline $\mathrm{B}-8 \mathrm{~km}$ & 0,98 & 0,97 & $-0,1 \%$ & 1,00 & 1,00 & $-0,2 \%$ & 0,99 & 0,99 & $-0,1 \%$ \\
\hline $\mathrm{B}-10 \mathrm{~km}$ & 0,81 & 0,81 & $-0,1 \%$ & 0,82 & 0,82 & $-0,1 \%$ & 0,82 & 0,82 & $-0,2 \%$ \\
\hline
\end{tabular}

Como pode ser observado, as diferenças entre os resultados são pequenas e são oriundas de pequenas limitações do software ETAP®, cuja barra infinita é modelada como uma fonte finita de potência muito elevada, e também alguns erros numéricos de truncamento da planilha. De toda a forma, as diferenças apresentadas são desprezíveis e considera-se que a planilha foi validada para fins de cálculo das correntes de curto-circuito. 


\subsection{Modelos Elétricos}

\section{a) Geradores}

Os geradores distribuídos podem ser classificados em três grandes grupos de acordo com a tecnologia de geração empregada, a saber:

I. Máquinas síncronas diretamente conectadas:

Geralmente são empregadas pelas termelétricas e hidrelétricas e representam quase a totalidade dos geradores com capacidade instalada até $5 \mathrm{MW}$ conectados na rede de distribuição, como já discutido no item 3.5. O modelo elétrico clássico da máquina síncrona é muito simples: uma fonte de tensão atrás de uma reatância (Stevenson, 1982). Elas contribuem permanentemente para a corrente de curto-circuito.

II. Máquinas assíncronas diretamente conectadas:

As máquinas assíncronas são normalmente empregadas na geração eólica e podem ser de velocidade fixa (FSIG), velocidade variável (VSIG) ou duplamente alimentadas (DFIG). As três tecnologias contribuem com uma corrente de curto-circuito que decai rapidamente, assim como ocorre com um motor de indução. A referência (Gevorgian \& Muljadi, 2010) demonstra que estes arranjos também podem ser representados por uma fonte de tensão atrás de uma impedância equivalente, da mesma maneira que um motor de indução ou uma máquina síncrona. Uma análise detalhada dos modelos elétricos de aerogeradores pode ser vista em (Salles, 2009).

III. Fontes conectadas através de conversores:

Alguns aerogeradores utilizam máquinas síncronas a imãs permanentes (ou não) que são conectadas à rede através de conversores de frequência. Os painéis fotovoltaicos também se conectam à rede através de inversores. Os conversores limitam o nível de curto-circuito no lado da rede, geralmente a valores pouco superiores a sua corrente nominal, e podem alimentar a falta por vários ciclos. 
Os modelos elétricos destas fontes são explicados de forma sucinta no Anexo A. Um modelo geral para as máquinas rotativas pode ser visto em (Gomez-Exposito, et al., 2011).

Para que este trabalho fosse generalista, o modelo clássico de fonte de tensão atrás de uma impedância foi adotado em todas as simulações e, tendo em vista a predominância da geração distribuída com máquinas rotativas, considerou-se uma reatância típica de $14 \%$.

\section{b) Transformadores de acoplamento}

Para os transformadores de acoplamento adotou-se uma reatância de dispersão $x_{c}=6 \%$. Este é um valor intermediário entre os limites mínimos de 5\% e 7\% que a norma IEC 60076-5 (IEC, 2004) impõe para transformadores entre $750 \mathrm{kVA}$ e $6300 \mathrm{kVA}$. Neste modelo não foi considerado o efeito de derivações (taps). A impedância de sequência zero foi fixada em $80 \%$ do valor da impedância de sequência positiva, o que é típico para transformadores de núcleo envolvido (Roeper, 1990).

\section{c) Rede externa}

A rede externa, incluindo a subestação da distribuidora, é modelada por seu equivalente de Thévénin e a impedância deste equivalente depende unicamente do nível de curto-circuito no secundário do transformador da concessionária. Na maioria dos casos foi utilizada uma potência de curto-circuito (trifásico e monofásico) de 125 MVA, que é típica para o nível de tensão de $13,8 \mathrm{kV}$.

\section{d) Linhas de distribuição}

Para as linhas de distribuição, foram usados três modelos apresentados no Anexo B, um para cada tipo de rede descrita abaixo:

- Redes aéreas convencionais (condutores de alumínio nu)

- Redes aéreas compactas (condutores de alumínio cobertos)

- Redes subterrâneas (condutores de cobre isolados) 
Nas redes aéreas convencionais com condutores nus, a isolação elétrica exige um maior espaçamento entre as fases, o que leva a uma maior reatância indutiva. Já no caso das redes aéreas compactas com condutores cobertos há uma maior proximidade entre as fases e, portanto, uma menor reatância indutiva. Por sua vez, nas redes subterrâneas com cabos isolados, os condutores ficam justapostos o que reduz significativamente a reatância indutiva deste tipo de rede em relação às redes aéreas.

Em relação à impedância de sequência zero, há grande diferença entre as redes aéreas e as redes subterrâneas. Será demonstrado nos próximos capítulos que o tipo de rede influencia significativamente as magnitudes das correntes de curto-circuito. 


\section{ImPACTOS DA GD NO CURTO-CIRCUITO DAS REDES DE DISTRIBUIÇÃO}

Para se demonstrar o impacto de um gerador sobre as correntes de curto-circuito e as proteções de uma rede de distribuição, foram feitas análises paramétricas para uma rede exemplo que, de certa forma, representa as redes típicas de distribuição que existem no Brasil. Trata-se de uma rede aérea de $13,8 \mathrm{kV}$, topologia radial, com condutor $336 \mathrm{kcmil}$, alimentada por uma fonte de 125 MVA, que também é típica para esse nível de tensão devido à limitação da corrente de disrupção dos disjuntores da subestação. A esta rede é conectado um gerador síncrono de $5 \mathrm{MW}$ através de um transformador de acoplamento de 6,3 MVA. Os parâmetros elétricos foram estimados conforme o item 4.4 e estão apresentados na Tabela 5.1.

Tabela 5.1 - Características elétricas da rede exemplo

\begin{tabular}{cc}
\hline Elemento & Características Elétricas \\
\hline Linha & Rede aérea com cabo $336,4 \mathrm{kcmil}$ \\
Fonte & $\dot{Z}^{\prime}=0,20+\mathrm{j} \cdot 0,38 \Omega / \mathrm{km} \mathrm{e} \dot{Z}_{0}^{\prime}=0,38+\mathrm{j} \cdot 1,95 \Omega / \mathrm{km}$ \\
Gerador & $S_{k}{ }^{\prime}=S_{k 0}{ }^{\prime \prime}=125 \mathrm{MVA}, U_{n}=13,8 \mathrm{kV}$ \\
Trafo GD & $P_{g}=5 \mathrm{MW}, \cos \varphi=0,80, x_{d}{ }^{\prime \prime}=14 \%$ \\
\end{tabular}

Basicamente foram feitas três análises variando-se as distâncias do ponto de falta e de conexão do gerador. A primeira avalia o impacto do gerador distribuído sobre os níveis de curto-circuito no alimentador em que está conectado (item 5.1). A segunda demonstra a alteração da contribuição da fonte para a formação da corrente de curto-circuito quando ocorre uma falta no mesmo alimentador do gerador (item 5.2). Por fim, a terceira determina o aumento dos níveis de curto-circuito em um alimentador adjacente àquele em que o gerador está conectado (item 5.3). 
Como será visto adiante, as análises serão feitas comparando-se as correntes de curtocircuito obtidas com as correntes que existiriam caso não houvesse um gerador conectado. Quando a rede não possui nenhum gerador, diz-se que ela é passiva e, por ser radial, suas correntes de curto-circuito diminuem ao longo de seus alimentadores, isto é, quanto mais distante da fonte menor será a corrente de falta. A Figura 5.1 ilustra esta redução para a rede exemplo, onde se verifica uma corrente de curto-circuito trifásica de 5,8 kA na subestação que é atenuada para $1,5 \mathrm{kA}$ à $10 \mathrm{~km}$ de distância dela. Para o caso de uma falta fase-terra, a corrente na subestação é de 5,8 kA contra 0,8 kA à 10 km de distância.

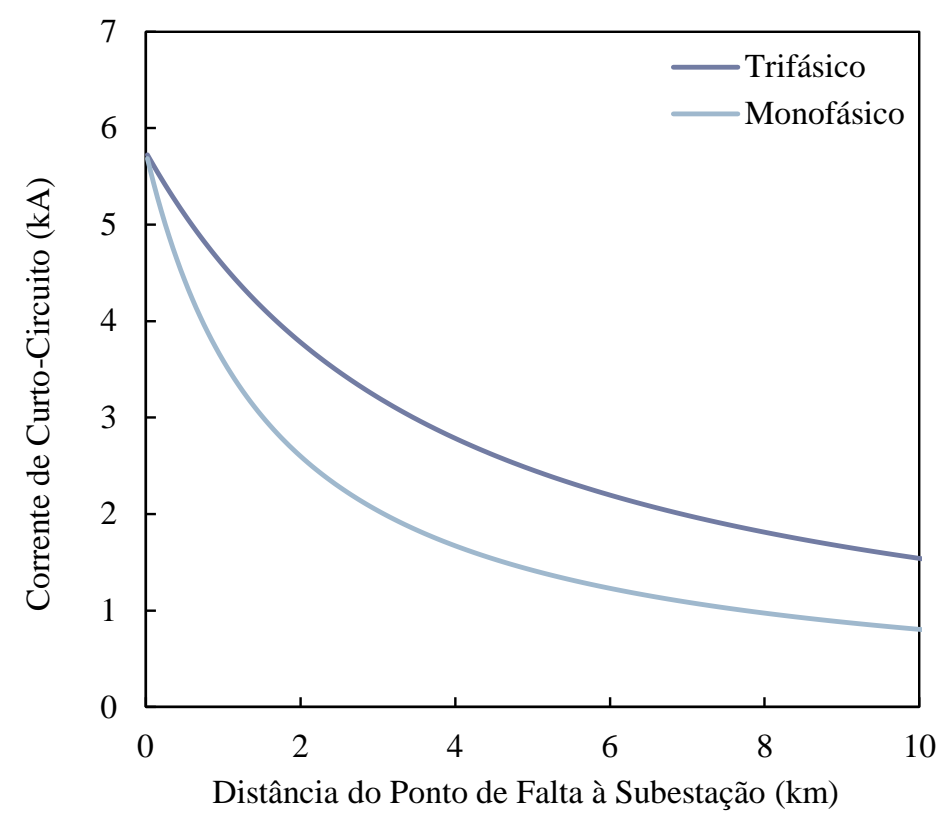

Figura 5.1 - Correntes de falta em um alimentador sem GD

É justamente esta característica de atenuação da corrente de curto-circuito com o aumento da distância do ponto de falta que permite o emprego da proteção por sobrecorrente. Dessa forma, os elementos de proteção à montante são ajustados para correntes e tempos de atuação maiores que os elementos de proteção a jusante.

A Equação 5.1 e a Equação 5.2 demonstram analiticamente a atenuação das correntes de falta para os curtos circuitos trifásico e monofásico, respectivamente. $\mathrm{O}$ asterisco sobrescrito indica que as correntes foram calculadas para uma rede sem gerador distribuído, isto é, uma 
rede passiva. Estas equações serão utilizadas nos próximos tópicos para ilustrar a relação das correntes de falta antes e depois da inserção de um gerador.

$\dot{I}_{k}^{\prime \prime *}=\frac{\dot{E}}{\dot{Z}_{s}+x \dot{Z}^{\prime}}$

Equação 5.1

$\dot{I}_{k 1}^{\prime n^{*}}=\frac{3 \dot{E}}{2\left(\dot{Z}_{s}+x \dot{Z}^{\prime}\right)+\left(\dot{Z}_{s 0}+x \dot{Z}_{0}^{\prime}\right)}$

Equação 5.2

$\dot{I}^{\prime \prime}{ }_{k}^{*} \quad$ Corrente subtransitória de curto-circuito trifásico sem o gerador

$\dot{I}^{\prime \prime}{ }_{k 1}{ }^{*} \quad$ Corrente subtransitória de curto-circuito monofásico sem o gerador

\subsection{Alteração nos Níveis de Curto-Circuito}

Um dos efeitos mais evidentes da conexão da geração na distribuição é o aumento dos níveis de curto-circuito das redes. O gerador se torna mais uma fonte a contribuir para a corrente de falta e isto pode trazer alguns problemas, como a superação da suportabilidade ao curto-circuito de linhas e equipamentos e a perda de coordenação da proteção.

Para demonstrar numericamente estes impactos, foram definidas quatro equações para calcular as variações absolutas e relativas das correntes de curto-circuito em relação aquelas que seriam obtidas caso não houvesse um gerador na rede de distribuição:

$$
\begin{aligned}
& \Delta I_{k}^{\prime \prime}=\left|\dot{I}_{k}^{\prime \prime}\right|-\left|\dot{I}_{k}^{\prime \prime *}\right| \\
& \delta I_{k}^{\prime \prime}=\frac{\left|\dot{I}_{k}^{\prime \prime}\right|-\left|\dot{I}_{k}^{\prime \prime *}\right|}{\left|\dot{I}_{k}^{\prime \prime *}\right|}
\end{aligned}
$$$$
\text { Equação } 5.3
$$

$\Delta I^{\prime \prime}{ }_{k} \quad$ Variação absoluta da corrente de curto-circuito trifásico

$\delta I^{\prime \prime}{ }_{k} \quad$ Variação relativa da corrente de curto-circuito trifásico

$\dot{I}^{\prime \prime}{ }_{k} \quad$ Corrente subtransitória de curto-circuito trifásico com o gerador

$\dot{I}^{\prime \prime}{ }_{k}^{*} \quad$ Corrente subtransitória de curto-circuito trifásico sem o gerador 
$\delta I_{k 1}^{\prime \prime}=\frac{\left|\dot{I}_{k 1}^{\prime \prime}\right|-\left|\dot{I}_{k 1}^{\prime \prime *}\right|}{\left|\dot{I}_{k 1}^{\prime \prime *}\right|}$

\section{Equação 5.6}

$\Delta I^{\prime \prime}{ }_{k 1} \quad$ Variação absoluta da corrente de curto-circuito monofásico

$\delta I^{\prime \prime}{ }_{k 1} \quad$ Variação relativa da corrente de curto-circuito monofásico

$\dot{I}^{\prime \prime}{ }_{k 1} \quad$ Corrente subtransitória de curto-circuito monofásico com o gerador

$\dot{I}^{\prime \prime}{ }_{k 1}^{*} \quad$ Corrente subtransitória de curto-circuito monofásico sem o gerador

Como as fases das correntes de curto-circuito trifásico antes e depois da conexão do gerador são próximas, toma-se a hipótese de que: $\left|\dot{I}_{k}^{\prime \prime}\right|-\left|\dot{I}_{k}^{\prime \prime}\right| \approx\left|\dot{I}_{k}^{\prime \prime}-\dot{I}_{k}^{\prime \prime}\right|$. Dessa forma, a partir da Equação 4.4, da Equação 4.10 e da Equação 5.1 podem ser estabelecidas as equações abaixo para a variação absoluta e relativa da corrente de curto-circuito trifásico.

$$
\begin{aligned}
& \Delta I_{k}^{\prime \prime} \approx\left|\dot{I}_{k}^{\prime \prime}-\dot{I}_{k}^{\prime \prime}\right|=\left|\frac{\dot{E}}{(d-x) \dot{Z}^{\prime}+\dot{Z}_{c}+\dot{Z}_{d g}}\right| \quad x \leq d \\
& \Delta I_{k}^{\prime \prime} \approx\left|\dot{I}_{k}^{\prime \prime}-\dot{I}_{k}^{\prime \prime *}\right|=\left|\frac{\dot{E}}{(x-d) \dot{Z}^{\prime}+\frac{\left(\dot{Z}_{s}+d \dot{Z}^{\prime}\right)\left(\dot{Z}_{c}+\dot{Z}_{d g}\right)}{\dot{Z}_{s}+d \dot{Z}^{\prime}+\dot{Z}_{c}+\dot{Z}_{d g}}}-\frac{\dot{E}}{\dot{Z}_{s}+x \dot{Z}^{\prime}}\right| \quad x \geq d \\
& \delta I_{k}^{\prime \prime} \approx\left|\frac{\dot{I}_{k}^{\prime \prime}-\dot{I}_{k}^{\prime *}}{\dot{I}_{k}^{\prime \prime}}\right|=\left|\frac{\dot{Z}_{s}+x \dot{Z}^{\prime}}{(d-x) \dot{Z}^{\prime}+\dot{Z}_{c}+\dot{Z}_{d g}}\right| \quad x \leq d \\
& \delta I_{k}^{\prime \prime} \approx\left|\frac{\dot{I}_{k}^{\prime \prime}-\dot{I}_{k}^{\prime \prime^{*}}}{\dot{I}_{k}^{\prime^{*}}}\right|=\left|\frac{\left(\dot{Z}_{s}+d \dot{Z}^{\prime}\right)^{2}}{(x-d) \dot{Z}^{\prime}\left(\dot{Z}_{s}+d \dot{Z}^{\prime}+\dot{Z}_{c}+\dot{Z}_{d g}\right)+\left(\dot{Z}_{s}+d \dot{Z}^{\prime}\right)\left(\dot{Z}_{c}+\dot{Z}_{d g}\right)}\right| \quad x \geq d
\end{aligned}
$$

A análise das quatro equações acima em relação à variável $x$ revela que, tanto do ponto de vista absoluto quanto do relativo, a corrente de curto-circuito trifásico aumenta conforme a 
falta se distancia da fonte (subestação da concessionária) até que se atinge um valor máximo no ponto de conexão do gerador, em seguida diminui conforme a falta se afasta do gerador. De outra forma, pode-se dizer que os impactos do gerador são mais significativos quanto mais próximas forem as faltas de seu ponto de conexão.

Esse fenômeno pode ser confirmado na Figura 5.2, que mostra a influência de um gerador distribuído no aumento marginal do nível de curto-circuito da rede, tanto para faltas trifásicas (Figura 5.2 a) quanto faltas monofásicas com o lado de média tensão do transformador ligado em Y (Figura 5.2 b) ou em $\Delta$ (Figura 5.2 c). Nota-se que para qualquer tipo de falta há um aumento marginal do nível de curto-circuito ao longo de todo o alimentador em que o gerador está conectado.

Ao se analisar a Figura 5.2 (a) é possível observar que a variação absoluta da corrente de curto-circuito trifásico atinge seu valor máximo no ponto de conexão do gerador e o valor deste máximo é independente do ponto em que ele está conectado. De fato, este máximo é a própria contribuição do gerador (Figura 5.3). Ademais, o incremento na corrente de curtocircuito trifásico será sempre a contribuição do gerador caso a falta seja à sua montante, e isso pode ser facilmente comprovado ao se estudar o diagrama da Figura 4.2.

Fato similar ocorre para as faltas monofásicas quando o transformador de acoplamento está ligado em Y solidamente aterrado no lado da rede, conforme mostra a Figura 5.2 (b). Entretanto, a sua demonstração matemática é muito mais complexa. Porém, quando o transformador de acoplamento está ligado em $\Delta$ no lado da rede, a variação absoluta da corrente de falta ao longo do alimentador assume um comportamento diferente justamente pela ausência de um caminho para a corrente de sequência zero. Portanto, a tendência é que a variação absoluta da corrente de falta se torne menor com o aumento da distância da falta em relação à subestação, conforme mostra a Figura 5.2 (c). Nota-se, também, que a magnitude da variação é significativamente menor. A princípio, espera-se que os impactos da conexão de geração com transformadores de acoplamento ligados em $\Delta$ no lado da rede sejam menores.

Os comportamentos das variações das correntes de falta mostradas na Figura 5.2 são análogos aos respectivos comportamentos das contribuições do gerador da Figura 5.3, como esperado, mas as magnitudes não são sempre idênticas. Isso ocorre porque a presença do gerador altera a contribuição da fonte, conforme será visto no item 5.2. 

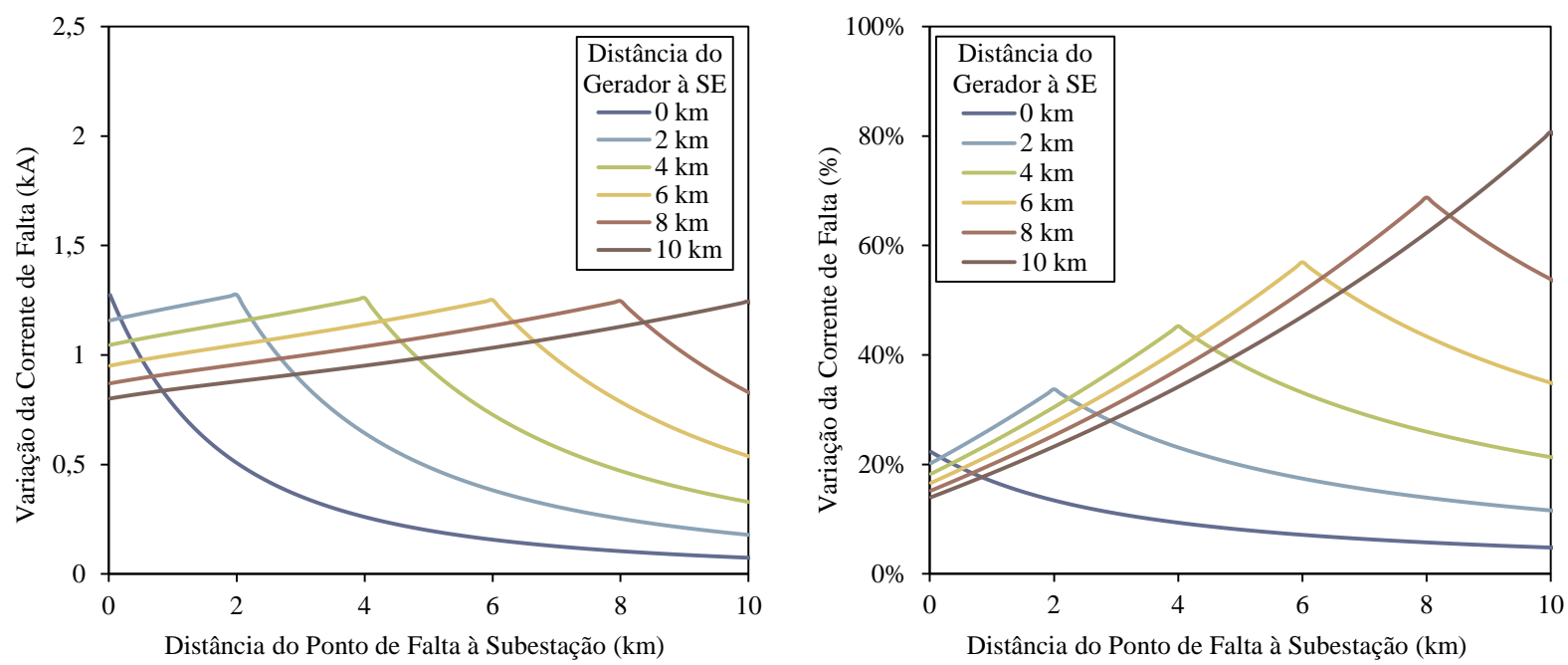

(a) falta trifásica
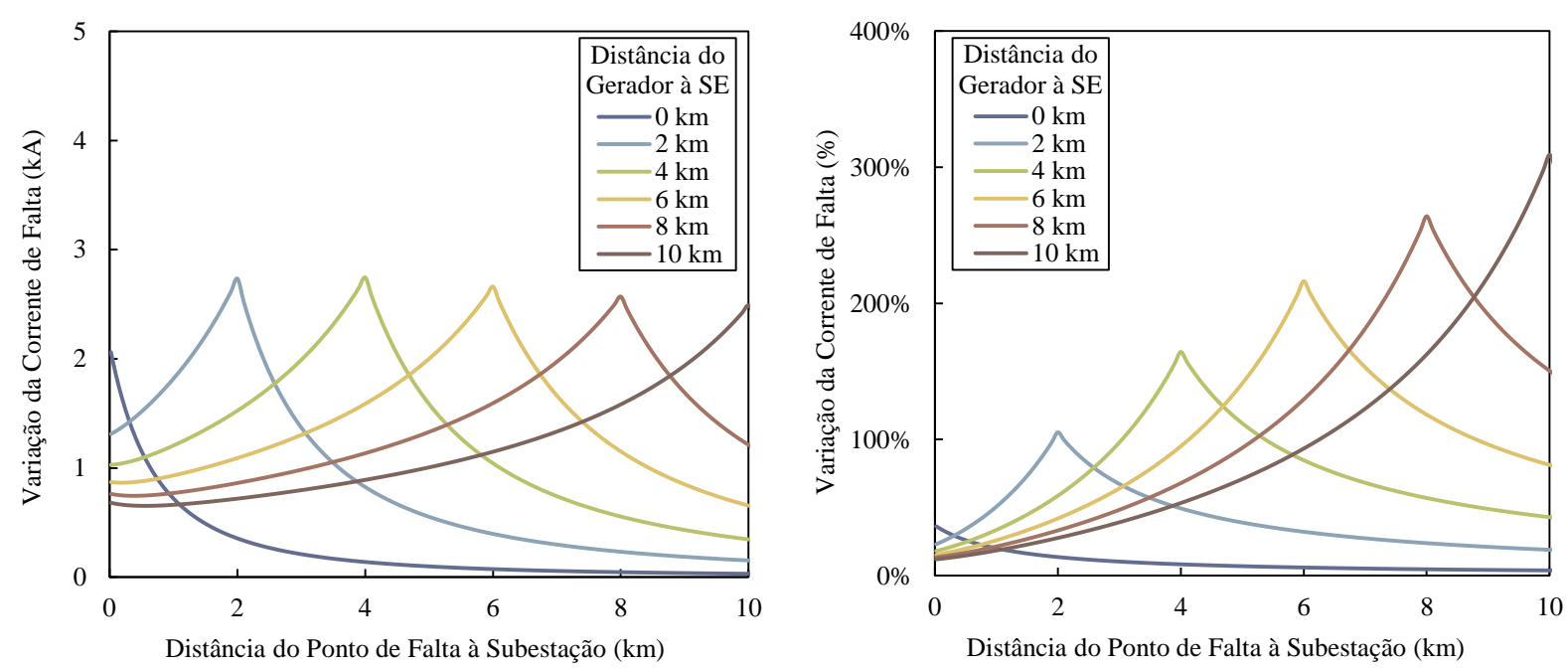

(b) falta fase-terra (ligação Y)
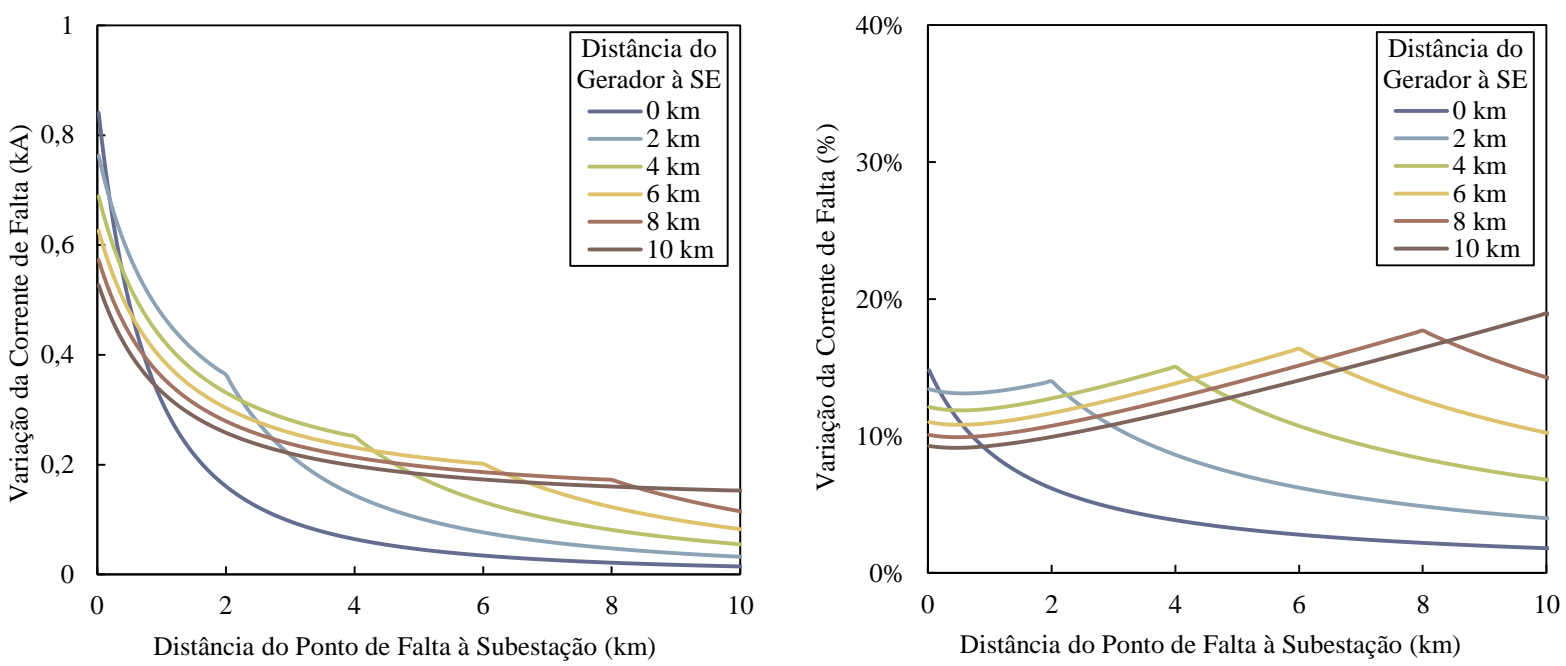

(c) falta fase-terra (ligação $\Delta$ )

Figura 5.2 - Variação absoluta (à esquerda) e relativa (à direita) da corrente de falta em função da distância do ponto de falta e de conexão do gerador à subestação. 


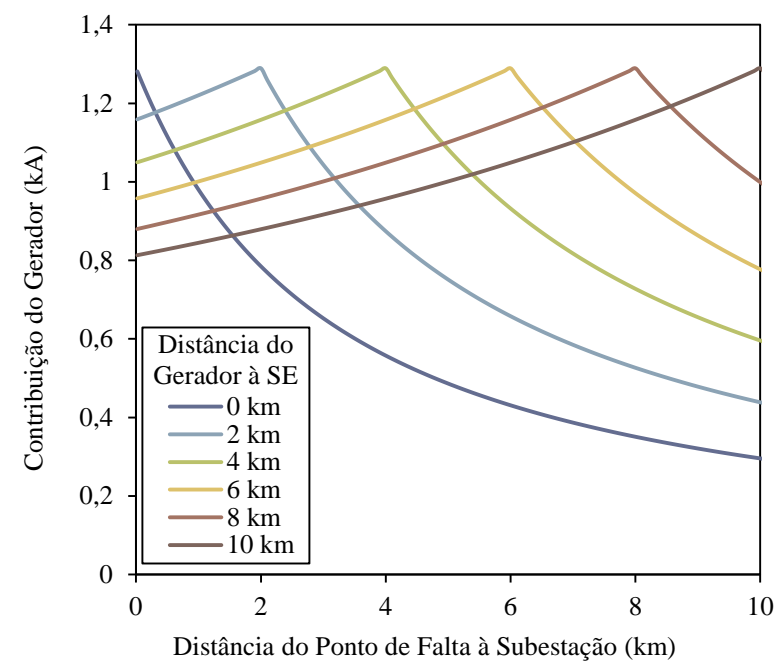

(a) falta trifásica

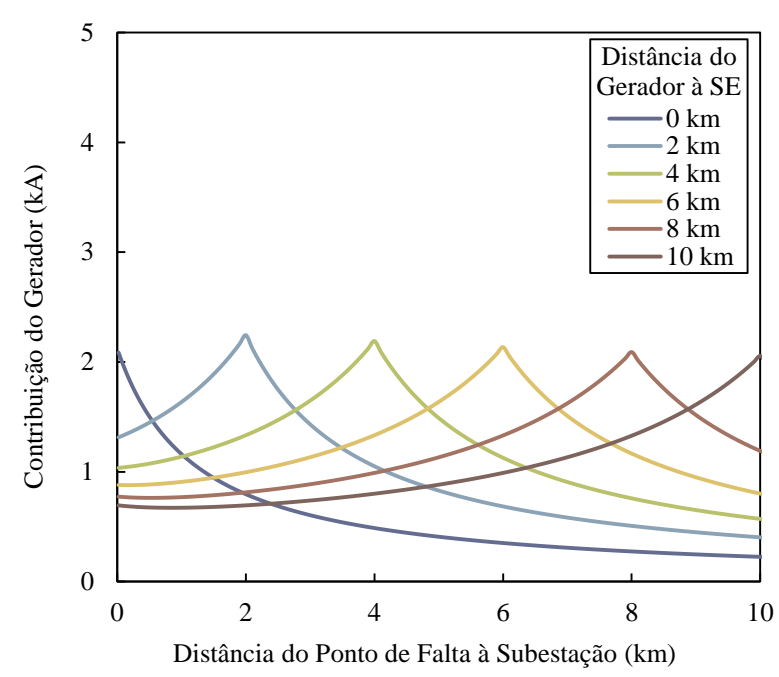

(b) falta fase-terra (ligação Y)

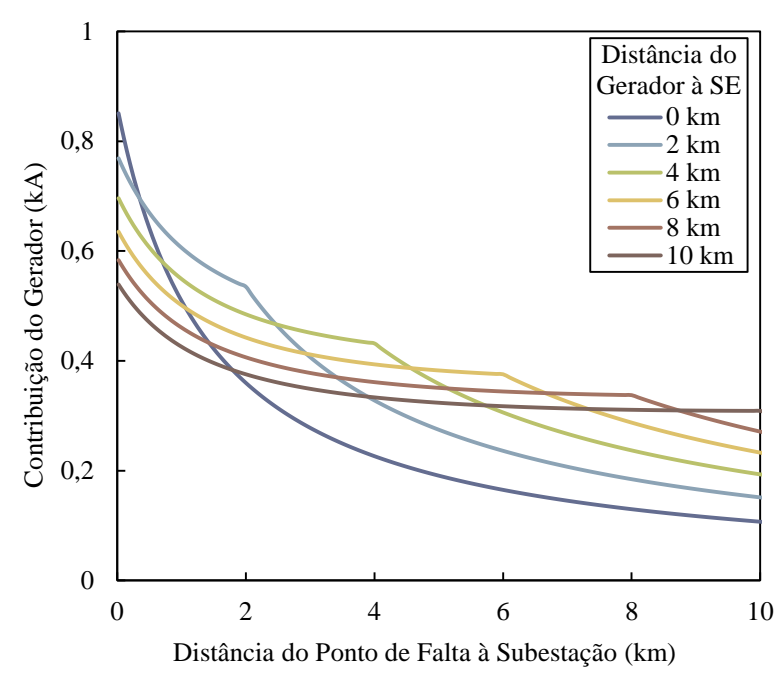

(c) falta fase-terra (ligação $\Delta$ )

Figura 5.3 - Contribuição do gerador para a falta em função da distância do ponto de falta e de conexão do gerador à subestação. 


\subsection{Alteração da Contribuição da Fonte}

A alteração da contribuição da fonte para a corrente de curto-circuito é outro efeito importante decorrente da conexão de um gerador na rede de distribuição, pois o aumento ou a redução dessa contribuição pode afetar a coordenação da proteção.

Nos casos em que a contribuição da fonte é reduzida por conta da conexão de um gerador na rede, pode haver perda de seletividade entre um religador e um fusível nas redes que utilizam o esquema de coordenação fuse saving. Neste caso, a redução da contribuição da fonte é tal que permite ao fusível à jusante do religador romper antes do religador tentar um religamento, conforme mostra a Figura 5.4.

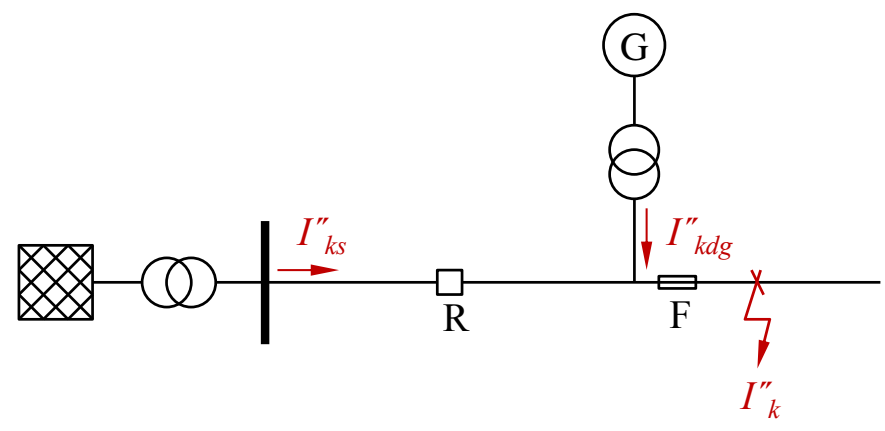

(a) sem $G D$

(b) $\operatorname{com} G D$
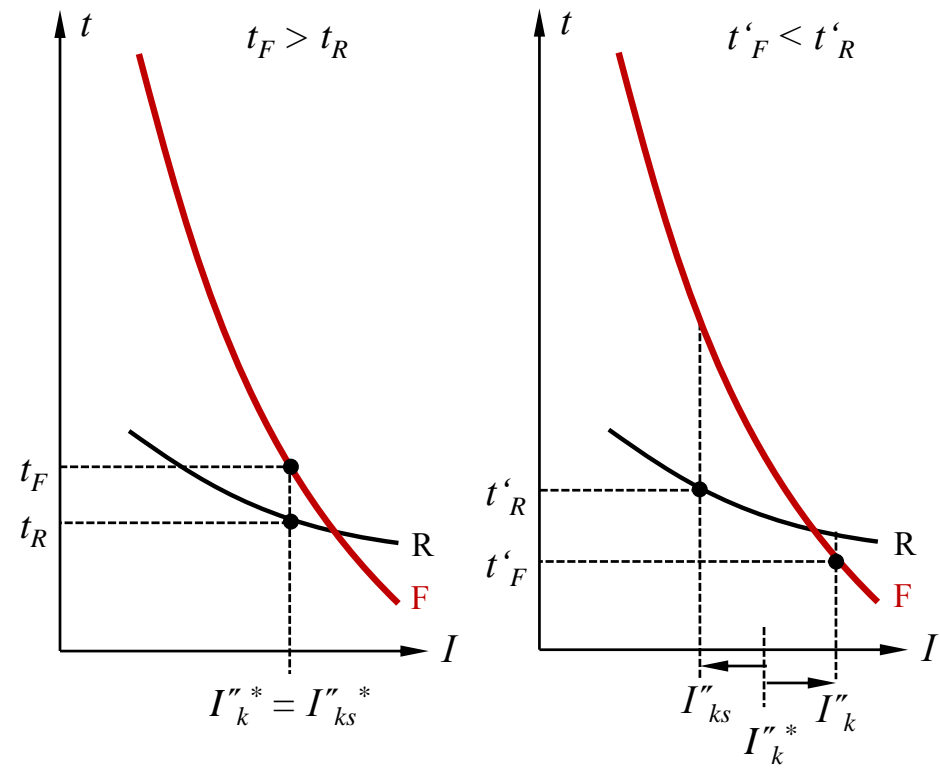

Figura 5.4 - Possibilidade de falha de coordenação entre religador $(R)$ e fusível $(F)$ devido à redução da contribuição da fonte e aumento da corrente de falta à jusante do gerador no esquema fuse saving. 
Caso contrário, quando a contribuição da fonte aumenta com a presença do gerador, também pode haver perda de seletividade entre fusíveis consecutivos, ou então pode ocorrer de que o disjuntor da subestação da concessionária atue indevidamente, pois a corrente de falta foi alta o suficiente a ponto da proteção atuar instantaneamente. Neste tópico a variação da contribuição da fonte é definida da seguinte maneira:

$$
\begin{aligned}
& \Delta I_{k s}^{\prime \prime}=\left|\dot{I}_{k s}^{\prime \prime}\right|-\left|\dot{I}_{k}^{\prime \prime *}\right| \\
& \delta I_{k s}^{\prime \prime}=\frac{\left|\dot{I}_{k s}^{\prime \prime}\right|-\left|\dot{I}_{k}^{\prime *}\right|}{\left|\dot{I}_{k}^{\prime \prime *}\right|}
\end{aligned}
$$$$
\text { Equação } 5.11
$$

$\Delta I^{\prime \prime}{ }_{k s} \quad$ Variação absoluta da contribuição da fonte para o curto-circuito trifásico

$\delta I^{\prime \prime}{ }_{k s} \quad$ Variação relativa da contribuição da fonte para o curto-circuito trifásico

$\dot{I}^{\prime \prime}{ }_{k s} \quad$ Contribuição da fonte para a corrente subtransitória de curto-circuito trifásico

$$
\begin{aligned}
& \Delta I_{k 1 s}^{\prime \prime}=\left|\dot{I}_{k 1 s}^{\prime \prime}\right|-\left|\dot{I}_{k 1}^{\prime \prime *}\right| \\
& \delta I_{k 1 s}^{\prime \prime}=\frac{\left|\dot{I}_{k 1 s}^{\prime \prime}\right|-\left|\dot{I}_{k 1}^{\prime \prime *}\right|}{\left|\dot{I}_{k 1}^{\prime \prime *}\right|}
\end{aligned}
$$

$\Delta I^{\prime \prime}{ }_{k l s}$ Variação absoluta da contribuição da fonte para o curto-circuito monofásico $\delta I^{\prime \prime}{ }_{k 1 s} \quad$ Variação relativa da contribuição da fonte para o curto-circuito monofásico $\dot{I}^{\prime \prime}{ }_{k l s} \quad$ Contribuição da fonte para a corrente subtransitória de curto-circuito monofásico

A partir dos diagramas da Figura 4.2 e da Figura 4.3 verifica-se que somente há redução da contribuição da fonte para as faltas trifásicas quando elas ocorrerem a jusante do gerador. Da Equação 4.10, Equação 4.11 e Equação 5.1 chegam-se às seguintes relações:

$$
\Delta I_{k s}^{\prime \prime} \approx\left|\dot{I}_{k s}^{\prime \prime}-\dot{I}_{k}^{\prime \prime}\right|=\left|\frac{\dot{E}}{(x-d) \dot{Z}^{\prime}+\frac{\left(\dot{Z}_{s}+d \dot{Z}^{\prime}\right)\left(\dot{Z}_{c}+\dot{Z}_{d g}\right)}{\dot{Z}_{s}+d \dot{Z}^{\prime}+\dot{Z}_{c}+\dot{Z}_{d g}}}-\frac{\dot{E}}{\dot{Z}_{s}+x \dot{Z}^{\prime}}\right| \quad x \geq d
$$


$\delta I_{k s}^{\prime \prime} \approx\left|\frac{\dot{I}_{k s}^{\prime \prime}-\dot{I}_{k}^{\prime *}}{\dot{I}_{k}^{\prime *}}\right|=\left|\frac{-(x-d) \dot{Z}^{\prime}\left(\dot{Z}_{s}+d \dot{Z}^{\prime}\right)}{(x-d) \dot{Z}^{\prime}\left(\dot{Z}_{s}+d \dot{Z}^{\prime}+\dot{Z}_{c}+\dot{Z}_{d g}\right)+\left(\dot{Z}_{s}+d \dot{Z}^{\prime}\right)\left(\dot{Z}_{c}+\dot{Z}_{d g}\right)}\right| \quad x \geq d \quad$ Equação 5.16

O comportamento da contribuição da fonte para um curto-circuito trifásico pode ser visto na Figura 5.5 (a). Em termos de variação absoluta, há um ponto à jusante do gerador que faz com que a redução da contribuição da fonte seja máxima. Contudo, em termos relativos, quão mais longe for a falta do gerador, maior será a redução relativa. É possível demonstrar que, no limite, quando a falta for infinitamente distante do gerador, a redução relativa tenderá a um dado valor, conforme a Equação 5.17:

$$
\lim _{x \rightarrow \infty} \delta I_{k s}^{\prime \prime} \approx\left|\frac{-\left(\dot{Z}_{s}+d \dot{Z}^{\prime}\right)}{\left.\mid \dot{Z}_{s}+d \dot{Z}^{\prime}+\dot{Z}_{c}+\dot{Z}_{d g}\right)}\right|
$$

A Figura 5.5 mostra que na presença de geração distribuída pode ocorrer tanto a redução quanto o aumento da contribuição da fonte para a corrente de curto-circuito a depender do tipo de falta e das ligações do transformador de acoplamento.

Para o caso de uma falta fase-terra, a contribuição da fonte é reduzida se o transformador de acoplamento não for aterrado no lado da rede, conforme a Figura 5.5 (c). Caso contrário, isto é, se o transformador for aterrado no lado da rede, há um aumento na contribuição da fonte para faltas à montante do gerador até que se atinge um máximo em seu ponto de conexão, conforme a Figura 5.5 (b). Faltas à jusante relativamente próximas do gerador ainda causam um aumento na contribuição da fonte, mas a partir de certa distância a fonte passa a ter uma contribuição menor que a original.

A alteração da contribuição da fonte associada ao aumento da corrente de falta à jusante do gerador pode ser crítica para a coordenação da proteção, sobretudo para geradores e faltas distantes da subestação da concessionária. A Figura 5.2 mostra, em seu lado esquerdo, o aumento relativo da corrente de curto-circuito em função da distância do ponto de falta e do gerador à subestação. Neste exemplo, os níveis de curto-circuito podem chegar a dobrar para 
geradores e faltas localizados ao final do alimentador de forma que a proteção existente poderá perder a coordenação.

Nota-se que as reduções da contribuição da fonte são maiores para as faltas monofásicas no caso em que o transformador de conexão está aterrado. Como a contribuição do gerador aumenta o nível de curto-circuito para faltas a sua jusante, como mostra a Figura 5.2, pode-se dizer que este é o caso mais crítico para a perda de coordenação religador-fusível, pois além da grande redução da contribuição da fonte os fusíveis também passam a atuar mais rapidamente. Por outro lado, a redução da contribuição da fonte pode ser útil em alguns casos excepcionais em que a margem de coordenação entre dois relés consecutivos do alimentador seja muito pequena.

Quando uma rede possui diversos geradores distribuídos os problemas da coordenação entre religadores e fusíveis se tornam muito complexos. É difícil encontrar uma solução que garanta que sempre haverá coordenação para qualquer falta que ocorrer na rede, entretanto é possível ajustar as curvas rápidas dos religadores de maneira a minimizar os casos de perda de coordenação. Este assunto foi tratado sob a forma de um exemplo de caso em (Naiem, et al., Dezembro 2010). 

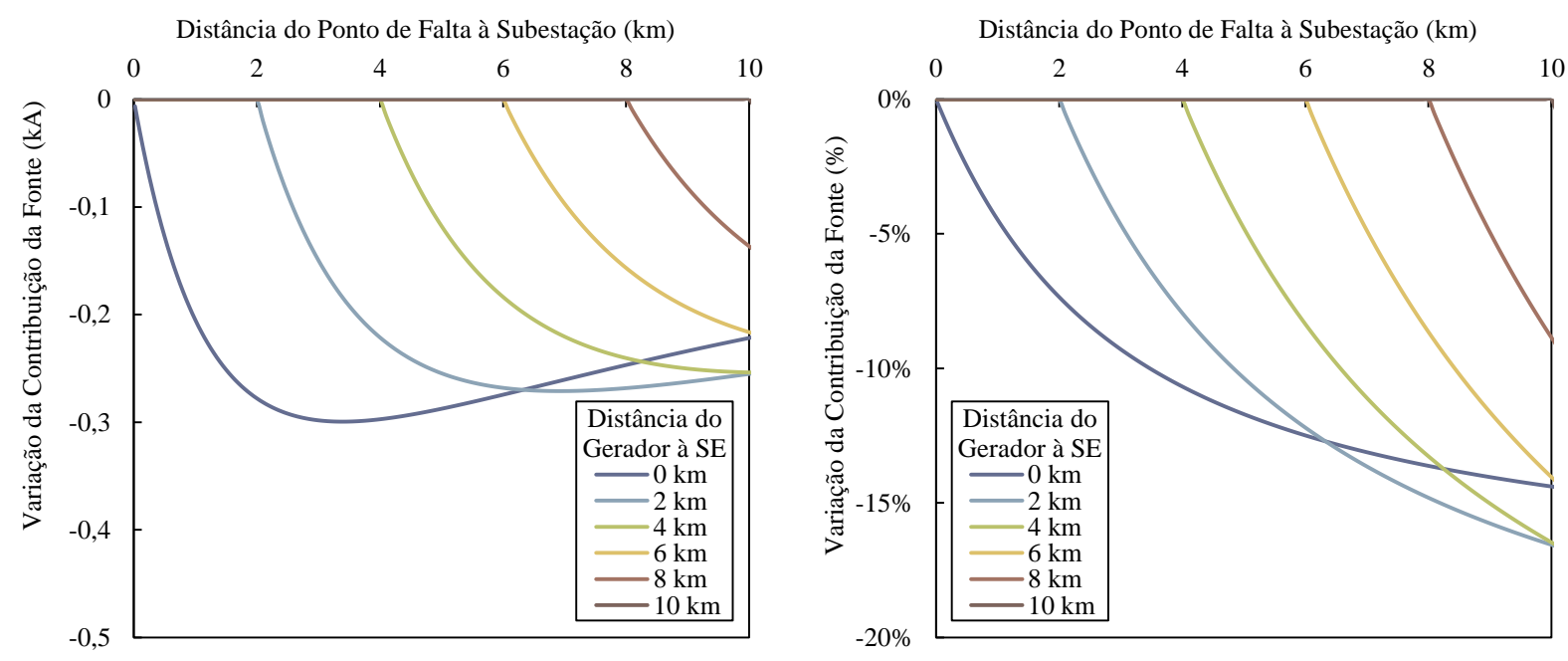

(a) falta trifásica
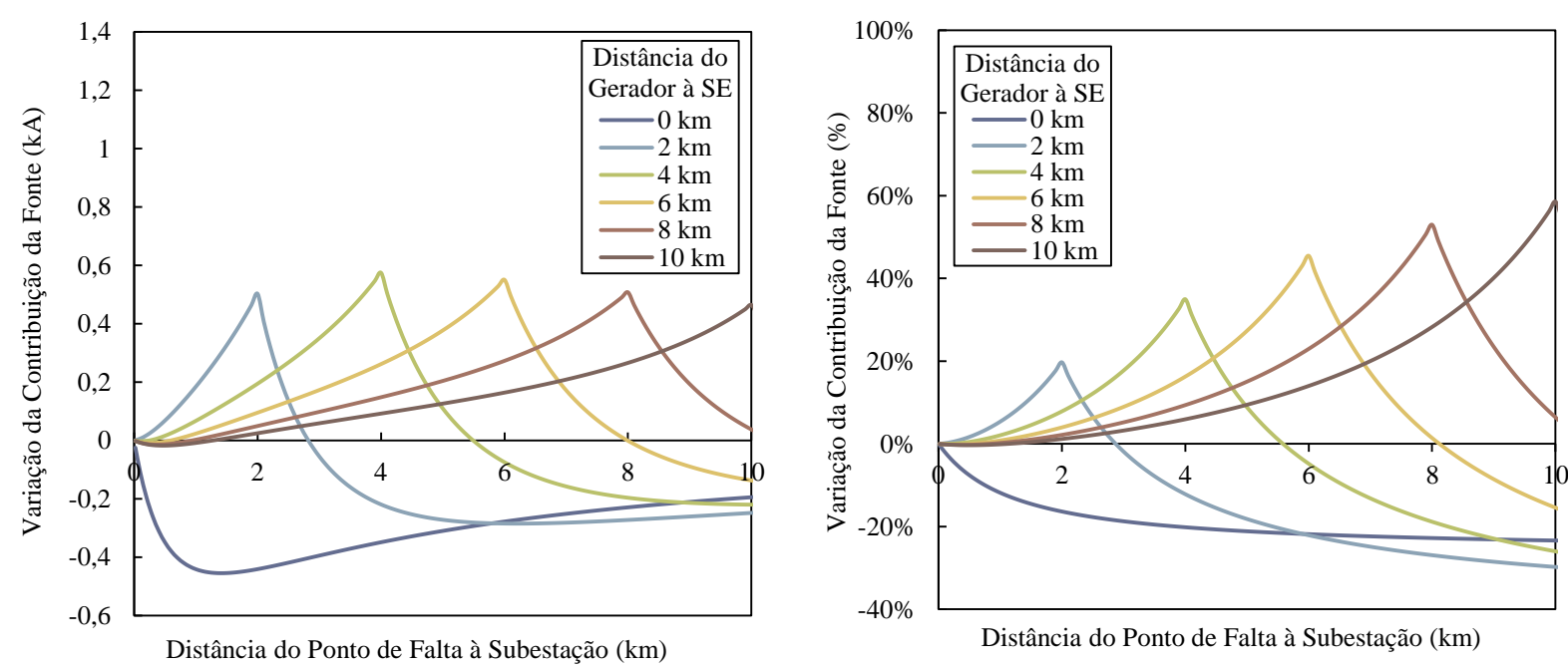

(b) falta fase-terra (ligação Y)
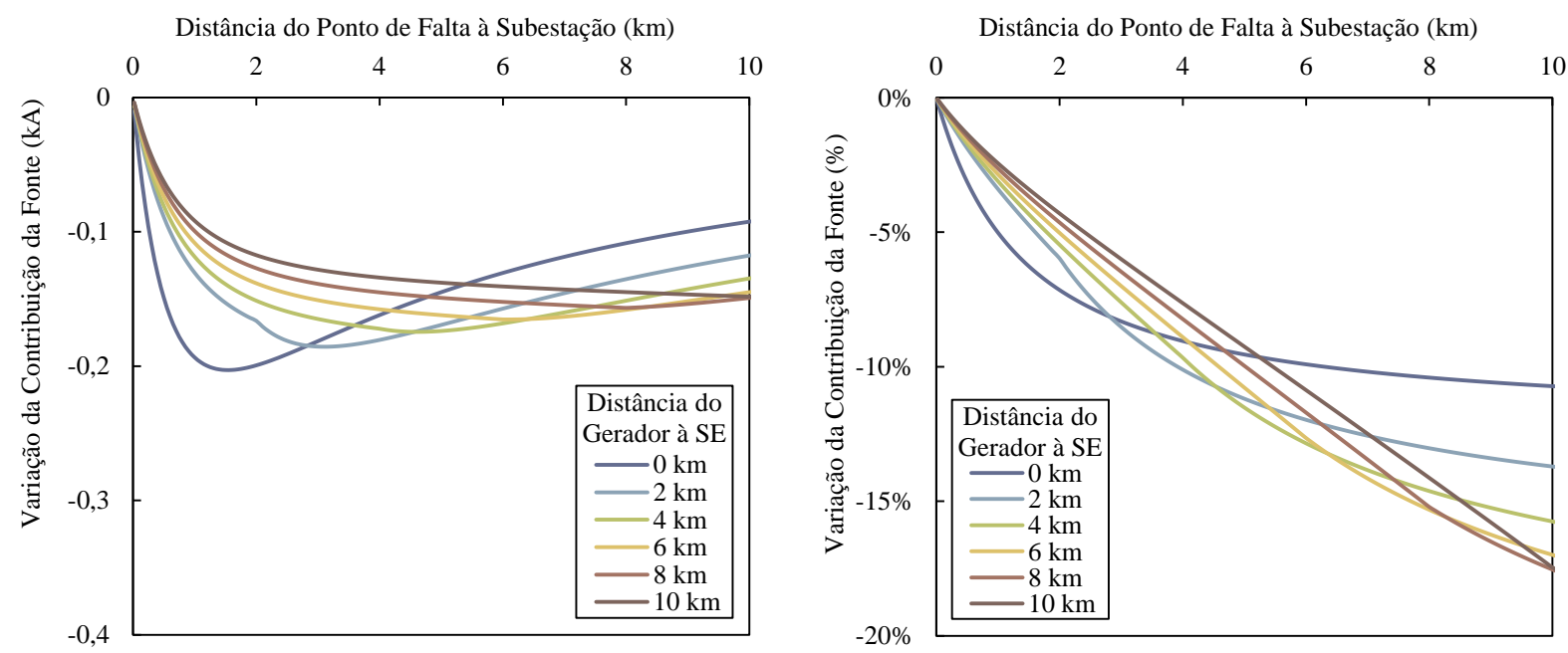

(c) falta fase-terra (ligação $\Delta$ )

Figura 5.5 - Variação absoluta (à esquerda) e relativa (à direita) da contribuição da fonte para o curtocircuito em função da distância do ponto de falta e de conexão do gerador à subestação. 


\subsection{Impacto nos Alimentadores Adjacentes}

Uma falta em um alimentador adjacente àquele em que o gerador está conectado também faz com que a fonte contribua menos para o curto-circuito. Entretanto, neste caso, a redução ajuda a coordenação da proteção, pois faz com que o disjuntor da fonte (do transformador da subestação) atue mais devagar do aquele que protege o alimentador sob falta.

O problema que pode ocorrer quando há uma falta em um alimentador adjacente àquele que contém o gerador é a perda de coordenação devido à elevação das correntes de curtocircuito. Isto quer dizer que as correntes podem aumentar a tal ponto que dispositivos de proteção em série no alimentador adjacente possam perder a seletividade, pois a rede não foi projetada para ser seletiva neste novo nível de curto-circuito. Este fenômeno pode ocorrer tanto entre religador e fusíveis, como entre fusíveis.

A perda de seletividade entre fusíveis consecutivos pode ocorrer pela redução da margem de coordenação entre eles, conforme mostra a Figura 5.6. Em decorrência de seu princípio de funcionamento, que é a fusão de um elemento metálico, o tempo necessário para a interrupção da corrente de falta pode variar numa faixa limitada pelo minimum melt e o total clearing. Em outras palavras, o minimum melt é o tempo mínimo necessário para a fusão e o total clearing o tempo máximo. Portanto, se a curva de total clearing do fusível a jusante estiver abaixo da curva de minimum melt do fusível a montante, há uma possibilidade de perda de seletividade.

Na prática, os manuais das concessionárias sugerem que o fusível à jusante atue em $75 \%$ do tempo que o fusível à montante atuaria para a máxima corrente de falta esperada no ponto em que o fusível de jusante se localiza. Portanto, uma pequena elevação nos níveis de falta pode fazer com que este critério seja invalidado. 

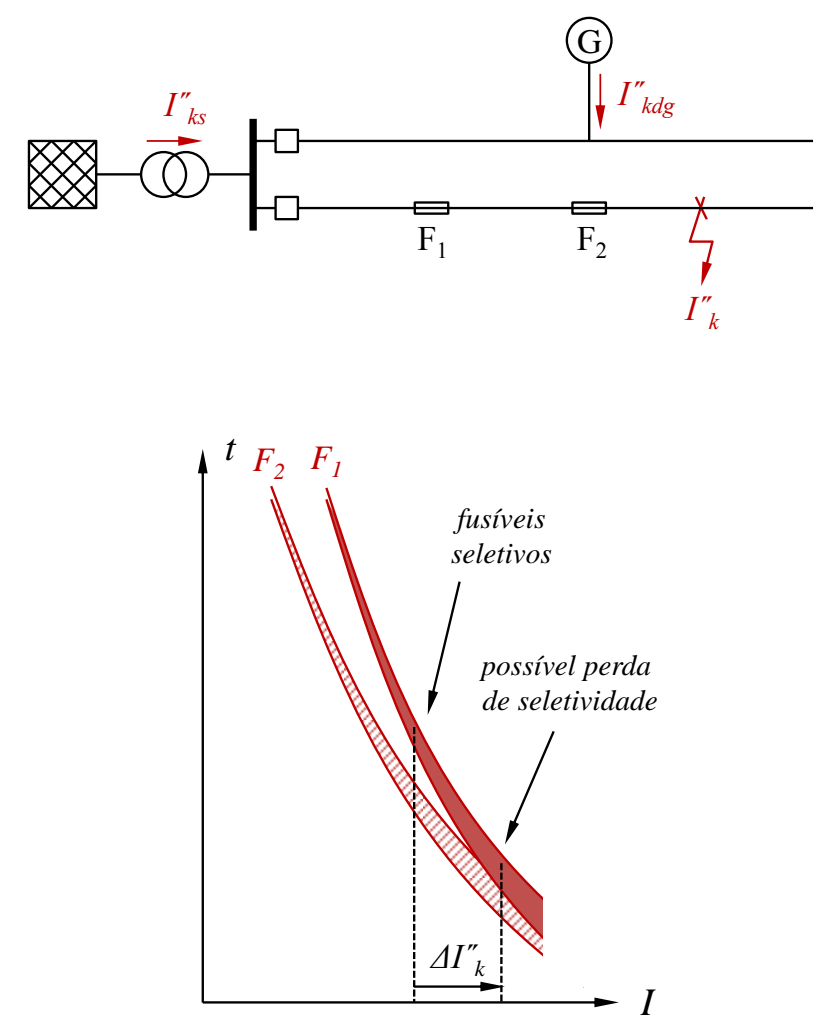

Figura 5.6 - Possibilidade de perda de seletividade entre fusíveis (F1 e F2) devido ao aumento da corrente de curto-circuito no alimentador adjacente.

Assim como foi feito nos itens anteriores, a Equação 5.18 e a Equação 5.19 descrevem as variações absoluta e relativa das correntes de curto-circuito trifásicas, respectivamente.

$$
\begin{gathered}
\Delta I_{k}^{\prime \prime}=\left|\dot{I}_{k}^{\prime \prime}-\dot{I}_{k}^{\prime \prime}\right|=\left|\frac{\dot{E}}{x \dot{Z}^{\prime}+\frac{\dot{Z}_{s}\left(d \dot{Z}^{\prime}+\dot{Z}_{c}+\dot{Z}_{d g}\right)}{\dot{Z}_{s}+d \dot{Z}^{\prime}+\dot{Z}_{c}+\dot{Z}_{d g}}}-\frac{\dot{E}}{\dot{Z}_{s}+x \dot{Z}^{\prime}}\right| \quad x \geq 0 \\
\delta I_{k}^{\prime \prime}=\left|\frac{\dot{I}_{k}^{\prime \prime}-\dot{I}_{k}^{\prime \prime \prime}}{\dot{I}_{k}^{\prime \prime}}\right|=\left|\frac{\left(\dot{Z}_{s}\right)^{2}}{x \dot{Z}^{\prime}\left(\dot{Z}_{s}+d \dot{Z}^{\prime}+\dot{Z}_{c}+\dot{Z}_{d g}\right)+\dot{Z}_{s}\left(d \dot{Z}^{\prime}+\dot{Z}_{c}+\dot{Z}_{d g}\right)}\right| \quad x \geq 0
\end{gathered}
$$


A análise dessas equações revela que as variações absolutas e relativas das correntes de curto-circuito trifásico diminuem conforme a falta no alimentador adjacente se distancia da fonte. Portanto, o impacto da conexão de um gerador em um alimentador adjacente àquele em que está conectado é máximo quando a falta se der no início do alimentador. Estas conclusões podem ser observadas na Figura 5.7.

Para a rede exemplo, a Figura 5.7 mostra que os níveis de curto-circuito podem se elevar até $35 \%$ a depender do tipo de falta, sua localização e a localização do gerador. Nota-se que o aumento do nível de curto-circuito diminui com o aumento da distância do ponto de falta e, em menor grau, com o aumento da distância do gerador.

Embora seja pouco provável, por conta da magnitude das correntes envolvidas, outro problema que pode surgir é a atuação precoce do disjuntor do alimentador são, antes mesmo do disjuntor do alimentador adjacente (sob falta) atuar. Isso pode ser resolvido através do emprego de relés direcionais (Seegers \& Birt, 2004), que possuem ajustes diferentes em função do sentido da corrente de curto-circuito. Uma falta em um alimentador adjacente produziria uma corrente reversa no alimentador do gerador e, portanto, bastaria ajustar uma curva mais lenta para seu disjuntor de maneira coordenar com o disjuntor do alimentador adjacente. Ainda assim, pode haver problemas caso existam fusíveis entre a fonte e o gerador, que poderiam romper devido à passagem da contribuição do gerador para o curto-circuito.

Este capítulo demonstrou três problemas oriundos da inserção da geração distribuída em uma rede convencional e dois pontos importantes serviram de premissa para as análises do próximo capítulo:

I. O impacto da GD sobre as correntes de curto-circuito da rede é máximo quando a falta se localiza no ponto de conexão do gerador.

II. O impacto da GD sobre as correntes de curto-circuito da rede em um alimentador adjacente àquele em que o gerador está conectado é máximo quando a falta se dá no início do alimentador. 

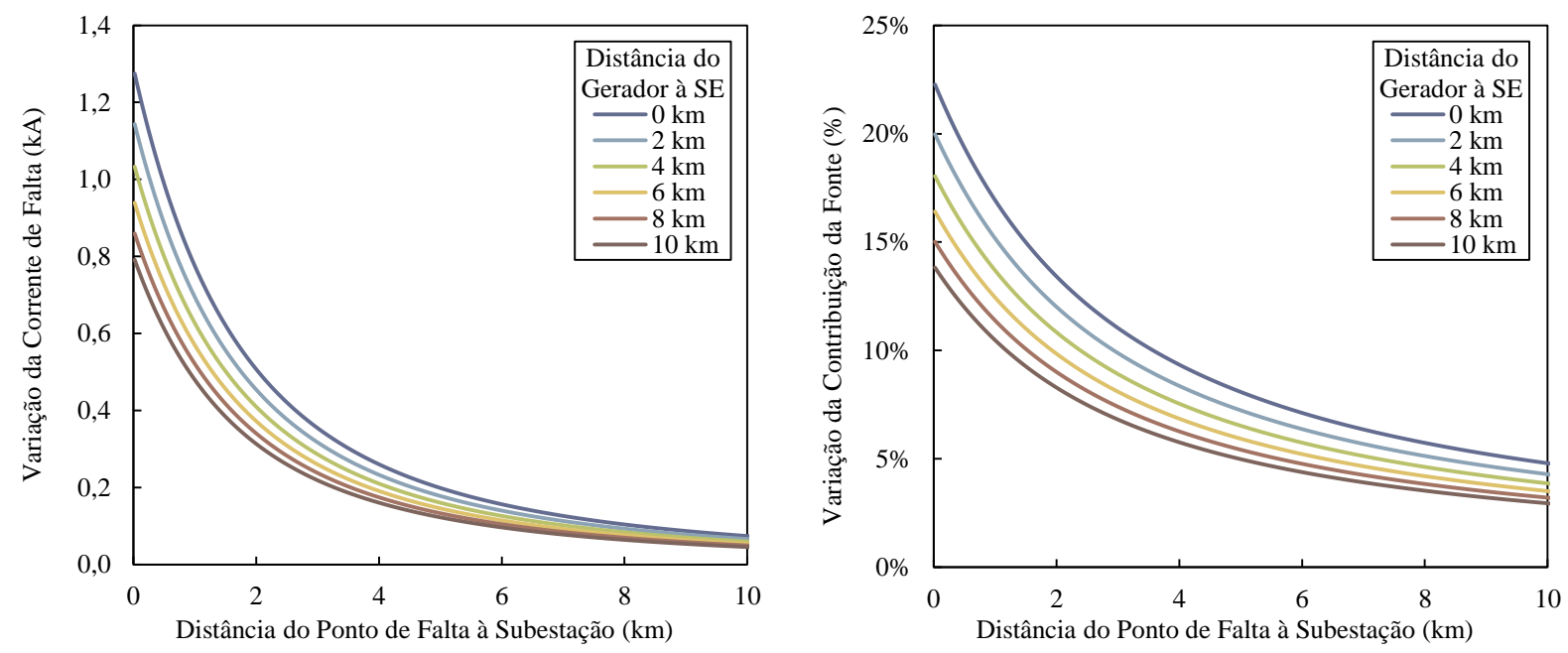

(a) 'falta trifásica
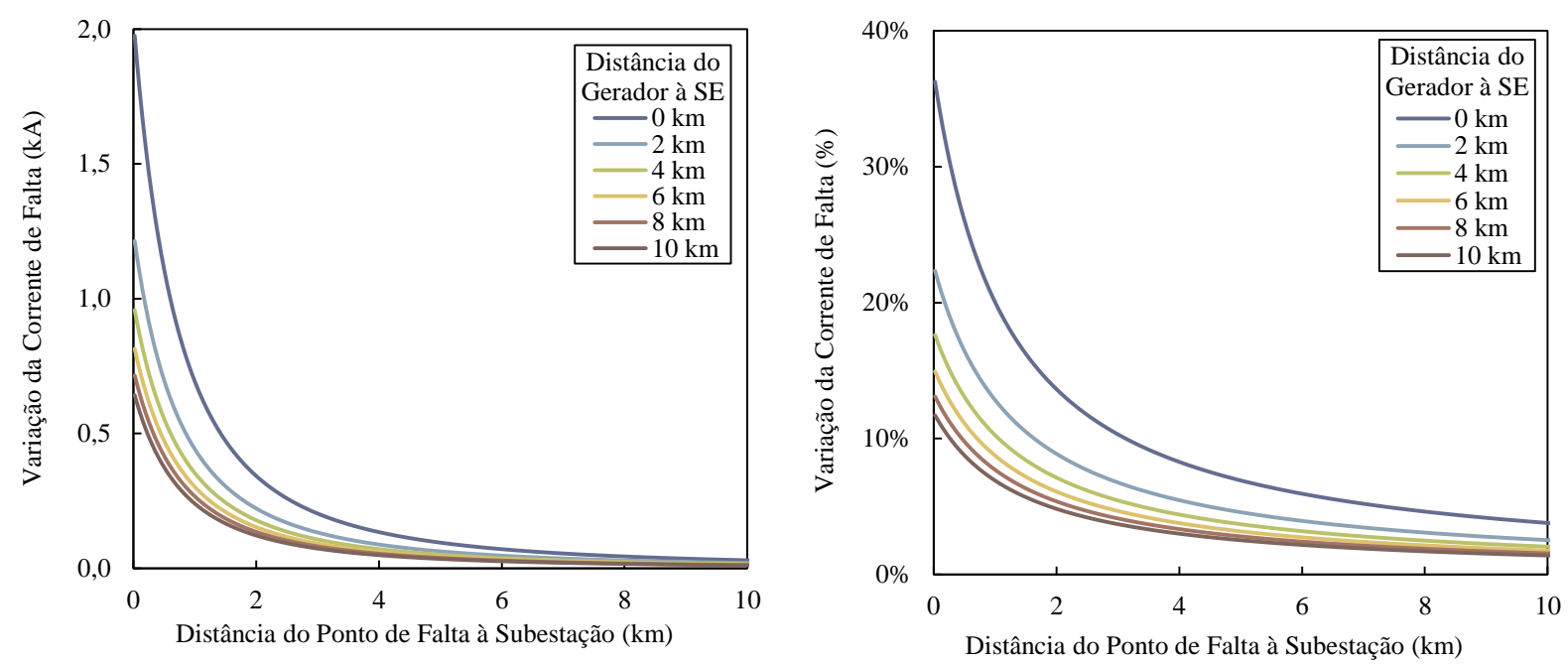

(b) falta fase-terra (ligação Y)
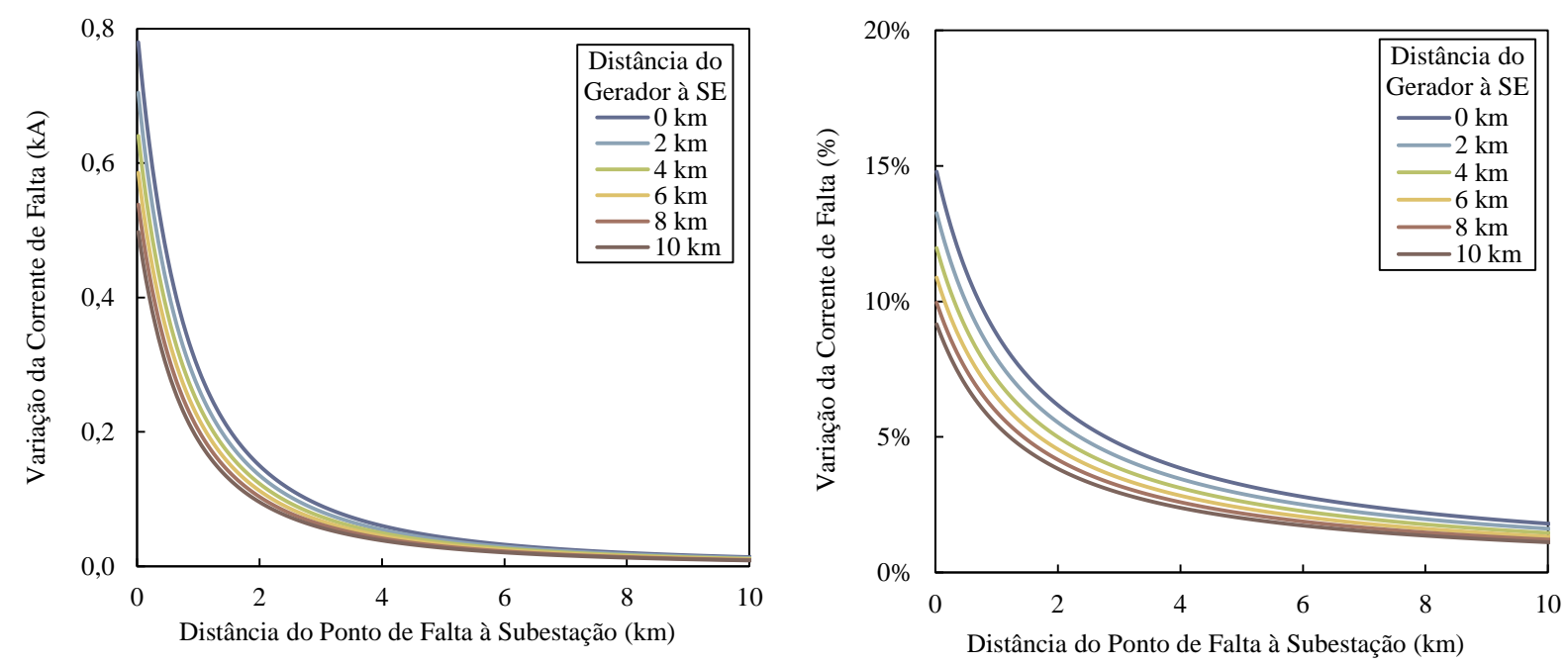

(c) falta fase-terra (ligação $\Delta$ )

Figura 5.7 - Variação da corrente de falta em um alimentador adjacente em função da distância do ponto de falta à subestação e da distância de conexão do gerador. 


\section{ANÁLISES PARAMÉTRICAS}

No capítulo anterior foram demonstrados três problemas oriundos da conexão da geração distribuída através de um caso exemplo. Neste capítulo o estudo é estendido para o caso geral através de análises paramétricas, onde se define três critérios de análise, sendo um para cada problema abordado. Posteriormente, analisando-se conjuntamente os três critérios encontra-se o mais restritivo entre os três. Por fim, realiza-se uma última análise paramétrica onde se determina a máxima potência admissível para um gerador entrante na rede de distribuição não ultrapasse um dado limite definido para o critério mais severo.

O primeiro critério (seção 6.1) representa a maior variação relativa que se pode esperar para as correntes de curto-circuito devido à inserção do gerador, refletindo o problema do aumento dos níveis de curto-circuito tratado na seção 5.1 .

O segundo critério (seção 6.2) representa a variação relativa entre o aumento do nível de curto-circuito local e a redução da contribuição da fonte para faltas a jusante do gerador. Esta variação é a responsável pelas ocorrências de perda de coordenação da proteção estudadas na seção 5.2.

O terceiro critério (seção 6.3) representa a maior variação relativa que se pode esperar para as correntes de curto-circuito em um alimentador adjacente àquele em que o gerador está conectado, problema que foi explicado na seção 5.3.

Como já demonstrado, as faltas devem ser investigadas em duas posições importantes da rede: no ponto de conexão do gerador $(x=d)$ e no início do alimentador adjacente $(x=0)$. Isto faz com que a distância do ponto de falta $x$ deixe de ser uma variável de interesse, pois ela passa a estar subentendida dentro da distância do ponto de conexão do gerador $d$.

O cálculo elétrico das correntes de curto-circuito se utiliza de números complexos para representar uma grandeza que varia senoidalmente no tempo, de forma que a variação entre correntes também resulta em números complexos. Portanto, a magnitude das correntes, que é um número real, foi usada para calcular os critérios deste capítulo. 


\subsection{Critério A - Aumento no Nível de Curto-Circuito Local}

Foi demonstrado, no capítulo anterior, que o impacto de um gerador sobre as correntes de curto-circuito é máximo quando a falta ocorre em seu ponto de conexão. Esta situação é ilustrada na Figura 6.1:

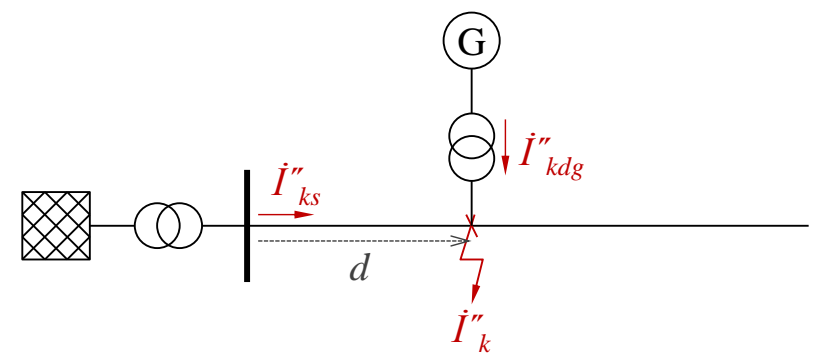

Figura 6.1 - Falta no ponto de conexão do gerador

Neste caso, o modelo elétrico para o curto-circuito trifásico é um caso particular do diagrama da Figura 4.2 e Figura 4.3 quando $x=d$, conforme ilustra a Figura 6.2:

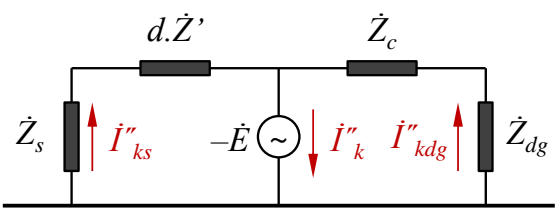

Figura 6.2 - Modelo elétrico para uma falta trifásica no ponto de conexão do gerador

Analogamente, a máxima variação relativa da corrente de curto-circuito trifásico ( $\left.\delta I_{k \max }^{\prime \prime}\right)$ é um caso especial da Equação 5.9 e da Equação 5.10 quando $x=d$, de forma que pode ser escrita de acordo com a Equação 6.1:

$\delta I_{k \max }^{\prime \prime} \approx\left|\frac{\dot{I}_{k}^{\prime \prime}-\dot{I}_{k}^{\prime *^{*}}}{\dot{I}_{k}^{\prime \prime^{*}}}\right|=\left|\frac{\dot{E} / \dot{Z}_{t h}}{\dot{E} /\left(\dot{Z}_{s}+d \dot{Z}^{\prime}\right)}-1\right|=\left|\frac{\dot{Z}_{s}+d \dot{Z}^{\prime}}{\dot{Z}_{c}+\dot{Z}_{d g}}\right|$ 
Esta equação releva que o impacto relativo do gerador para o curto-circuito trifásico cresce linearmente com a distância, descontado o efeito da fonte $\left(\dot{Z}_{S}\right)$. Essa característica já poderia ser inferida a partir da Figura 5.2. Como as impedâncias das redes subterrâneas são menores devido ao menor espaçamento entre as fases, o impacto na corrente de curto-circuito trifásico tende a ser menor neste tipo de rede.

Outro aspecto que a equação evidencia é que o impacto é menor quando a impedância da fonte é menor, isto é, quando a fonte é dita forte, com elevada potência de curto-circuito. De fato, a fonte infinita é um caso ideal que será estudado com mais detalhes adiante.

Além disso, como era esperado, quanto maior o gerador, maior é o impacto sobre a rede, pois sua impedância e a de seu transformador se tornam menores. É importante lembrar que a potência do transformador é casada com a do gerador e, dessa forma, suas impedâncias estão relacionadas.

Por sua vez, o caso monofásico é mostrado na Figura 6.3, que é um caso particular dos diagramas da Figura 4.2 e Figura 4.3 quando $x=d$. É possível notar que o aterramento do transformador de acoplamento determina a impedância $\dot{Z}_{g}$ e, portanto, impacta sobremaneira na magnitude da corrente de curto-circuito.

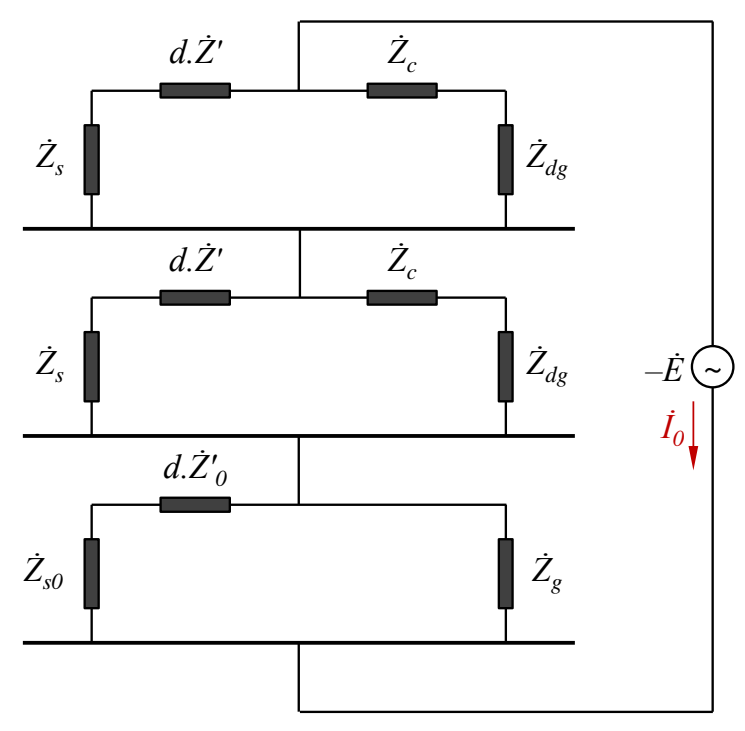

Figura 6.3 - Modelo elétrico para uma falta monofásica no ponto de conexão do gerador 
De forma análoga, a máxima variação da corrente de curto-circuito monofásica $\left(\delta I_{k 1 \max }^{\prime \prime}\right)$ pode ser calculada de acordo com a Equação 6.2:

$$
\delta I_{k 1 \text { max }}^{\prime \prime} \approx\left|\frac{\dot{I}_{k 1}^{\prime \prime}-\dot{I}_{k 1}^{\prime *}}{\dot{I}_{k 1}^{\prime \prime 1}}\right|=\left|\frac{3 \dot{E} /\left(2 \dot{Z}_{t h}+\dot{Z}_{t h 0}\right)}{3 \dot{E} /\left(2\left(\dot{Z}_{s}+d \dot{Z}^{\prime}\right)+\left(\dot{Z}_{s 0}+d \dot{Z}_{0}^{\prime}\right)\right)}-1\right|=\left|\frac{2\left(\dot{Z}_{s}+d \dot{Z}^{\prime}\right)+\left(\dot{Z}_{s 0}+d \dot{Z}_{0}^{\prime}\right)}{2 \frac{\left(\dot{Z}_{s}+d \dot{Z}^{\prime}\right)\left(\dot{Z}_{c}+\dot{Z}_{d g}\right)}{\left.\dot{Z}_{s}+d \dot{Z}^{\prime}+\dot{Z}_{c}+\dot{Z}_{d g}+d \dot{Z}_{0}^{\prime}\right)}+\dot{Z}_{g}}-1\right|
$$

Trata-se de uma equação significativamente mais complexa do que aquela desenvolvida para o caso trifásico, não só apenas pelo maior número de variáveis envolvidas, mas também porque as ordens de grandeza das impedâncias são semelhantes, o que impossibilita fazer outras hipóteses simplificadoras sem que se incorra em erros grosseiros. Contudo, é fácil notar que o impacto cresce com a distância de conexão do gerador, assim como acontece com o caso trifásico.

As duas equações demonstradas neste tópico compõem o critério do aumento do nível de curto-circuito, pois elas representam as máximas variações da corrente de curto-circuito trifásico e monofásico que seriam observadas no alimentador em que o gerador está ligado. Este é um critério importante porque garante que em nenhum outro ponto da rede haverá variações maiores do que as calculadas.

\subsection{Critério B - Perda de Coordenação para Faltas a Jusante do Gerador}

Outro problema abordado no capítulo anterior é a possibilidade de ocorrer perda de coordenação da proteção quando a falta ocorre à jusante do ponto de conexão do gerador, isto é, quando $x \geq d$. Dois aspectos são fundamentais neste processo: a redução da contribuição da fonte para a corrente de falta e o aumento do curto-circuito local devido à inserção do gerador. Portanto, um critério para a perda de coordenação deve refletir estes dois aspectos.

Para tanto, foi criado um critério que é a relação entre a contribuição relativa do gerador e a contribuição relativa da fonte. Esse critério pode ser visto sob diversos ângulos, conforme mostra a Equação 6.3. Por exemplo, pode ser entendido como a relação entre a contribuição 
absoluta do gerador e a contribuição absoluta da fonte ou então como a diferença relativa entre o aumento relativo do curto-circuito local e a variação relativa da contribuição da fonte.

$\frac{\dot{I}_{k d g}^{\prime \prime}}{\dot{I}_{k s}^{\prime \prime}}=\frac{\dot{I}_{k}^{\prime \prime}-\dot{I}_{k s}^{\prime \prime}}{\dot{I}_{k s}^{\prime \prime}}=\frac{\left(\dot{I}_{k}^{\prime \prime}-\dot{I}_{k s}^{\prime \prime}\right) / \dot{I}_{k}^{\prime^{*}}}{\dot{I}_{k s}^{\prime \prime} / \dot{I}_{k}^{\prime *}}=\frac{\delta I_{k}^{\prime \prime}-\delta I_{k s}^{\prime \prime}}{1+\delta I_{k s}^{\prime \prime}}=\frac{1+\delta I_{k}^{\prime \prime}}{1+\delta I_{k s}^{\prime \prime}}-1$

Equação 6.3

Para tornar o entendimento deste critério um pouco mais fácil, toma-se o exemplo da Figura 6.4. Antes da conexão de um gerador, a corrente de falta no ponto $x$ é de 5 kA. Após a conexão, a corrente de falta no mesmo ponto passa a $6 \mathrm{kA}$, sendo $2 \mathrm{kA}$ oriundos do gerador e mais $4 \mathrm{kA}$ da fonte, que teve sua contribuição reduzida em $1 \mathrm{kA}$.

Neste exemplo, o critério de perda de coordenação vale $I_{k d g}^{\prime \prime} / I_{k s}^{\prime \prime}=50 \%$. De outra forma, pode-se dizer que a contribuição do gerador vale $50 \%$ da contribuição da fonte, ou então que a diferença relativa entre o aumento do nível de falta local $\left(\delta I_{k}^{\prime \prime}=+20 \%\right)$ e a redução da contribuição da fonte para a falta $\left(\delta I_{k s}^{\prime \prime}=-20 \%\right)$ resulta em $50 \%$.

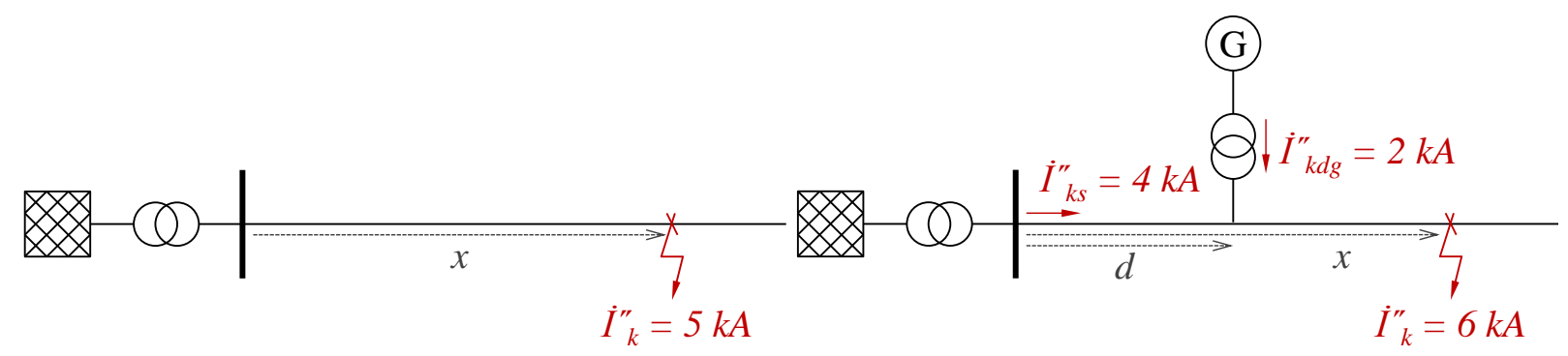

(a) Antes da conexão do gerador

(b) Depois da conexão do gerador

$$
\begin{aligned}
& \frac{\dot{I}_{k d g}^{\prime \prime}}{\dot{I}_{k s}^{\prime \prime}}=\frac{\dot{I}_{k}^{\prime \prime}-\dot{I}_{k s}^{\prime \prime}}{\dot{I}_{k s}^{\prime \prime}}=\frac{6 k A-4 k A}{4 k A}=\frac{2 k A}{4 k A}=50 \% \\
& \frac{\delta I_{k}^{\prime \prime}-\delta I_{k s}^{\prime \prime}}{1+\delta I_{k s}^{\prime \prime}}=\frac{1+\delta I_{k d g}^{\prime \prime}}{1+\delta I_{k s}^{\prime \prime}}-1=\frac{1+20 \%}{1-20 \%}-1=50 \%
\end{aligned}
$$

Figura 6.4 - Exemplo de cálculo do critério de perda de coordenação 
A grande vantagem deste critério é que ele independe da localização da falta $(x)$, pois um dos objetivos deste capítulo é eliminar esta variável das análises. Este fato pode ser observado na Figura 6.5, tanto para a falta trifásica quanto para a falta monofásica, para dois tipos de ligação do transformador de acoplamento. Pode-se notar que a relação entre a contribuição do gerador e a contribuição da fonte torna-se constante quando a falta é a jusante do ponto de conexão do gerador, isto é, quando $x \geq d$.

De outra forma, este fato pode ser comprovado através da Equação 6.4 e da Equação 6.5, derivadas dos modelos elétricos da Figura 4.3. Nota-se que em nenhuma das equações aparece a variável $x$, apenas a variável $d$, pois as contribuições relativas do gerador e da fonte para a corrente de falta dependem apenas do divisor de correntes formado à montante do gerador.

$$
\begin{aligned}
& \left|\frac{\dot{I}_{k}^{\prime \prime}-\dot{I}_{k s}^{\prime \prime}}{\dot{I}_{k s}^{\prime \prime}}\right|=\left|\frac{\dot{I}_{k d g}^{\prime \prime}}{\dot{I}_{k s}^{\prime \prime}}\right|=\left|\frac{\dot{Z}_{s}+d \dot{Z}^{\prime}}{\dot{Z}_{c}+\dot{Z}_{d g}}\right| \\
& \left|\frac{\dot{I}_{k 1}^{\prime \prime}-\dot{I}_{k 1 s}^{\prime \prime}}{\dot{I}_{k 1 s}^{\prime \prime}}\right|=\left|\frac{\dot{I}_{k 1 d g}^{\prime \prime}}{\dot{I}_{k 1 s}^{\prime \prime}}\right|=\left|\frac{\left(\dot{Z}_{s}+d \dot{Z}^{\prime}\right)\left(\dot{Z}_{s 0}+d \dot{Z}_{0}^{\prime}+\dot{Z}_{g}\right)+\left(\dot{Z}_{s 0}+d \dot{Z}_{0}^{\prime}\right)\left(\dot{Z}_{s}+d \dot{Z}^{\prime}+\dot{Z}_{c}+\dot{Z}_{d g}\right)}{\left(\dot{Z}_{c}+\dot{Z}_{d g}\right)\left(\dot{Z}_{s 0}+d \dot{Z}_{0}^{\prime}+\dot{Z}_{g}\right)+\dot{Z}_{g}\left(\dot{Z}_{s}+d \dot{Z}^{\prime}+\dot{Z}_{c}+\dot{Z}_{d g}\right)}\right|
\end{aligned}
$$

Um ponto interessante é que, para o caso trifásico, o critério para a perda de coordenação (critério B) é idêntico ao critério do aumento do nível de curto-circuito local (critério A). Portanto, a mesma equação consegue tratar de dois aspectos distintos da inserção de um gerador síncrono distribuído às redes de distribuição.

Por outro lado, a equação para o caso monofásico é significativamente mais complexa e incorre na mesma dificuldade do critério anterior. O que se pode afirmar é que o critério de perda de coordenação aumenta com a distância. 


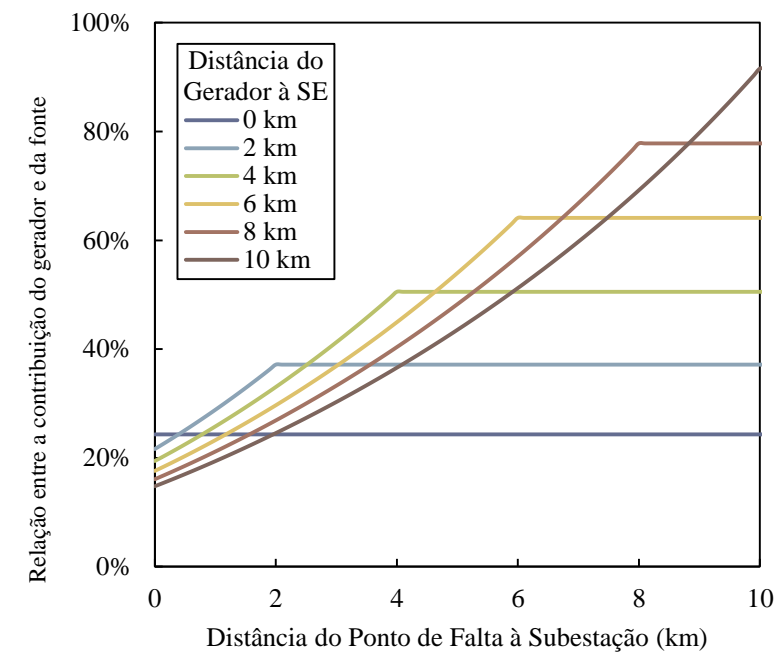

(a) falta trifásica

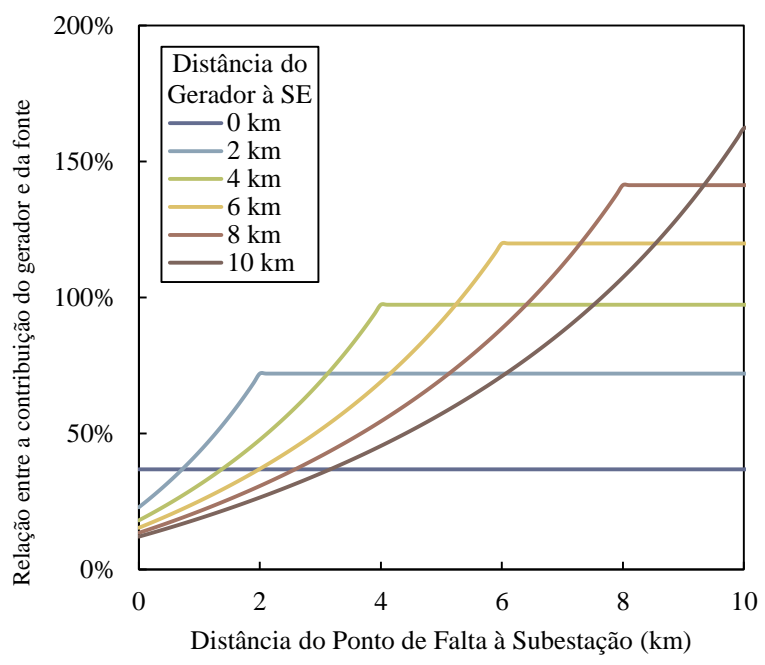

(b) falta fase-terra (ligação Y)

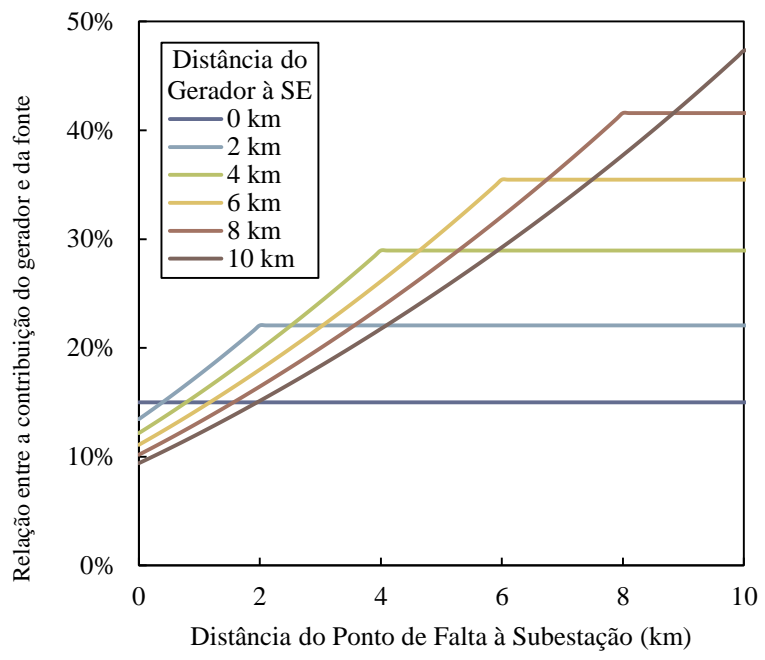

(c) falta fase-terra (ligação $\Delta$ )

Figura 6.5 - Relação entre a contribuição do gerador e da fonte 


\subsection{Critério C - Impacto Máximo no Alimentador Adjacente}

O último problema apresentado no capítulo anterior é o impacto causado por um gerador em um alimentador adjacente àquele em que está conectado. Neste caso, o impacto é máximo quando a falta ocorre no início do alimentador, conforme mostra a Figura 6.6:

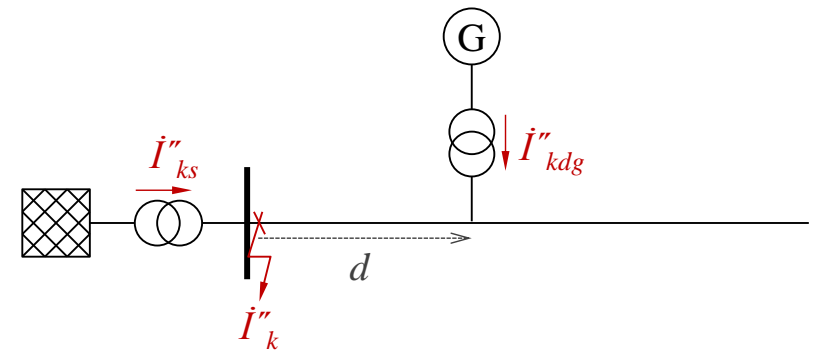

Figura 6.6 - Falta na origem do alimentador (saída da subestação)

O modelo elétrico neste caso é um caso particular da Figura 4.4 quando $x=0$, conforme mostra a Figura 6.7 e a Figura 6.8. A análise do circuito revela que, na ocasião de um curtocircuito trifásico, a contribuição da fonte mantém-se igual ao que seria caso não houvesse um gerador conectado. Portanto, a variação da corrente de curto-circuito trifásico local deve-se apenas à contribuição do gerador.

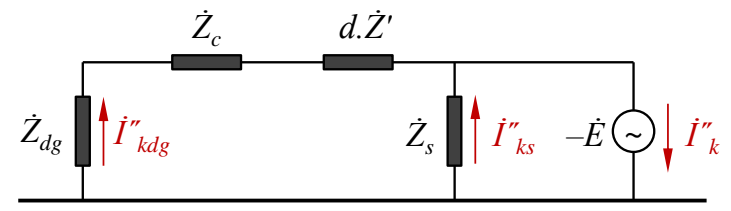

Figura 6.7 - Modelo elétrico para uma falta trifásica na origem do alimentador (saída da subestação) 


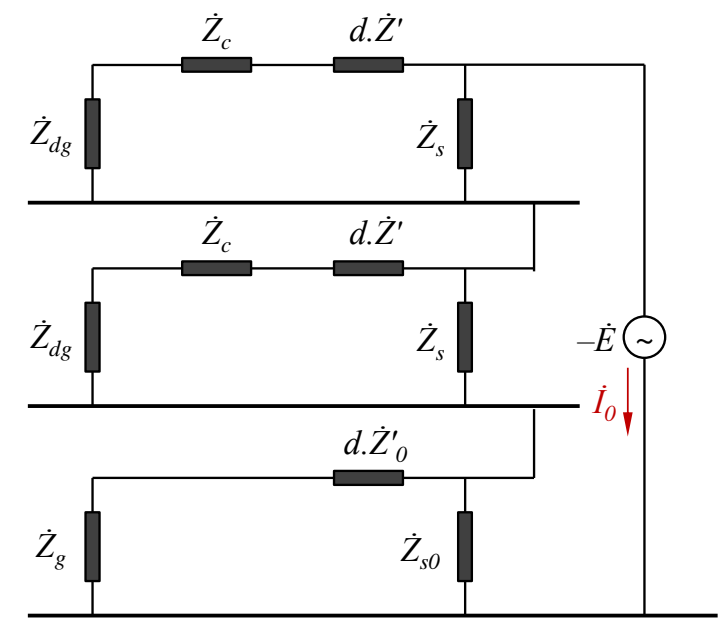

Figura 6.8 - Modelo elétrico para uma falta monofásica na origem do alimentador (saída da subestação)

A variação local da corrente de falta trifásica $\left(\delta I_{k}^{\prime \prime}\right)$ pode ser calculada a partir da Equação 4.16 e da Equação 5.1, conforme demonstra a Equação 6.6:

$\delta I_{k}^{\prime \prime}=\left|\frac{\dot{I}_{k}^{\prime \prime}-\dot{I}_{k}^{\prime \prime *}}{\dot{I}_{k}^{\prime \prime *}}\right|=\left|\frac{\dot{E} / \dot{Z}_{t h}}{\dot{E} / \dot{Z}_{s}}-1\right|=\left|\frac{\dot{Z}_{s}}{d \dot{Z}^{\prime}+\dot{Z}_{c}+\dot{Z}_{d g}}\right|$

A análise da Equação 6.6 revela que a variação da corrente de falta trifásica é máxima quando o gerador é conectado ao lado da subestação da concessionária, isto é, quando $d=0$, e que esta variação diminui conforme o gerador se distancia da fonte. Além disso, esta variação cresce com o aumento da impedância equivalente da fonte, isto é, com a diminuição de sua potência de curto-circuito. Este fato é esperado, pois a variação pode ser vista como a razão entre a contribuição do gerador e a contribuição da fonte. Se a contribuição da fonte diminui e a contribuição do gerador mantém-se constante, então a variação do nível de falta aumenta.

Outra forma de se entender essa variação é visualizá-la como a corrente reversa relativa que passa pelo disjuntor do alimentador em que o gerador está conectado. Quanto maior for essa variação, maior será a probabilidade deste disjuntor atuar indevidamente. 
A variação da corrente de curto-circuito monofásica local $\left(\delta I_{k 1}^{\prime \prime}\right)$, no início do alimentador adjacente, pode ser calculada através da Equação 6.7, que foi derivada da Equação 4.19 e da Equação 5.2:

$$
\delta I_{k 1}^{\prime \prime}=\left|\frac{\dot{I}_{k 1}^{\prime \prime}-\dot{I}_{k 1}^{\prime \prime}}{\dot{I}_{k 1}^{\prime \prime}}\right|=\left|\frac{3 \dot{E} /\left(2 \dot{Z}_{t h}+\dot{Z}_{t h 0}\right)}{3 \dot{E} /\left(2 \dot{Z}_{s}+\dot{Z}_{s 0}\right)}-1\right|=\left|\frac{2 \dot{Z}_{s}+\dot{Z}_{s 0}}{2 \frac{\dot{Z}_{s}\left(d \dot{Z}^{\prime}+\dot{Z}_{c}+\dot{Z}_{d g}\right)}{\dot{Z}_{s}+d \dot{Z}^{\prime}+\dot{Z}_{c}+\dot{Z}_{d g}}+\frac{\dot{Z}_{s 0}\left(d \dot{Z}_{0}^{\prime}+\dot{Z}_{g}\right)}{\dot{Z}_{s 0}+d \dot{Z}_{0}^{\prime}+\dot{Z}_{g}}}-1\right|
$$

Novamente, a equação para o caso monofásico é significativamente mais complexa e algumas poucas conclusões podem ser tiradas. Em primeiro lugar, verifica-se que a variação da corrente de falta monofásica diminui com o aumento da distância do ponto de conexão do gerador em relação à subestação da concessionária. Também é possível verificar que a fonte se comporta de maneira semelhante ao caso trifásico, isto é, quanto mais forte for a fonte, menor será a variação da corrente de falta monofásica.

Por fim, nota-se que quanto maior for o gerador, maior será o impacto sobre a variação da corrente de falta no início do alimentador adjacente, tanto para o caso monofásico quanto para o caso trifásico. 


\subsection{Análise Conjunta dos Critérios}

Com o intuito de se avaliar qual dos critérios apresentados é o mais restritivo e, portanto, o mais importante na limitação da potência dos geradores, os três critérios foram comparados entre si em três análises paramétricas, tanto para o caso trifásico quanto para o caso monofásico, onde foram variados os seguintes parâmetros:

- Potência de curto-circuito da fonte (Figura 6.9);

- Tipo de rede e condutor (Figura 6.10);

- Tensão nominal da rede (Figura 6.11).

Nas figuras citadas aparecem seis linhas, cada uma representado um caso de cada critério apresentado neste capítulo, conforme relacionado na Tabela 6.1. A letra maiúscula indica o critério, sendo A para o critério de aumento do nível de curto circuito, B para o critério de perda de coordenação e $\mathrm{C}$ para o critério de impacto no alimentador adjacente. $\mathrm{O}$ termo entre parêntesis indica se o critério se aplica ao caso trifásico $(3 \varphi)$ ou ao caso monofásico $(1 \varphi)$.

Tabela 6.1 - Denominação dos critérios e suas descrições

\begin{tabular}{cl}
\hline Critério & \multicolumn{1}{c}{ Descrição } \\
\hline $\mathbf{A ~ ( 3 \varphi )}$ & Máxima variação relativa do nível de curto-circuito trifásico \\
$\mathbf{A ~ ( 1 \varphi )}$ & Máxima variação relativa do nível de curto-circuito monofásico \\
$\mathbf{B ~ ( 3 \varphi )}$ & Relação entre a contribuição relativa do gerador e da fonte para o curto-circuito trifásico \\
$\mathbf{B ~ ( 1 \varphi )}$ & Relação entre a contribuição relativa do gerador e da fonte para o curto-circuito monofásico \\
$\mathbf{C ~ ( 3 \varphi )}$ & Máxima variação relativa do nível de curto-circuito trifásico no alimentador adjacente \\
$\mathbf{C ~ ( 1 \varphi )}$ & Máxima variação relativa do nível de curto-circuito monofásico no alimentador adjacente
\end{tabular}

Conforme foi visto na seção 6.2, os critérios de aumento no nível de curto-circuito e de perda de coordenação são idênticos para o caso trifásico. Sendo assim, as curvas dos critérios $\mathrm{A}(3 \varphi)$, em azul escuro, e $\mathrm{B}(3 \varphi)$, em verde claro, se sobrepõem em todos os gráficos, de forma que apenas o último critério é percebido. 
Em todas as figuras, os gráficos do lado esquerdo são aqueles em que o transformador de acoplamento está solidamente aterrado do lado da concessionária e os gráficos do lado direito são aqueles em que o transformador está isolado (ligado em $\Delta$ ). Comparando-se os gráficos do lado esquerdo com os do lado direito verifica-se que os impactos do curto-circuito monofásico são mais severos do que o trifásico apenas nos casos em que o transformador está solidamente aterrado. Este efeito já se verificava nos exemplos do Capítulo 5.

Como já discutido, os critérios de aumento do nível de curto-circuito (A) e de perda da coordenação (B) se tornam mais severos conforme aumenta a distância do ponto de conexão do gerador, ao passo que o critério do impacto no alimentador adjacente (C) se torna menos rígido. Nota-se, também, que os três critérios são idênticos quando o gerador está conectado ao lado da subestação $(d=0)$.

A Figura 6.9 demonstra que os impactos da conexão de um gerador síncrono na rede de distribuição se tornam maiores conforme aumenta a impedância da fonte, isto é, quanto mais fraco for o sistema (menor potência de curto-circuito). Por sua vez, a Figura 6.10 mostra que os impactos são parecidos para redes aéreas e são menores nas redes subterrâneas, devido à sua menor reatância. Por fim, a Figura 6.11 mostra que, mantida fixa a potência de curtocircuito da fonte, o aumento da tensão nominal da rede reduz os impactos causados pelo gerador e tem um efeito similar ao de se reduzir a distância do ponto de conexão.

A análise dos gráficos evidencia que o critério do aumento do nível de curto-circuito (A) é sempre o mais restritivo, com exceção caso da Figura 6.10 (c), situação em que o critério da perda de coordenação (B) para o curto-circuito monofásico foi ligeiramente mais severo. Por fim, o critério do impacto sobre o alimentador adjacente (C) é sempre o menos severo. É interessante verificar que esse ranking entre os critérios se mantém independentemente da potência de curto-circuito da fonte, do tipo de rede e condutor ou da tensão nominal da rede.

De forma geral, pode-se dizer que o critério do aumento do nível de curto-circuito (A) é o mais crítico e, portanto, foi escolhido como o critério que limita a máxima potência admissível a ser instalada em um alimentador. 
TRANSFORMADOR ATERRADO (Y)

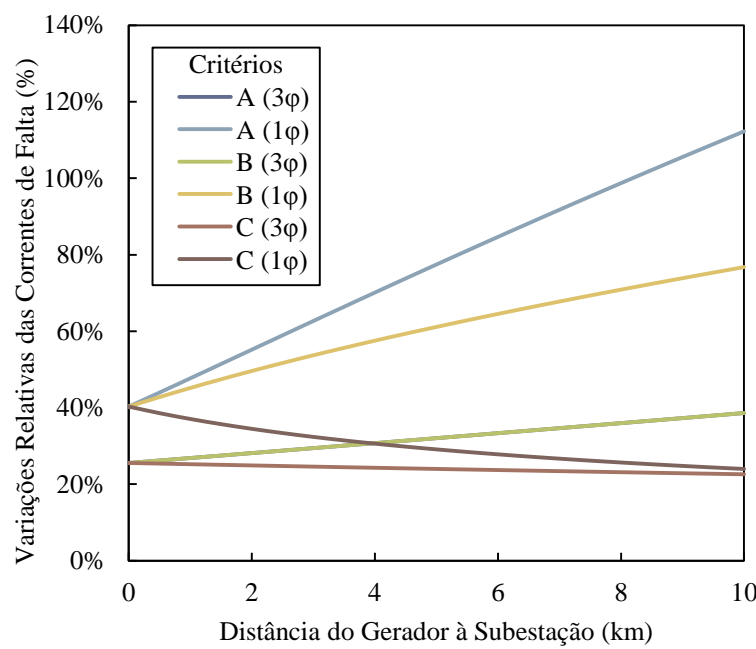

TRANSFORMADOR ISOLADO $(\Delta)$

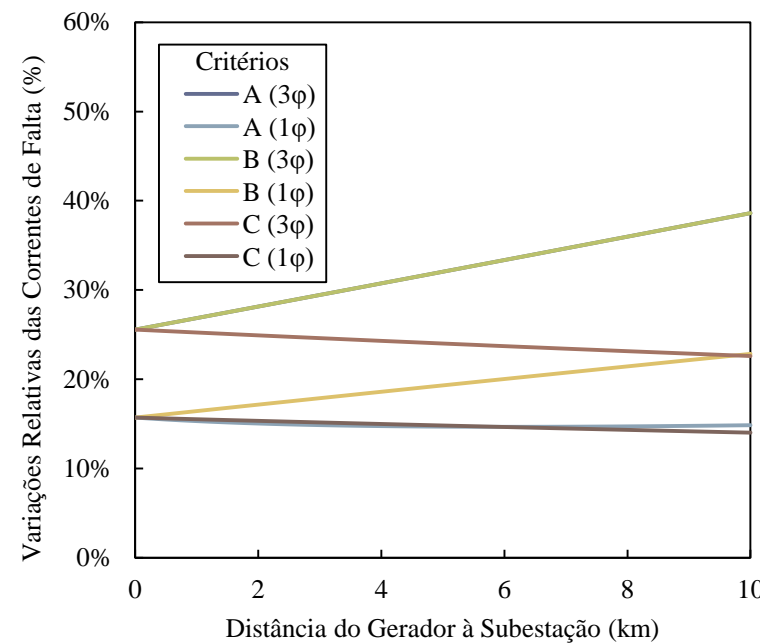

(a) Variação dos critérios para potência de curto-circuito da fonte de 25 MVA
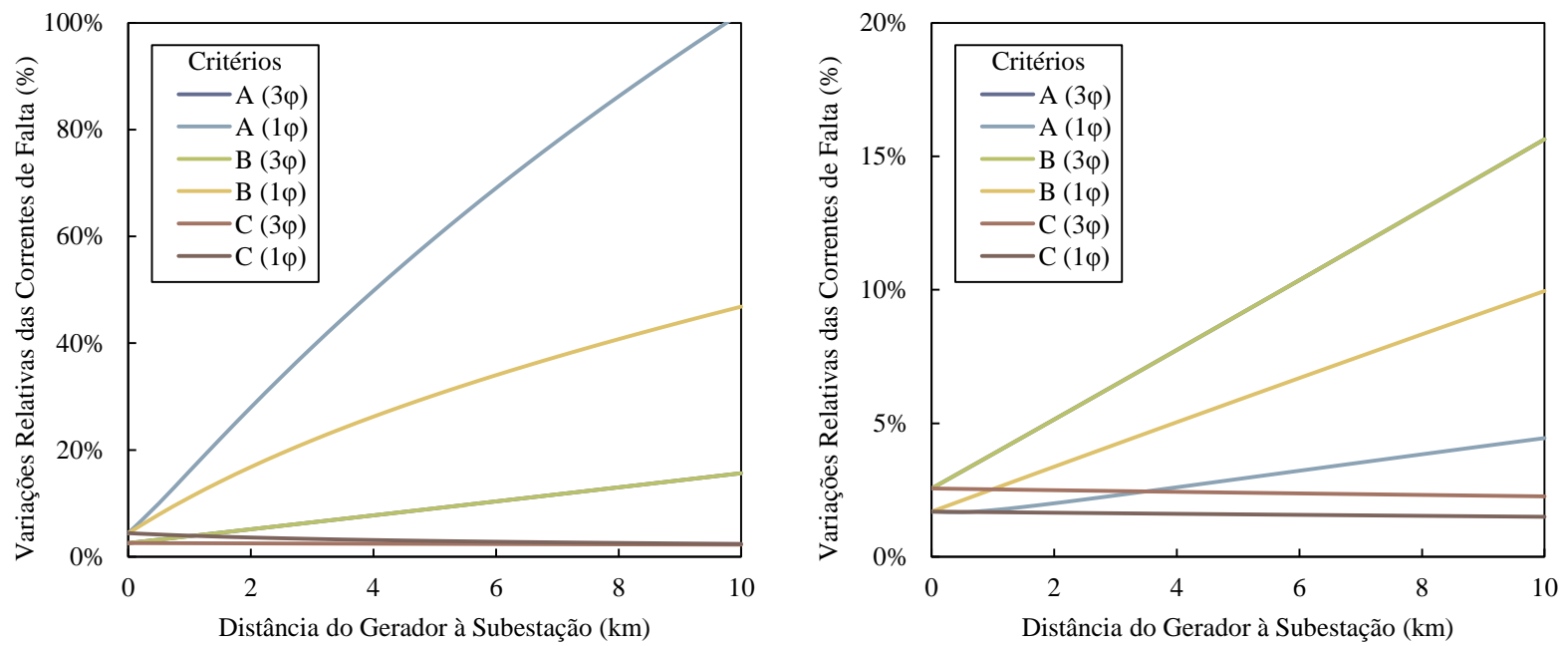

(b) Variação dos critérios para potência de curto-circuito da fonte de 250 MVA
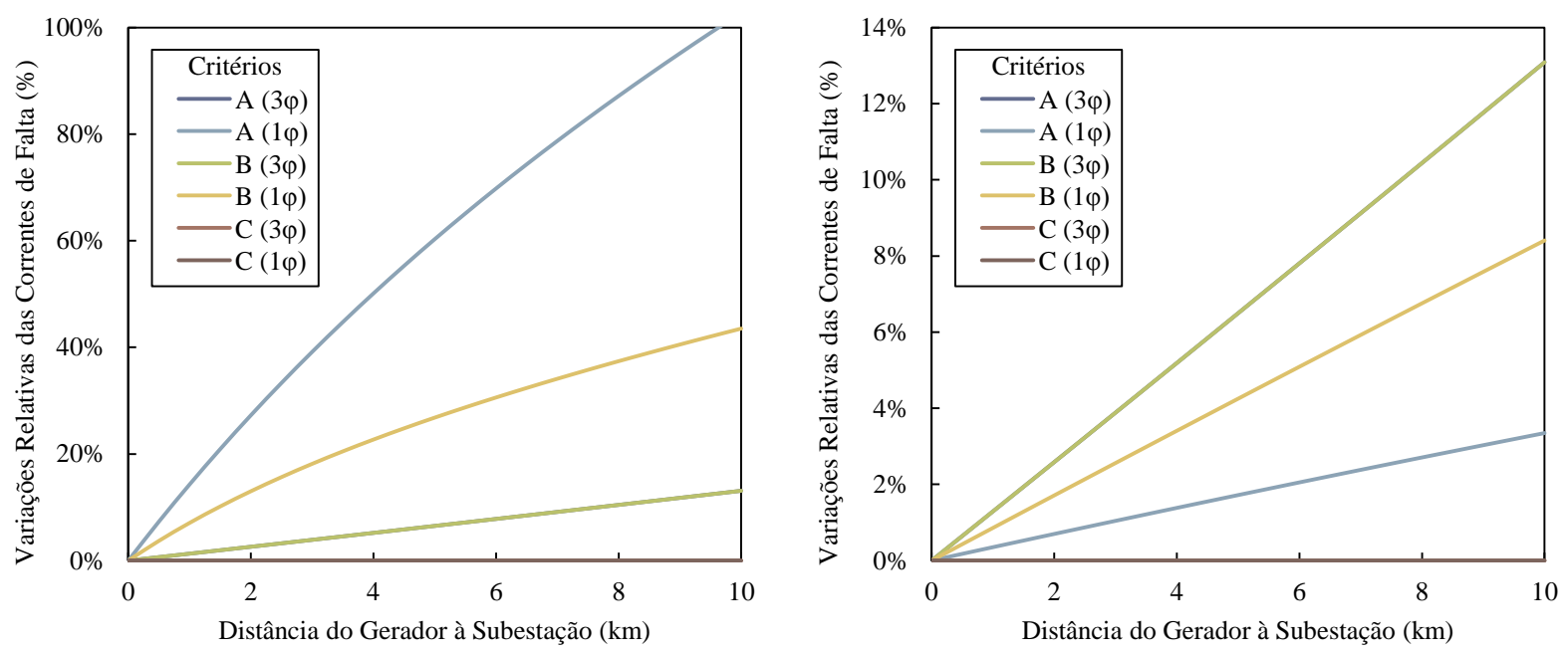

(c) Variação dos critérios para potência de curto-circuito da fonte infinita

Figura 6.9 - Efeito da potência de curto-circuito da fonte sobre as variações dos critérios propostos. Na esquerda, transformador de acoplamento aterrado, na direita, isolado.

$\left(P_{d g}=1 \mathrm{MW}, U_{n}=13,8 \mathrm{kV}\right.$, rede aérea c/ condutor 336,4 MCM, $\left.x_{c}=6 \%, x_{d} "=14 \%, \cos \varphi=0,8\right)$. 
TRANSFORMADOR ATERRADO (Y)

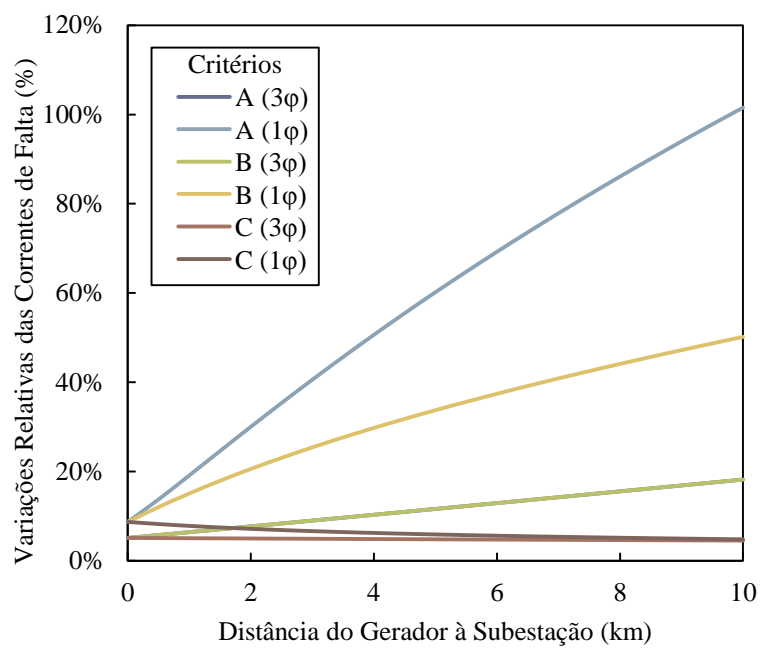

TRANSFORMADOR ISOLADO $(\Delta)$

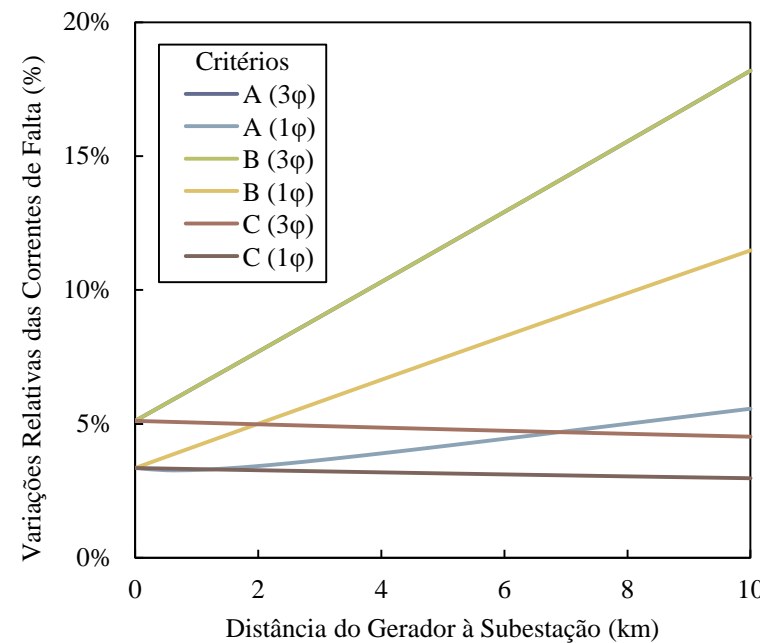

(a) Variação dos critérios para uma rede aérea (cabo: CAA 336,4 MCM)
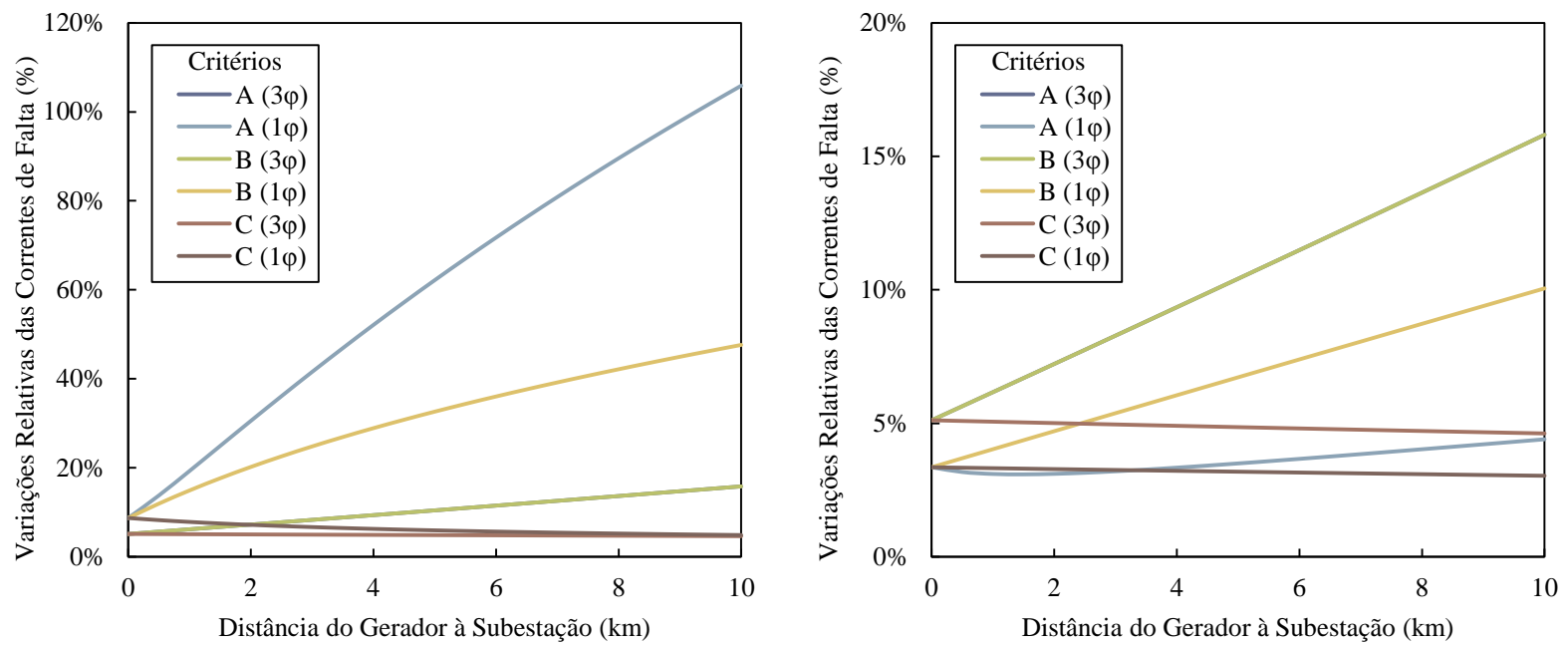

(b) Variação dos critérios para uma rede aérea compacta (cabo: XLPE $185 \mathrm{~mm}^{2}$ )
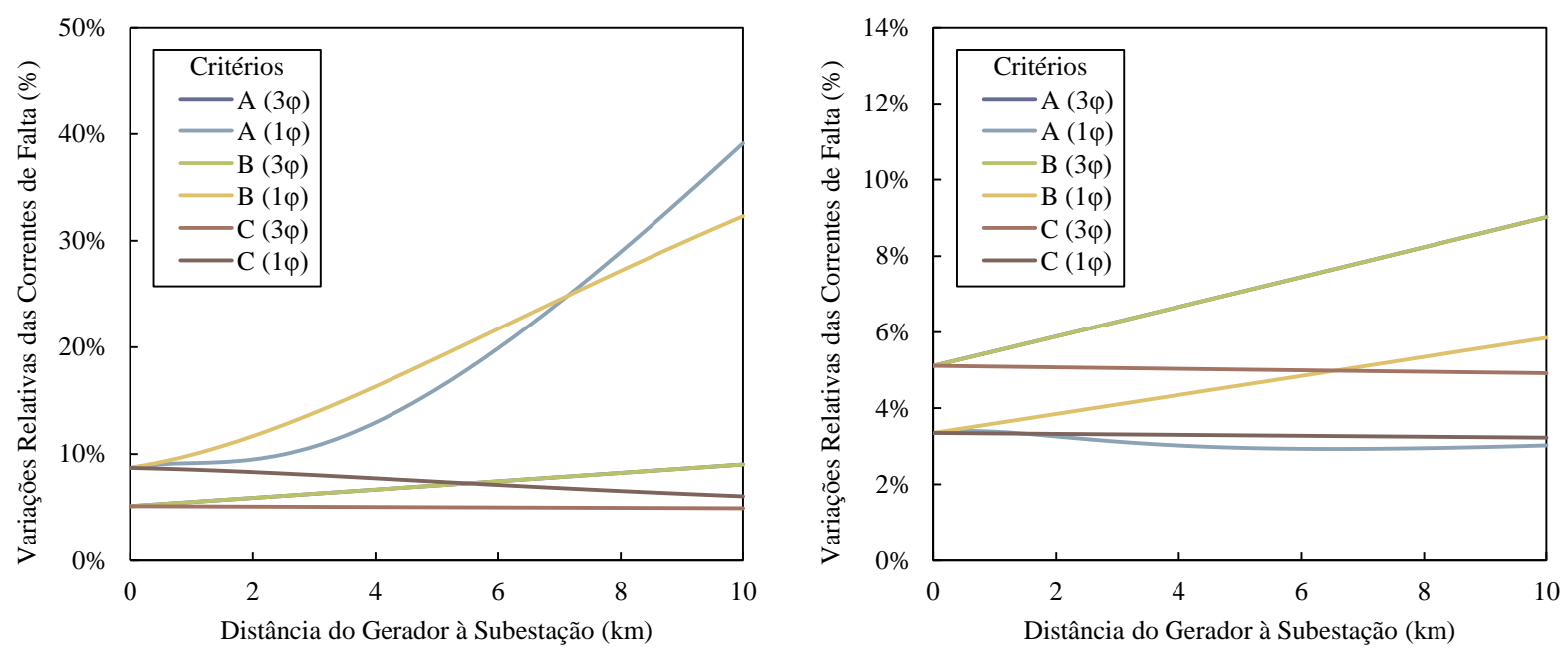

(c) Variação dos critérios para uma rede subterrânea (cabo: XLPE 240 mm²)

Figura 6.10 - Efeito do tipo de rede (impedância da rede) sobre as variações dos critérios propostos. Na esquerda, transformador de acoplamento aterrado, na direita, isolado.

$\left(P_{d g}=1 \mathrm{MW}, U_{n}=13,8 \mathrm{kV}, S^{\prime \prime}{ }_{k s}=125 \mathrm{MVA}, x_{c}=6 \%, x_{d}{ }^{\prime}=14 \%, \cos \varphi=0,8\right)$. 
TRANSFORMADOR ATERRADO (Y)

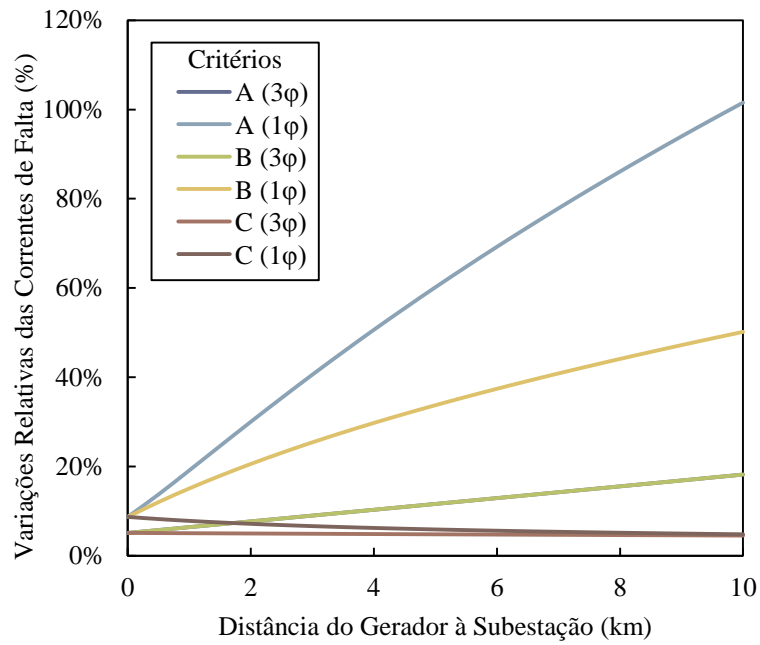

TRANSFORMADOR ISOLADO $(\Delta)$

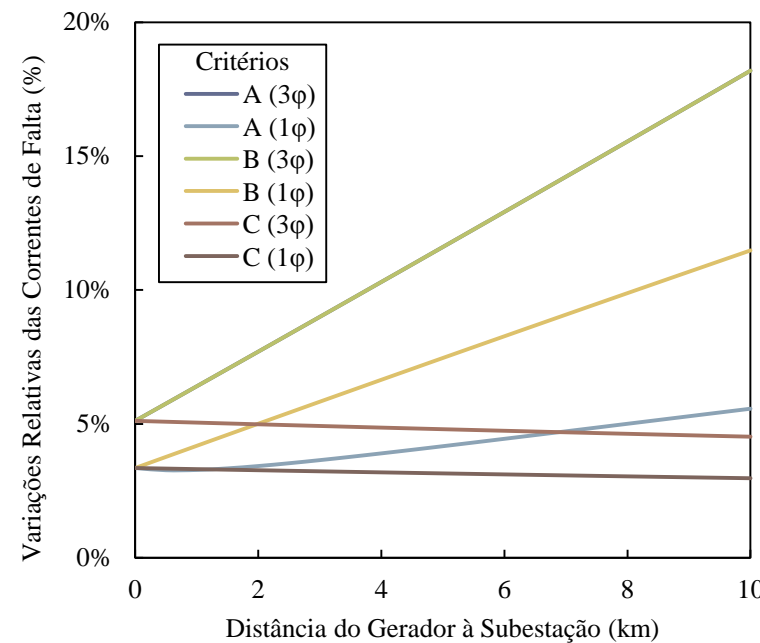

(a) Variação dos critérios para tensão nominal da rede de $13,8 \mathrm{kV}$
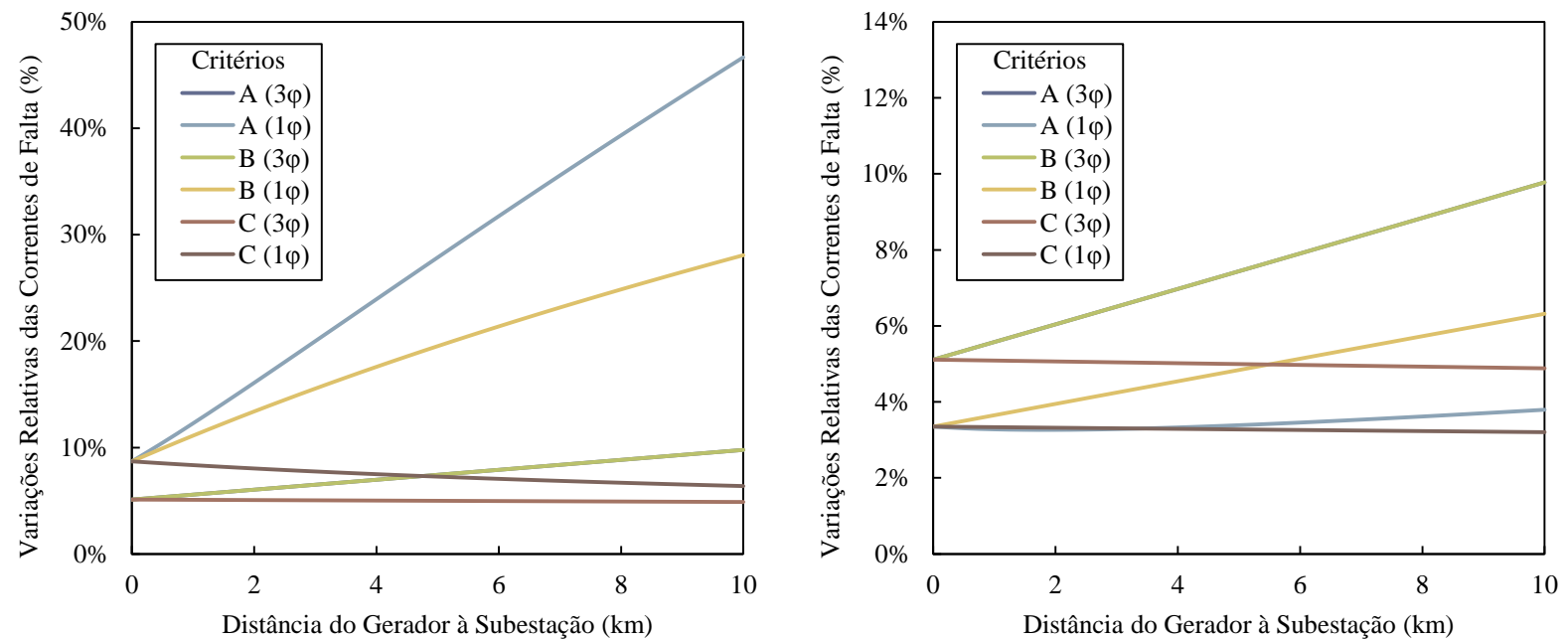

(b) Variação dos critérios para tensão nominal da rede de $23 \mathrm{kV}$
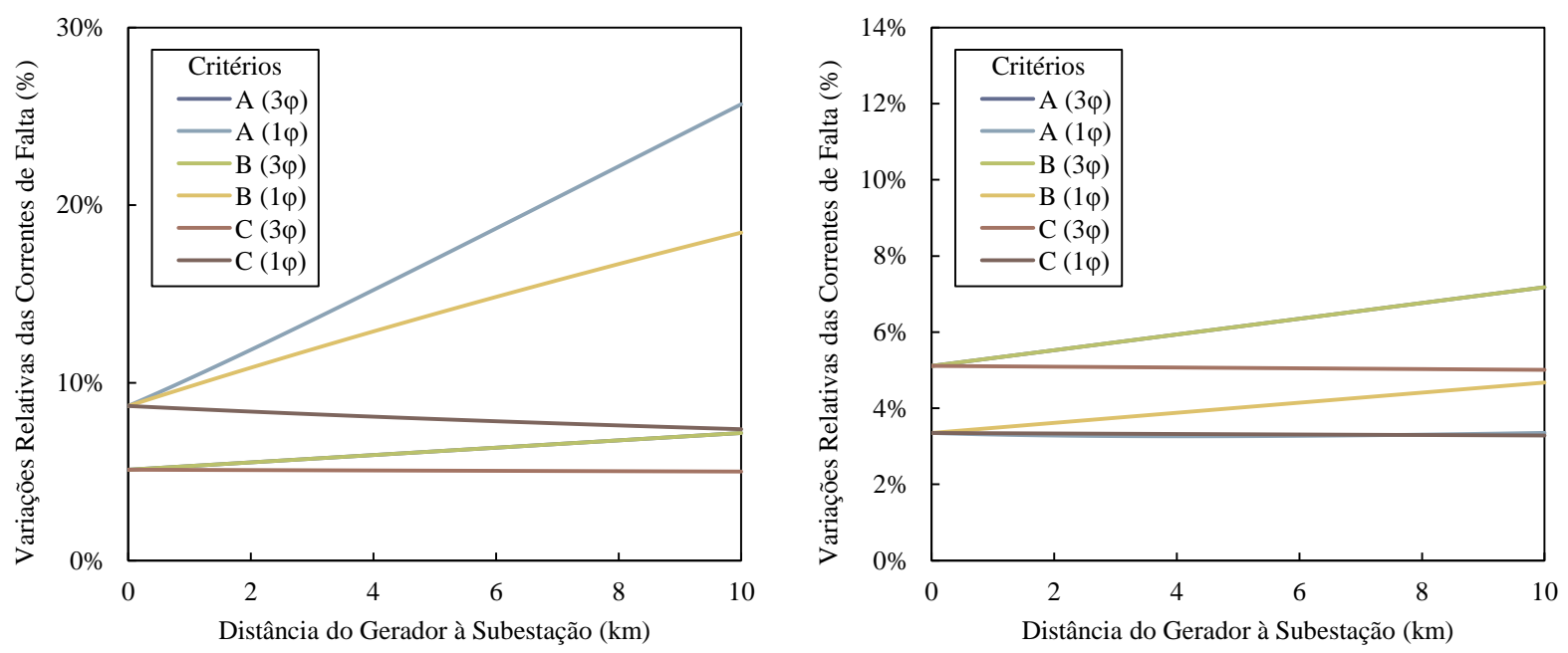

(c) Variação dos critérios para tensão nominal da rede de $34,5 \mathrm{kV}$

Figura 6.11 - Efeito da tensão nominal da rede sobre as variações dos critérios propostos. Na esquerda, transformador de acoplamento aterrado, na direita, isolado.

$\left(P_{d g}=1 \mathrm{MW}\right.$, rede aérea c/ condutor 336,4 MCM, $\left.S^{\prime \prime}{ }_{k s}=125 \mathrm{MVA}, x_{c}=6 \%, x_{d} "=14 \%, \cos \varphi=0,8\right)$. 


\subsection{Determinação da Máxima Potência Admissível}

Um dos principais propósitos deste trabalho é determinar a máxima potência admissível de um gerador síncrono conectado à rede de distribuição dado um limite para os impactos que ele causará sobre as correntes de curto-circuito. Na seção anterior foi visto que o aumento dos níveis de curto-circuito é o caso mais restritivo e, portanto, este critério foi adotado para se calcular os limites para as potências dos geradores. Novamente, foram feitas diversas análises paramétricas, mas desta vez para se mostrar os efeitos dos parâmetros sobre a máxima potência admissível. Os parâmetros estudados foram:

- Limite para a variação relativa máxima das correntes de falta (Figura 6.12)

- Potência de curto-circuito da fonte (Figura 6.13)

- Tensão nominal da rede (Figura 6.14)

- Tipo da rede e condutor (Figura 6.15)

Para realizar estas análises, foi elaborada uma programação na planilha eletrônica para determinar a potência do gerador que levaria a uma dada variação relativa na corrente de curto-circuito.

A Figura 6.12 é a primeira destas análises e demonstra que a máxima potência admissível cresce com o aumento do limite para a variação máxima da corrente de curto-circuito, como esperado. O aumento da potência máxima é praticamente linear com o limite estabelecido, por exemplo, de acordo com a Figura 6.12, a máxima potência para um gerador conectado à $1 \mathrm{~km}$ da fonte seria 1,56 MW para um limite de $10 \%$ de variação máxima do curto-circuito trifásico ou 3,12 MW para um limite de $20 \%$. Caso o transformador de acoplamento seja solidamente aterrado do lado da rede, a potência máxima admissível é de 0,50 MW para um limite de 10\% de variação máxima do curto-circuito monofásico ou de 1,05 MW para um limite de $20 \%$. As análises adiante foram conduzidas assumindo-se um limite de $20 \%$ para as alterações das correntes de falta. 


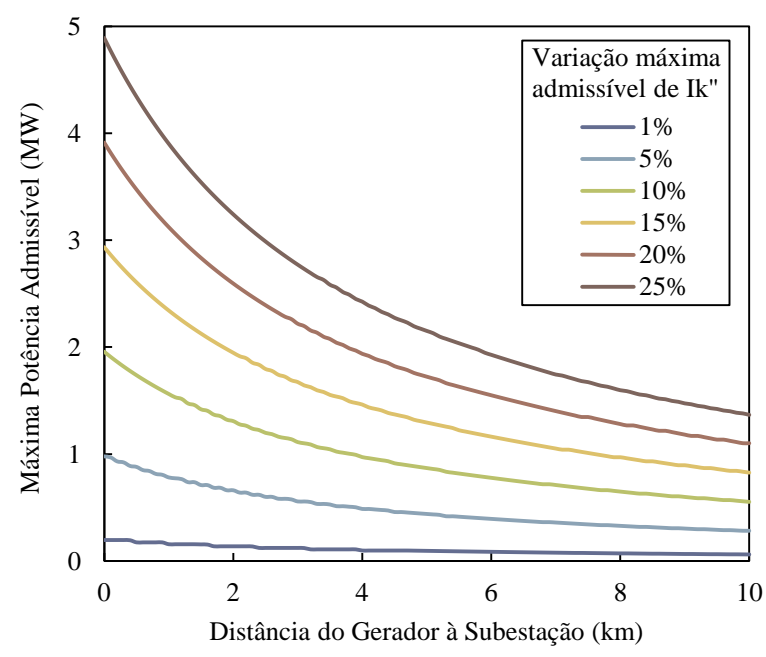

(a) Limitada pela variação do nível de curto-circuito trifásico (transformador de acoplamento isolado)

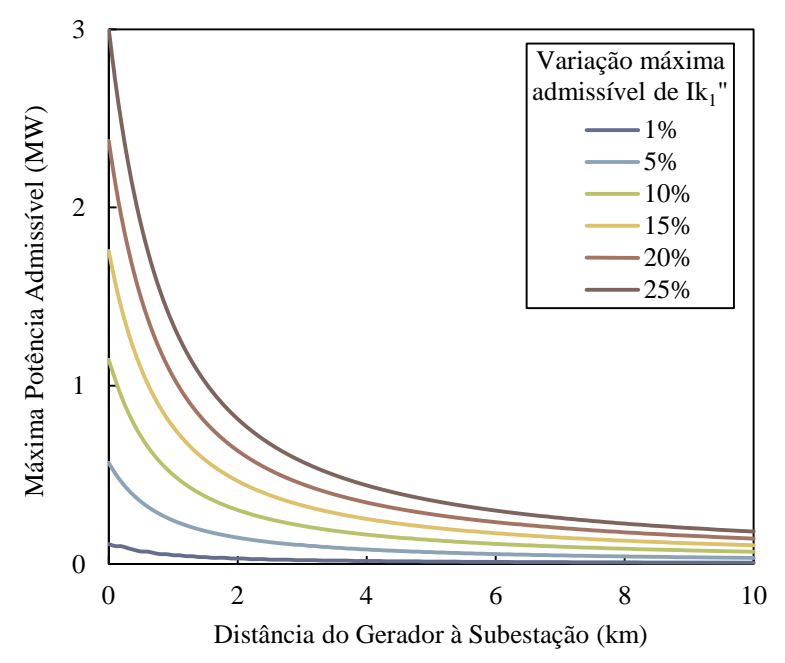

(b) Limitada pela variação do nível de curto-circuito monofásico (transformador de acoplamento solidamente aterrado)

Figura 6.12 - Efeito do limite de máximo de variação da corrente de falta na potência admissível (rede aérea c/ condutor 336,4 MCM, $S{ }^{\prime}{ }_{k s}=125 \mathrm{MVA}, U=13,8 \mathrm{kV}, x_{c}=6 \%, x_{d}{ }^{\prime}=14 \%, \cos \varphi=0,8$ ).

Os números mostrados neste exemplo deixa explícita a notável diferença entre as curvas limitadas pela variação do nível de curto-circuito trifásico, na Figura 6.12 (a), e as limitadas pelo curto-circuito monofásico, na Figura 6.12 (b). No caso monofásico, além da máxima potência admissível ser significativamente menor do que no caso trifásico, ela diminui muito mais rapidamente com a distância do ponto de conexão do gerador.

É importante notar que nesta, e em todas as demais figuras em diante, o caso monofásico se refere aos geradores cujo transformador de acoplamento está solidamente aterrado do lado da rede, pois se assim não fosse, o curto-circuito trifásico seria o mais crítico, como já foi visto anteriormente. Esta característica indica o quão importante é a ligação do transformador de acoplamento na determinação da máxima potência admissível do gerador.

Outro parâmetro que tem grande influência na máxima potência admissível do gerador é a potência de curto-circuito da fonte, conforme a Figura 6.13. Como esperado, quanto maior for a potência de curto-circuito da fonte, maior poderá ser o gerador. Além disso, há um caso ideal que é a fonte infinita, que se coloca como um limite superior para a máxima potência admissível. Novamente, o caso monofásico é muito mais restritivo. 


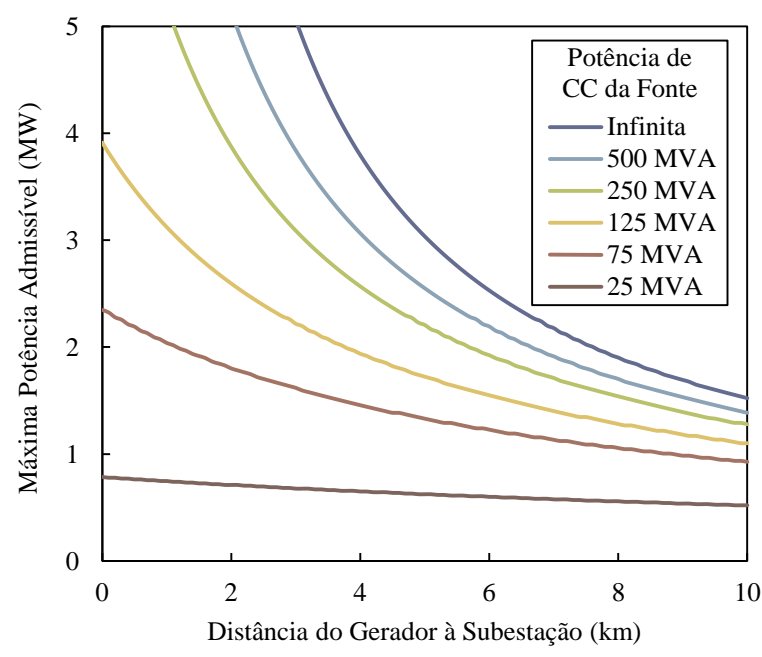

(a) Limitada pela variação do nível de curto-circuito trifásico (transformador de acoplamento isolado)

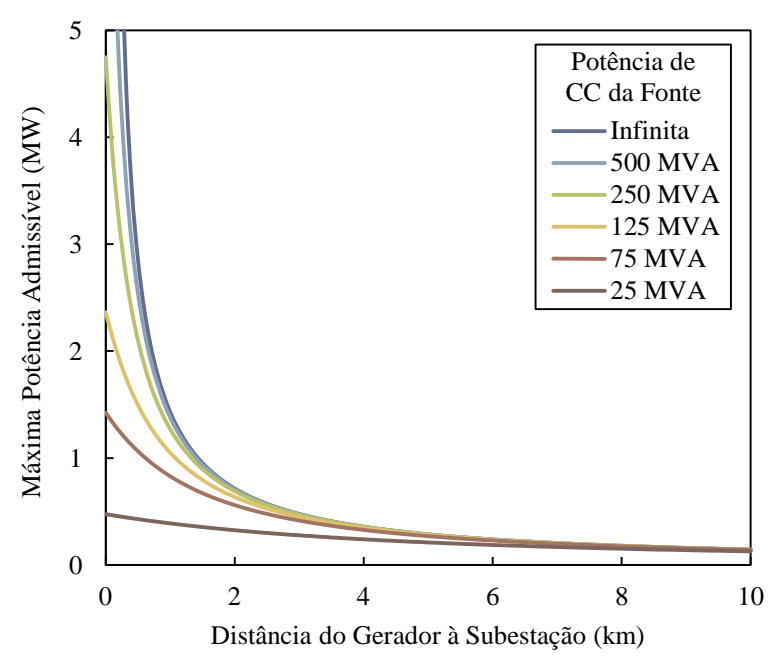

(b) Limitada pela variação do nível de curto-circuito monofásico (transformador de acoplamento solidamente aterrado)

Figura 6.13 - Efeito da potência de curto-circuito da fonte na máxima potência admissível (rede aérea c/ condutor 336,4 MCM, $U=13,8 \mathrm{kV}, x_{c}=6 \%, x_{d} "=14 \%, \cos \varphi=0,8, \delta I^{\prime \prime}{ }_{k m a x}=20 \%$ ).

A tensão nominal da rede também influencia a máxima potência admissível do gerador, conforme mostra a Figura 6.14. Para tornar esta análise mais adequada, considerou-se que a potência de curto-circuito da fonte é proporcional ao nível de tensão. Por exemplo, para o nível de 13,8 kV ela vale 125 MVA e para o nível de 34,5 kV ela vale 312,5 MVA.

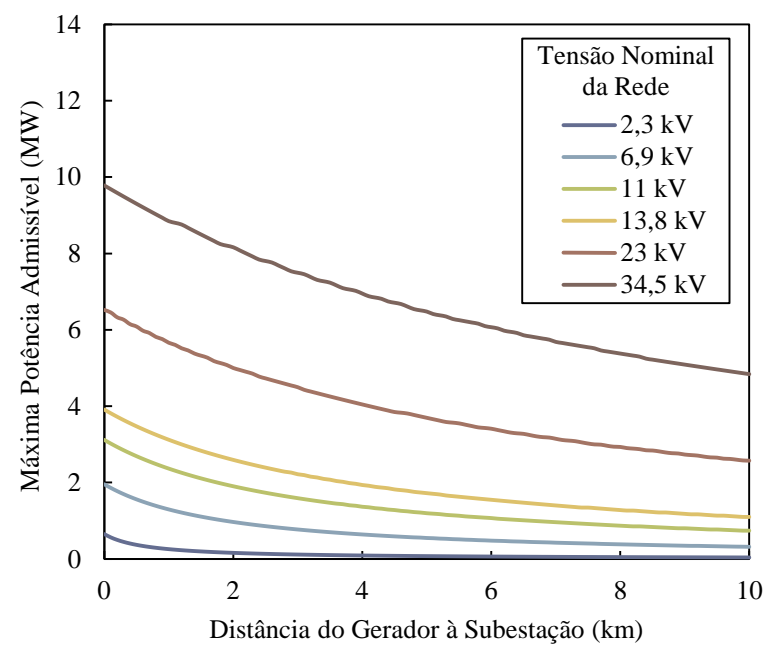

(a) Limitada pela variação do nível de curtocircuito trifásico (transformador de acoplamento isolado)

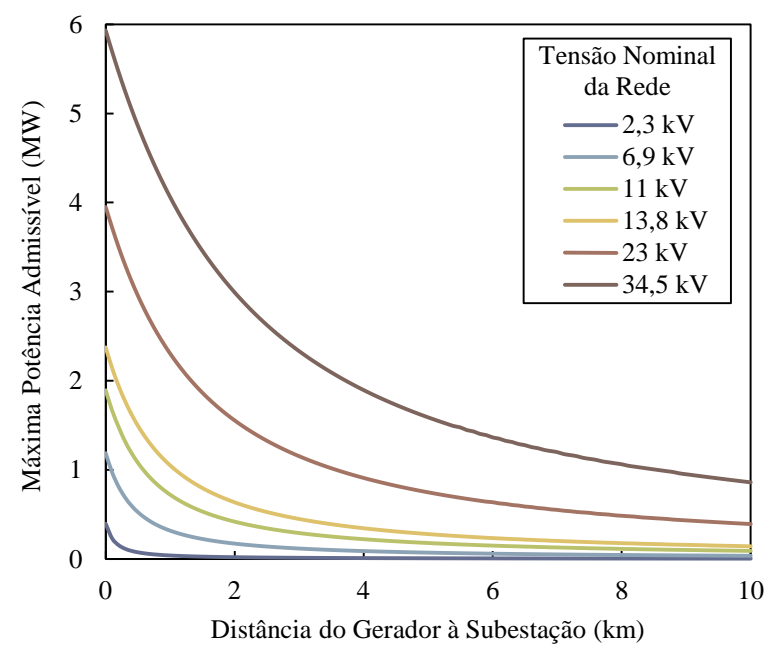

(b) Limitada pela variação do nível de curto-circuito monofásico (transformador de acoplamento solidamente aterrado)

Figura 6.14 - Efeito da tensão nominal da rede na máxima potência admissível (rede aérea c/ condutor 336,4 MCM, $I{ }_{k s}=5,23 \mathrm{kA}, x_{c}=6 \%, x_{d} "=14 \%, \cos \varphi=0,8, \delta I{ }_{k \max }=20 \%$ ). 
Pode-se constatar, pela análise da Figura 6.14, que as redes com níveis de tensão maiores comportam geradores maiores. Adicionalmente, o aumento do nível de tensão faz com que as impedâncias dos condutores se tornem relativamente menor, fazendo com que a máxima potência admissível decresça mais lentamente com a distância.

Por fim, as análises paramétricas demonstraram que o tipo de rede e seu condutor tem um impacto menor do que os outros parâmetros sobre a máxima potência admissível do gerador, conforme mostra a Figura 6.15. Como a magnitude das impedâncias de sequência positiva e sequência zero das redes aéreas convencionais e compactas são parecidas, independentemente da seção do condutor, estas redes comportam geradores de capacidades parecidas. A diferença está entre as redes aéreas e as subterrâneas, pois as impedâncias das redes subterrâneas são menores devido ao menor espaçamento entre as fases. A consequência disso é o fato das redes subterrâneas comportarem geradores maiores, sobretudo no caso monofásico, uma vez que as reatâncias de sequência zero são significativamente menores.

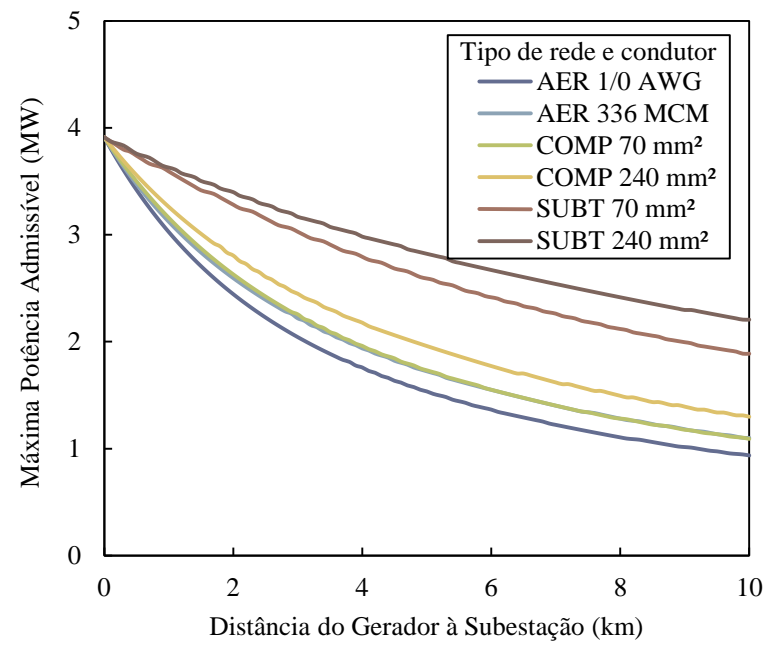

(a) Limitada pela variação do nível de curtocircuito trifásico (transformador de acoplamento isolado)

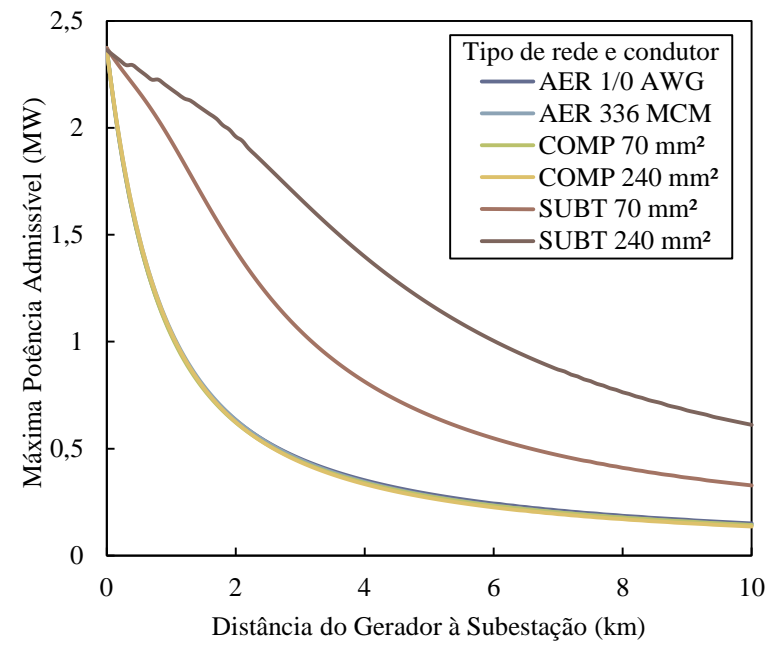

(b) Limitada pela variação do nível de curto-circuito monofásico (transformador de acoplamento solidamente aterrado)

Figura 6.15 - Efeito do tipo de rede e do condutor na máxima potência admissível $\left(U=13,8 \mathrm{kV}, S{ }_{k s}=125 \mathrm{MVA}, x_{c}=6 \%, x_{d}{ }^{\prime}=14 \%, \cos \varphi=0,8, \delta I{ }_{k \max }=20 \%\right)$. 
As análises realizadas para o caso trifásico podem ser resumidas na Equação 6.8, que é derivada da Equação 6.1, supondo que a potência aparente do transformador de acoplamento é igual à potência aparente do gerador.

$$
P_{g d}=\frac{\left(x_{c}+x_{d}^{\prime \prime}\right) \cos \varphi}{U^{2} / S_{k s}^{\prime \prime}+d \dot{Z}^{\prime}} U^{2} \delta I_{k \max }^{\prime \prime}
$$

A equação leva às mesmas conclusões que foram encontradas através dos gráficos, isto é, a influência linear do limite $\delta I_{k m a x}$, a redução da potência máxima admissível com a distância do ponto de conexão, seu aumento com a potência de curto circuito da fonte e com a tensão nominal da rede. Além disso, a equação também revela a influência da impedância do gerador e do transformador.

Uma equação similar para o caso monofásico (com transformador de acoplamento ligado em estrela aterrada no lado da concessionária) só poderia ser derivada da Equação 6.2 se hipóteses muito simplistas fossem adotadas, o que levaria a erros grosseiros. Apesar disso, pode-se estimar a potência máxima admissível através de ábacos como os desenvolvidos neste capítulo. 


\section{CONCLUSÕES}

\subsection{Conclusões deste trabalho}

A geração distribuída é um conceito que vem ganhando importância ao longo dos últimos anos e os impactos que decorrem dela sempre foram preocupantes para as concessionárias de distribuição. Este tema ganhou uma maior relevância recentemente em virtude das Consultas Públicas $n^{\circ}$ 005/2014 e no 026/2015 realizadas pela ANEEL, que debateu a ampliação do conceito de net-metering para o limite de potência do registro da ANEEL (3 MW para CGHs e 5 MW para outras fontes).

A análise paramétrica demonstrou ser uma ferramenta adequada para se estudar estes impactos, pois através dela foi possível compreender os problemas envolvidos, avaliar o impacto de cada variável e por fim estabelecer um possível limite para a potência de um gerador síncrono a ser conectado na rede de distribuição em função de parâmetros como a distância de seu ponto de conexão, a potência de curto-circuito da fonte, o nível de tensão nominal da rede, o tipo de rede e seu condutor.

Ao longo de todo o estudo ficou evidente a influência da ligação do transformador de acoplamento sobre as correntes de curto-circuito monofásico. Também foi discutida a importância do regime de neutro da concessionária e seus requisitos em relação à ligação dos transformadores da geração distribuída. Embora haja a predominância da ligação $\Delta$ do lado da concessionária, algumas delas exigem que grandes geradores possuam uma referência de terra no lado da rede, como através de um neutro solidamente aterrado ou de um transformador de aterramento, para proteger a rede de sobretensões.

A exigência de prover uma referência de terra pode limitar significativamente a potência de um gerador que deseja se conectar à rede de distribuição se seus impactos forem limitados. Uma forma de se contornar este problema é o uso do aterramento através de impedância, de maneira que a variação da falta monofásica se torne menor do que a da falta trifásica. Outra solução seria admitir a conexão em $\Delta$ do lado da rede da concessionária e limitar as sobretensões ocasionadas pelas faltas monofásicas através do uso de para-raios. 


\subsection{Sugestões para Trabalhos Futuros}

Este trabalho foi conduzido sob a ótica da análise paramétrica, através da modelagem de uma rede radial simples com um único gerador distribuído conectado. O estudo poderia ser expandido para uma análise mais geral, com diversos geradores ligados à rede de distribuição. Provavelmente isso exigiria o uso de outras técnicas de análise como, por exemplo, o método de Monte Carlo para se analisar diversas possibilidades ou então uma análise extensiva onde se estudaria todas as possibilidades em um determinado universo.

Uma abordagem interessante seria o estudo de casos reais, onde se analisaria os impactos de geradores sobre redes de distribuição existentes, com parâmetros conhecidos, inclusive os ajustes da proteção. Por exemplo, com este tipo de análise seria possível verificar os pontos em que houve perda de coordenação da proteção e seria possível demonstrar o conjunto de ajustes da proteção que mitigariam este problema.

Outro aspecto é que a modelagem dos geradores como uma fonte de tensão atrás de uma impedância é relativamente limitada para a geração fotovoltaica, caso em que uma fonte de corrente seria mais apropriada. Adicionalmente, espera-se que o crescimento da geração solar fotovoltaica distribuída se dê em conjuntos de baixa potência, o que requereria sua instalação na rede de baixa tensão, de acordo com o PRODIST. Por esta razão, o estudo da contribuição desta fonte para o curto-circuito talvez exigisse um estudo dedicado.

As análises feitas até aqui poderiam estar dentro de um contexto mais amplo, em conjunto com outras análises que considerassem a capacidade de condução da rede (fluxo de potência), os impactos causados pela produção de harmônicos devido ao uso de conversores eletrônicos pela geração distribuída, os distúrbios causados sobre a qualidade de tensão e a confiabilidade do suprimento, etc. 


\subsection{Considerações finais}

É importante lembrar que a evolução das redes elétricas inteligentes fará com que muitos dos problemas causados pela introdução da geração distribuída sejam mitigados e alguns dos problemas apresentados nesta dissertação se tornem irrelevantes. Por exemplo, o aumento da automação e uso da proteção adaptativa permitirá que os ajustes dos dispositivos de proteção se alterem em tempo real conforme o estado operativo da rede, diminuindo os casos de perda de coordenação. No futuro, talvez o único problema remanescente fosse o aumento dos níveis de curto-circuito, pois os equipamentos da rede e seus condutores são dimensionados para suportar um dado nível que poderia ser superado pela presença da geração distribuída.

Ainda assim, este trabalho tem relevância, pois durante a transição tecnológica haverá casos de geradores síncronos conectados às redes de distribuição cujas proteções continuarão a ser executadas da forma tradicional.

Este trabalho foi dedicado ao entendimento dos impactos da geração distribuída sobre os níveis de curto-circuito das redes de distribuição, um problema que deverá persistir por ainda muitos tempo com a participação cada vez mais relevante da geração distribuída. Por fim, o desenvolvimento desta dissertação contribuiu com a publicação de um artigo no Simpósio Brasileiro de Sistemas Elétricos (SBSE), em 2014. 


\section{BIBLIOGRAFIA}

Ackermann, T., Andersson, G. \& Soder, L., 2001. Distributed Generation: a definition. Electric Power Systems Research, D, Issue 57, pp. 195 - 204.

Ackermann, T. \& Knyazkin, V., 2002. Interaction between Distributed Generation and the Distribution Network: Operation Aspects. Transmission and Distribution Conference and Exhibition 2002: Asia Pacific, 2(IEEE/PES), pp. 1357-1362.

ANEEL, 2012. Procedimentos de Distribuição - Módulo 3 - Acesso aos Sistemas de Distribuição - Rev5, Brasília: Agência Nacional de Energia Elétrica.

Barker, P. P. \& Mello, R. W. D., 2000. Determining the Impact of Distributed Generation on Power Systems. I. Radial Distribution Systems. Power Engineering Society Summer Meeting, 3(IEEE), pp. 1645-1656.

Blackburn, J. L., 2006. Protective Relaying: Principles and Applications. 3a Ed. Boca Raton: CRC Press.

Bollen, M. H. \& Hassan, F., 2011. Integration of Distributed Generation in the Power System. New Jersey: John Wiley \& Sons.

Brahma, S. M. \& Girgis, A. A., 2001. Impact of Distributed Generation on Fuse and Relay Coordination: Analysis and Remedies. Proceedings 2001 IAESTED International Conference on Power and Energy Systems, Issue pp. 384-389.

CIGRÈ, 1998. Impact of Increasing Contributions of Dispersed Generation on the Power Systems, Paris: Final report of Working Group 37-23.

CIRED, 1999. Preliminary Report: Dispersed Generation, Nice, 2 June: General Conference - Working Group 04.

Dietrich Oeding, B. R. O., 2011. Elektrische Kraftwerke und Netze. Heidelberg: SpringerVerlag.

EIA, 2013. Annual Energy Outlook 2013 with projections to 2040, Washington DC: U.S. Energy Information Administration. 
EPE, 2014. Plano Decenal de Energia (PDE 2023), Rio de Janeiro: Empresa de Planejamento Energético (EPE).

Fitzgerald, A. E. \& Charles Kingsley, J., 1975. Electric Machinery. 3a Ed. New York: McGraw-Hill.

Freitas, W., Xu, W., Affonso, C. M. \& Huang, Z., 2005. Comparative Analysis Between ROCOF and Vector Surge Relays for Distributed Generation Applications. Power Delivery, IEEE Transactions on, 20(2), pp. 1315-1324 .

Geidl, M., 2005. Protection of Power Systems with Distributed Generation, State of the Art, Zurich: Power Systems Laboratory Technical Report, ETH.

Gers, J. M. \& Holmes, E. J., 2004. Protection of Electricity Distribution Networks. 2a Ed. Londres: IEE Power \& Energy Series n. 47.

Gevorgian, V. \& Muljadi, E., 2010. Short circuit current contribution for different wind turbine generator types. Minneapolis, Power and Energy Society General Meeting, 2010 IEEE , pp. 1-8.

Girgis, A. A. \& Brahma, S. M., 2001. Effect of distributed generation on protective device coordination in distribution system. Halifax, Power Engineering, 2001. LESCOPE '01. 2001 Large Engineering Systems Conference on, pp. 115 - 119.

Gomez-Exposito, A., Conjeo, A. S. \& Cañizares, C., 2011. Sistemas de Energia Elétrica Análise e Operação. São Paulo: LTC.

Gomez, J. C., Nesci, S. M. \& Barbero, F. A., 2009. Short-circuit currents supplied for induction generators. Praga, Electricity Distribution - Part 1, 2009. CIRED 2009. 20th International Conference and Exhibition on .

Guthmann, O. et al., 1982. Manual de Instalações Eléctricas, Brown Boveri \& Cie.. Porto: Ordem dos Engenheiros-Região Norte.

Hugues, T. P., 1983. Networks of Power - Eletrification in Western Society 1880-1930. Maryland: The John Hopkins Press.

IEA, 2013. World Energy Outlook 2013, Paris: International Energy Agency. 
IEC, 2001. IEC 60909 - Short Circuit Currents in Three Phase A.C. Systems, Genebra: International Electrotechnical Comission.

IEC, 2004. IEC 60076 - Power Transformers, Genebra: International Electrotechnical Comission.

IEEE, 1993. IEEE Std 141 - IEEE Recommended Practice for Electric Power Distribution for Industrial Plants, New Jersey: Institute of Electrical and Electronics Engineers.

IEEE, 2003. IEEE Std 1547 - Standard for Interconnecting Distributed Resources With Electric Power Systems, New Jersey: Institute of Electrical and Electronics Engineers.

INEE, 2002. Geração Distribuída e Conexão ao Sistema Elétrico - Proposta de Revisão da Resolução ANEEL 281/99, Brasília: Instituto Nacional de Eficiência Energética.

Jeff Roberts, H. J. A. D. H., 2001. Review of Ground Fault Protection Methods for Grounded, Ungrounded and Compensated Distribution Systems, Pulmann, WA: Schweitzer Engineering Laboratories, Inc..

Jenkins, N. et al., 2000. Embedded Generation. London: IET Power and Energy Series 31.

Lopes, J. A. P., 2002. Integration of dispersed generation on distribution networks-impact studies. s.1., Power Engineering Society Winter Meeting, 2002. IEEE, pp. 323-328.

Metz-Noblat, B. d., 2005. Analyse des Réseaux Triphasés en Régime Perturbé à l'Aide des Composantes Symétriques, Grenoble: Schneider Electric.

Naiem, A., Hegazy, Y., Abdelaziz, A. Y. \& El-Sharkawy, M. A., Dezembro 2010. A Classification Technique for Protection Coordination Assessment of Distribution Systems with Distributed Generation. Cairo, Proceedings of the Fourteenth International Middle-East Power Systems Conference MEPCON'10, Cairo University, Cairo, Egypt, December 2010 (2010): 404-409.

Nimpitiwan, N. \& Heydt, G., 2006. Consequences of Fault Currents Contributed by Distributed Generation, Arizona State University: PSERC - Power Systems Engineering Research Center.

Puret, C., 1991. Cahier Technique no. 155 - Les Réseaux de Distribution Publique MT Dans Le Monde, Grenoble: Merlin Gerin. 
Roeper, R., 1990. Correntes de Curto-circuito em Redes Trifásicas. São Paulo: Nobel, Siemens S.A..

Salles, M. B. d. C., 2009. Modelagem e Análises de Geradores Eólicos de Velocidade Variável Conectados em Sistemas de Energia Elétrica, São Paulo: Tese de Doutorado, PEA Escola Politécnica da USP.

Schlabbach, J., 2005. Short Circuit Currents. IEE Power \& Energy Series 51: IET.

Seegers, T. \& Birt, K., 2004. Impact of distributed resources on distribution relay protection, New Jersey: IEEE-PES Working Group D3.

Short, T. A., 2014. Electric Power Distribution Handbook. 2a Ed. Boca Raton: CRC Press.

Stevenson, W. D., 1982. Power System Analysis. 4a Ed. New York: McGraw-Hill. 


\section{ANEXo A - Modelos ElÉTRICOS PARA OS GERADORES DISTRIBUÍDOS}

A máquina síncrona é representada classicamente por uma fonte de tensão atrás de uma reatância, conforme demonstra (Figura A.1). Esta reatância pode ser subtransitória, transitória ou síncrona, a depender do intervalo de tempo em que se deseja analisar a corrente de curtocircuito (Fitzgerald \& Charles Kingsley, 1975).

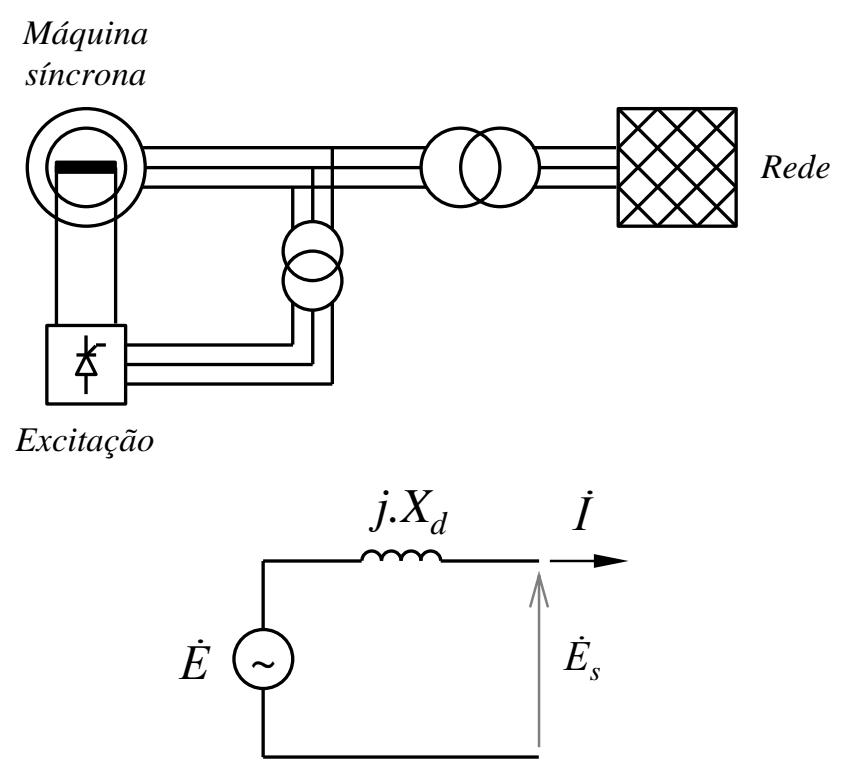

Figura A.1 - Modelo elétrico para a máquina síncrona (MS)

Por sua vez, as centrais eólicas empregam diversas tecnologias de geração. Os primeiros aerogeradores desenvolvidos utilizam máquinas assíncronas de velocidade fixa ou Fixed Speed Induction Generator (FSIG), conforme a Figura A.2. Nesta tecnologia um controle de torque mecânico garante que a máquina opere em uma estreita faixa de escorregamento negativo em que se pode desenvolver potência elétrica. Como a máquina de indução consome potência reativa ela é geralmente compensada com um banco de capacitores em paralelo. 

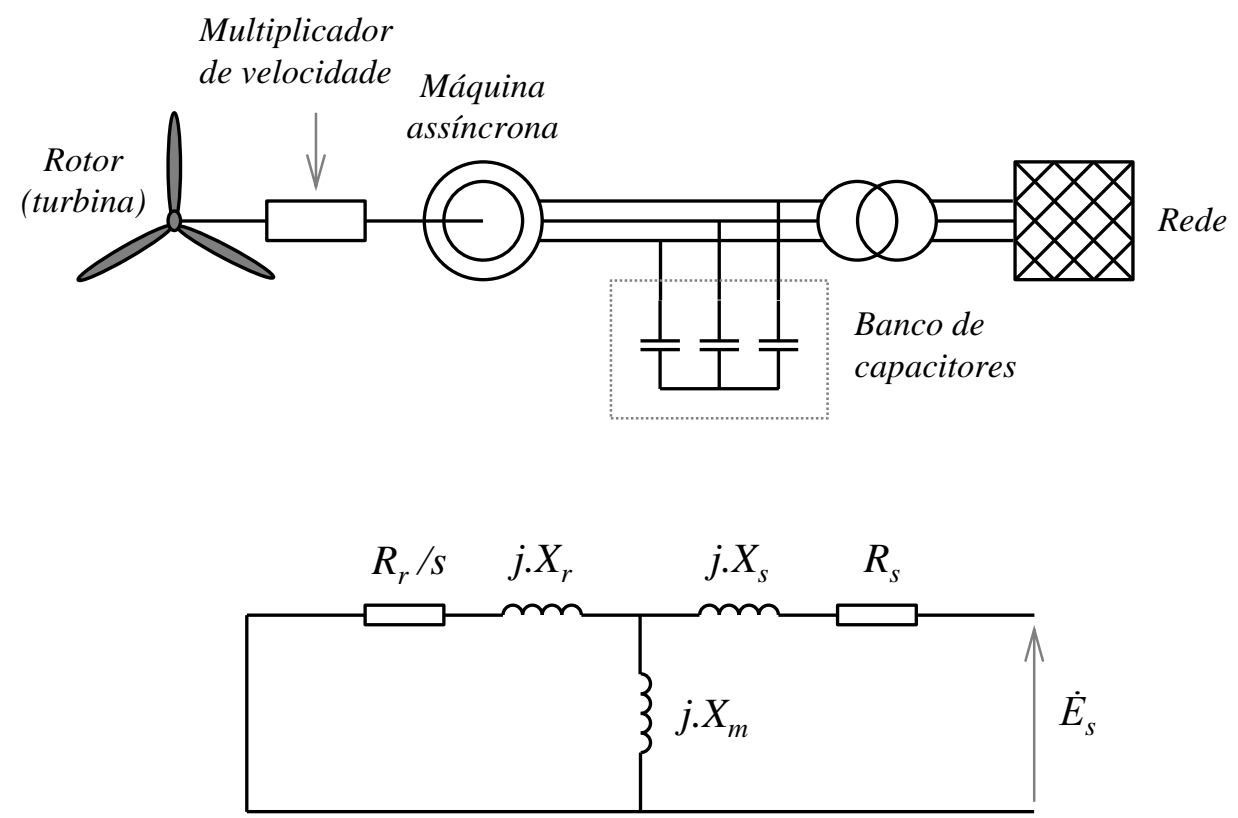

Figura A.2 - Modelo elétrico para o gerador assíncrono de velocidade fixa (FSIG)

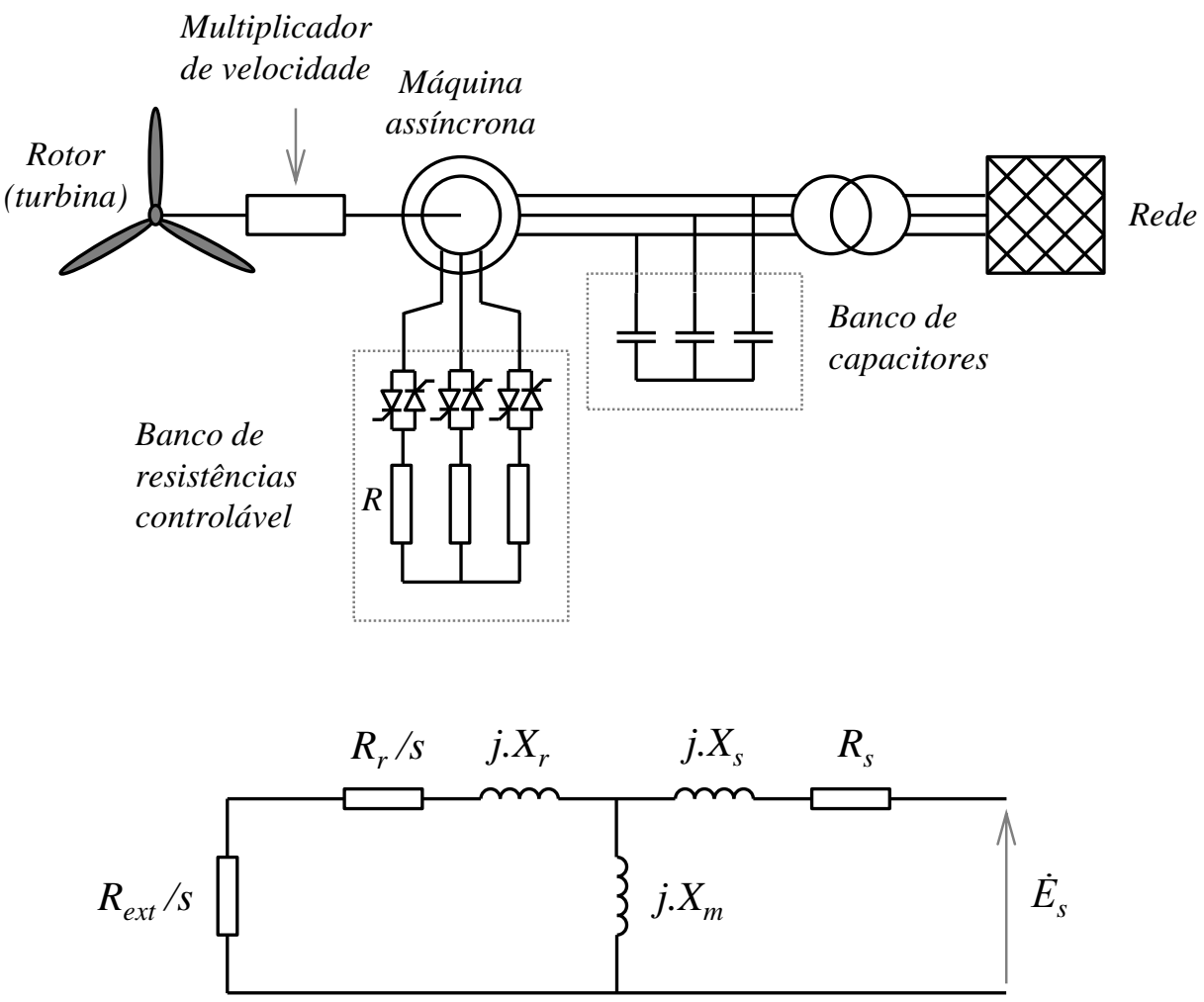

Figura A.3 - Modelo elétrico para o gerador assíncrono de velocidade variável (VSIG) 
Para superar a limitação da velocidade, uma segunda geração de aerogeradores passou a utilizar rotores bobinados, também chamados de Variable Speed Induction Generator (VSIG), como mostra a Figura A.3. Nesta tecnologia um banco de resistores é inserido em série com os enrolamentos do rotor, permitindo que a máquina opere em uma faixa de escorregamento significativamente maior.

As gerações posteriores passaram a incorporar conversores estáticos, como o gerador de indução duplamente alimentado ou Doubly Fed Induction Generator (DFIG), ilustrado na Figura A.4. Um conversor estático alimentado pela rede fornece corrente de excitação para o rotor em frequência que seja compatível com a velocidade da turbina, de forma que o estator possa operar à frequência da rede (velocidade síncrona). Além disso, o controle da fase da corrente de excitação do rotor permite determinar o fator de potência da máquina, o que é uma grande vantagem.

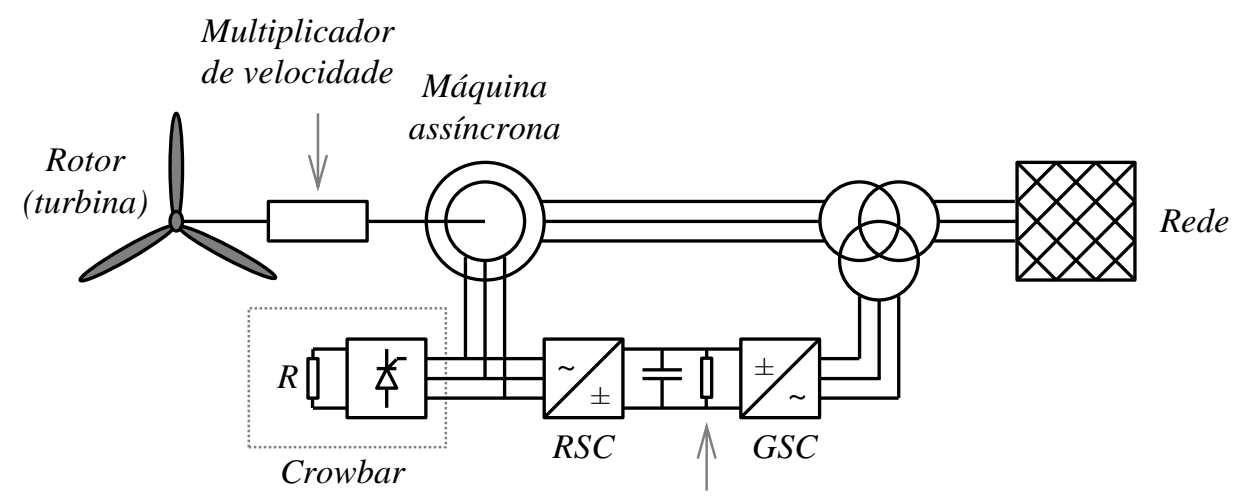

Chopper

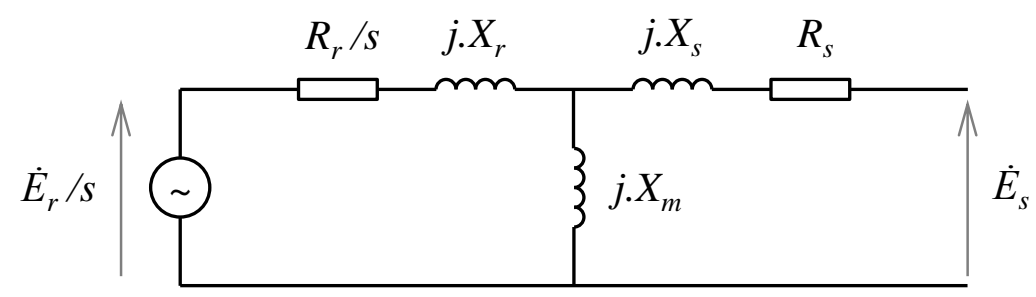

Figura A.4 - Modelo elétrico para o gerador assíncrono duplamente alimentador (DFIG) 
Por fim, há fontes que são conectadas à rede através de conversores estáticos, como é o caso da geração eólica síncrona a imãs permanentes ou Permanent Magnet Synchronous Generator (PMSG) (Figura A.5) e da fotovoltaica (Figura A.6). Geralmente, estes conversores limitam a contribuição da fonte até sua corrente nominal. Idealmente eles seriam mais bem representados por uma fonte de corrente, mas também podem ser modelados por uma fonte de tensão atrás de uma impedância com um menor grau de fidelidade.

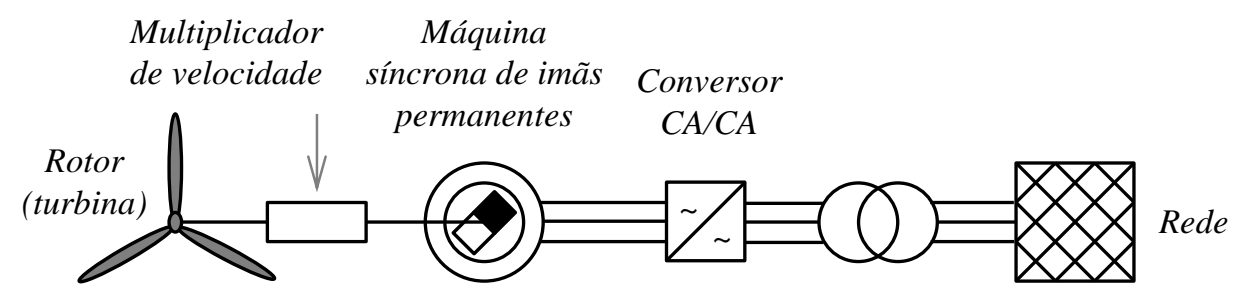

Figura A.5 - Gerador eólico conectado através de conversor

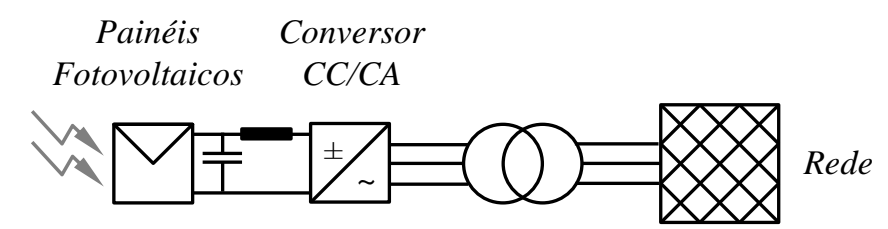

Figura A.6 - Geração fotovoltaica conectada através de conversor 


\section{ANEXo B - MODELos ElÉtRICOS}

\section{PARA LINHAS DE DISTRIBUIÇÃO}

A resistência elétrica da linha é função do material e da seção do condutor em maior grau e da temperatura do condutor, em menor grau:

$$
R^{\prime}=f \frac{\rho}{S}\left[1+\alpha\left(\theta_{c}-\theta_{r}\right)\right]
$$

$R^{\prime} \quad$ resistência unitária da linha $(\Omega / \mathrm{km})$

$f \quad$ fator de encordoamento do cabo $(f \approx 1,02)$

$\rho \quad$ resistividade do material condutor

$$
\begin{array}{ll}
\text { para o cobre: } & \rho=17,86 \Omega \cdot \mathrm{mm}^{2} / \mathrm{km} \text { a } 20^{\circ} \mathrm{C} \\
\text { para o alumínio: } & \rho=27,78 \Omega \cdot \mathrm{mm}^{2} / \mathrm{km} \text { a } 20^{\circ} \mathrm{C}
\end{array}
$$

$\alpha \quad$ coeficiente de dilatação do material $\left(\alpha \approx 4 \times 10^{-3}\right)$

$S \quad$ seção do condutor $\left(\mathrm{mm}^{2}\right)$

$\theta_{c} \quad$ temperatura do condutor $\left({ }^{\circ} \mathrm{C}\right)$

$\theta_{r} \quad$ temperatura de referência $\left(20^{\circ} \mathrm{C}\right)$

Por sua vez, a reatância de sequência positiva da linha é função da frequência da rede e da distância média geométrica dos condutores de fase (Roeper, 1990):

$$
X^{\prime}=\omega \frac{\mu_{0}}{2 \pi}\left[\ln \left(\frac{D}{r}\right)+\frac{1}{4}\right]
$$

$X^{\prime} \quad$ reatância unitária da linha $(\Omega / \mathrm{km})$

$\omega \quad$ frequência cíclica $(\omega=2 . \pi \cdot f=377 \mathrm{rad} / \mathrm{s})$

$\mu_{0} \quad$ permeabilidade magnética do vácuo $\left(\mu_{0}=4 \pi \times 10^{-4} \mathrm{H} / \mathrm{km}\right)$

$D$ distância geométrica entre os eixos das fases $(\mathrm{m})$

$r \quad$ raio do condutor $(\mathrm{m})$

As distâncias médias geométricas dos condutores de fase dependem basicamente do arranjo dos cabos nas estruturas. A Figura B.1 demonstra as distâncias típicas para três tipos principais de redes de distribuição. 
Rede aérea

convencional

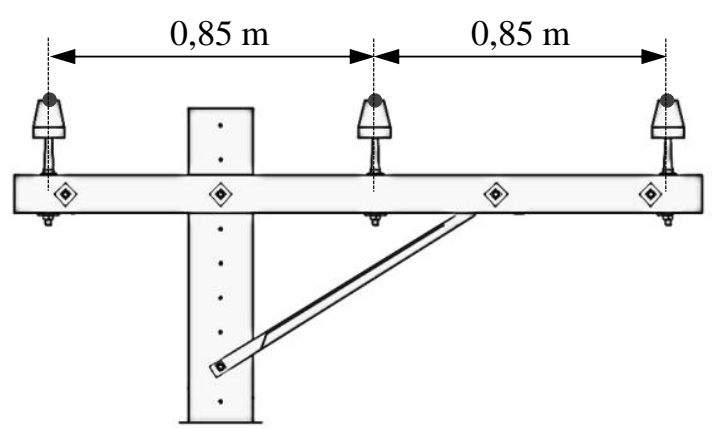

Rede aérea compacta

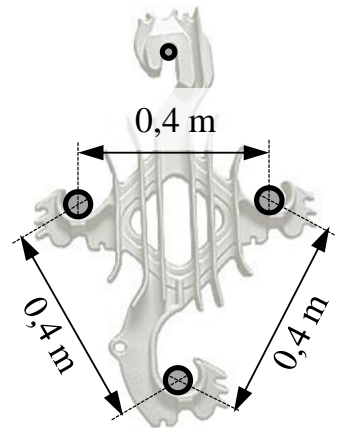

Rede subterrânea

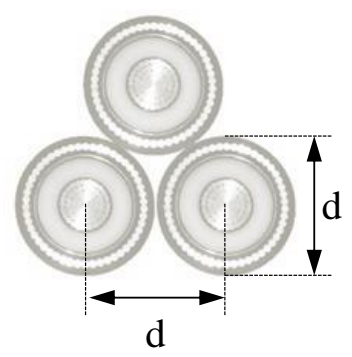

Figura B.1 - Espaçamento típico entre as fases para diferentes tipos de redes de distribuição

As equações simplificadas para cálculo da resistência e reatância de sequência zero estão demonstradas abaixo e são oriundas dos estudos de Carson. A reatância depende do fator $\delta$, que representa uma profundidade fictícia no solo por onde a corrente de sequência zero retorna à fonte. Essa profundidade é função da resistividade do solo.

$$
\begin{aligned}
& R_{0}^{\prime}=R^{\prime}+3 \frac{\omega \mu_{0}}{8} \\
& X_{0}^{\prime}=\omega \frac{\mu_{0}}{2 \pi}\left[3 \ln \left(\frac{\delta}{\sqrt[3]{r D^{2}}}\right)+\frac{1}{4}\right] \\
& \delta=\frac{1,850}{\sqrt{\omega \mu_{0} / \rho_{\text {solo }}}}
\end{aligned}
$$

$\rho_{\text {solo }} \quad$ resistividade elétrica do solo $\left(\rho_{\text {solo }}=1000 \Omega . \mathrm{m}\right)$

$\delta \quad$ profundidade fictícia de retorno da corrente homopolar

$$
\begin{aligned}
& \text { para } \rho_{\text {solo }}=100 \Omega . \mathrm{m} \text { temos } \delta=850 \mathrm{~m} \\
& \text { para } \rho_{\text {solo }}=1000 \Omega . \mathrm{m} \text { temos } \delta=2.688 \mathrm{~m}
\end{aligned}
$$

O cálculo da impedância de sequência zero para as redes subterrâneas é muito complexo, pois depende de inúmeros fatores como a ligação das blindagens dos cabos, as perdas por indução nos eletrodutos metálicos, etc. Por esta razão foram utilizados valores típicos retirados do livro (Guthmann, et al., 1982). 
Tabela B.1 - Parâmetros das redes aéreas convencionais com condutor de alumínio nu

\begin{tabular}{c|ccccccc}
\hline \multirow{2}{*}{ Bitola } & $\begin{array}{c}\text { Seção } \\
\left(\mathrm{mm}^{2}\right)\end{array}$ & $\begin{array}{c}\text { Diâmetro } \\
(\mathrm{mm})\end{array}$ & \multicolumn{2}{c}{ Impedância } & \multicolumn{2}{c}{ Impedância } & Capacidade \\
& $\mathrm{S}$ & $\mathrm{d}$ & $\mathrm{R}^{\prime}$ & $\mathrm{X}^{\prime}$ & $\mathrm{R}_{0}^{\prime}$ & $\mathrm{X}_{0}^{\prime}$ & $\mathrm{I}_{\max }(\mathrm{A})$ \\
\hline 4 AWG & 21,1 & 5,9 & 1,64 & 0,46 & 1,82 & 2,03 & 155 \\
2 AWG & 33,7 & 7,4 & 1,03 & 0,45 & 1,21 & 2,01 & 208 \\
1 AWG & 42,4 & 8,3 & 0,82 & 0,44 & 1,00 & 2,00 & 240 \\
$1 / 0 \mathrm{AWG}$ & 53,5 & 9,4 & 0,65 & 0,43 & 0,83 & 1,99 & 278 \\
2/0 AWG & 67,5 & 10,5 & 0,51 & 0,42 & 0,69 & 1,98 & 322 \\
3/0 AWG & 85,0 & 11,8 & 0,41 & 0,41 & 0,59 & 1,97 & 372 \\
4/0 AWG & 107,3 & 13,3 & 0,32 & 0,40 & 0,50 & 1,96 & 430 \\
266,8 MCM & 135,3 & 14,9 & 0,26 & 0,39 & 0,43 & 1,96 & 497 \\
336,4 MCM & 170,6 & 16,9 & 0,20 & 0,38 & 0,38 & 1,95 & 578 \\
397,5 MCM & 201,5 & 18,4 & 0,17 & 0,38 & 0,35 & 1,94 & 640 \\
477,0 MCM & 241,5 & 20,1 & 0,14 & 0,37 & 0,32 & 1,93 & 718 \\
556,5 MCM & 281,9 & 21,7 & 0,12 & 0,36 & 0,30 & 1,93 & 790 \\
\hline
\end{tabular}

Tabela B.2 - Parâmetros das redes aéreas compactas com condutor de alumínio coberto

\begin{tabular}{c|ccccccc}
\hline \multirow{2}{*}{ Bitola } & $\begin{array}{c}\text { Seção } \\
\left(\mathrm{mm}^{2}\right)\end{array}$ & $\begin{array}{c}\text { Diâmetro } \\
(\mathrm{mm})\end{array}$ & \multicolumn{2}{c}{ Impedância } & \multicolumn{2}{c}{ Impedância } & \multicolumn{2}{c}{ Capacidade } \\
& $\mathrm{S}$ & $\mathrm{d}$ & $\mathrm{R}^{\prime}$ & $\mathrm{X}^{\prime}$ & $\mathrm{R}_{0}^{\prime}$ & $\mathrm{X}_{0}^{\prime}$ & $\mathrm{I}_{\max }(\mathrm{A})$ \\
\hline $35 \mathrm{~mm}^{2}$ & 35 & 7,1 & 1,04 & 0,38 & 1,22 & 1,96 & 187 \\
$50 \mathrm{~mm}^{2}$ & 50 & 8,2 & 0,73 & 0,36 & 0,91 & 1,95 & 225 \\
$70 \mathrm{~mm}^{2}$ & 70 & 9,7 & 0,52 & 0,35 & 0,70 & 1,94 & 282 \\
$95 \mathrm{~mm}^{2}$ & 95 & 11,5 & 0,38 & 0,34 & 0,56 & 1,92 & 345 \\
$120 \mathrm{~mm}^{2}$ & 120 & 12,9 & 0,30 & 0,33 & 0,48 & 1,91 & 401 \\
$150 \mathrm{~mm}^{2}$ & 150 & 14,2 & 0,24 & 0,32 & 0,42 & 1,91 & 456 \\
$185 \mathrm{~mm}^{2}$ & 185 & 16,15 & 0,20 & 0,31 & 0,37 & 1,90 & 525 \\
$240 \mathrm{~mm}^{2}$ & 240 & 18,4 & 0,15 & 0,30 & 0,33 & 1,89 & 625 \\
$300 \mathrm{~mm}^{2}$ & 300 & 20,65 & 0,12 & 0,29 & 0,30 & 1,88 & 721 \\
\hline
\end{tabular}

Tabela B.3 - Parâmetros das redes subterrâneas com cabos de cobre isolados a XLPE

\begin{tabular}{c|ccccccc}
\hline \multirow{2}{*}{ Bitola } & \multirow{2}{*}{$\begin{array}{c}\text { Seção } \\
\left(\mathrm{mm}^{2}\right)\end{array}$} & $\begin{array}{c}\text { Diâmetro } \\
(\mathrm{mm})\end{array}$ & \multicolumn{2}{c}{ Impedância } & \multicolumn{2}{c}{ Impedância } & \multicolumn{2}{c}{ Capacidade } \\
& $\mathrm{S}$ & $\mathrm{d}$ & $\mathrm{R}^{\prime}$ & $\mathrm{X}^{\prime}$ & $\mathrm{R}_{0}^{\prime}$ & $\mathrm{X}_{0}^{\prime}$ & $\mathrm{I}_{\max }(\mathrm{A})$ \\
\hline $50 \mathrm{~mm}^{2}$ & 50 & 8,2 & 0,47 & 0,14 & 2,00 & 0,40 & 138 \\
$70 \mathrm{~mm}^{2}$ & 70 & 9,7 & 0,33 & 0,13 & 1,80 & 0,35 & 168 \\
$95 \mathrm{~mm}^{2}$ & 95 & 11,5 & 0,25 & 0,13 & 1,60 & 0,30 & 200 \\
$120 \mathrm{~mm}^{2}$ & 120 & 12,9 & 0,20 & 0,12 & 1,40 & 0,25 & 227 \\
$150 \mathrm{~mm}^{2}$ & 150 & 14,2 & 0,16 & 0,12 & 1,30 & 0,22 & 254 \\
$185 \mathrm{~mm}^{2}$ & 185 & 16,15 & 0,13 & 0,12 & 1,20 & 0,21 & 286 \\
$240 \mathrm{~mm}^{2}$ & 240 & 18,4 & 0,10 & 0,12 & 1,15 & 0,20 & 330 \\
\hline
\end{tabular}

